\title{
ipen
}

AUTARQUIA ASSOCIADA À UNIVERSIDADE DE SÃO PAULO

\section{Uso de Diodos Epitaxiais de Si em \\ Dosimetria de Fótons}

\author{
Lilian Nunes Pereira
}

Dissertação apresentada como parte dos requisitos para a obtenção do Grau de Mestre em Ciências na Área de Tecnologia Nuclear - Aplicações

Orientadora:

Dra Josemary A. Corrêa Gonçalves

São Paulo, 2013 
Aos meus pais Israel e Neuza que me ensinaram e guiaram meus passos até aqui e que nunca deixaram de estar ao meu lado me apoiando incondicionalmente sempre. E a Célia minha grande amiga. 


\section{AGRADECIMENTOS}

A Prof ${ }^{a}$. Dr ${ }^{\text {a }}$ Josemary Angélica Corrêa Gonçalves, pela oportunidade e pelos valiosos ensinamentos transmitidos durante a realização deste trabalho.

A Prof ${ }^{a}$. Dr ${ }^{a}$ Carmen Cecília Bueno pelas valiosas discussões e contribuições ao longo do desenvolvimento deste trabalho.

Ao Dr. Vitor Vivolo e a Dra Maria da Penha Albuquerque Potiens, pelo suporte ao longo das irradiações junto ao Laboratório de Calibração de Instrumentos (LCI) e pelas importantes sugestões a este trabalho.

Aos Doutores Ioana Pintilie, do Depto. de Física de Semicondutores e Estruturas Complexas do Instituto Nacional de Física dos Materiais da Romênia, G. Lindström e E. Fretwurst, ambos do Instituto de Física Experimental da Universidade de Hamburgo, Alemanha, por nos cederem sem custo as amostras de diodos epitaxiais e de fusão zonal.

Ao Dr. Jonas Oliveira da Silva pelo auxílio durante o início das irradiações no Laboratório de Calibração de Instrumentos (LCI).

Ao Eng. José Carlos de Souza, responsável pela Oficina Mecânica do Depto. de Física Experimental do IFUSP, pela confecção das sondas em polimetilmetacrilato.

A Divisão de Microssistemas e Empacotamento do Centro de Tecnologia da Informação Renato Archer nas pessoas de seu gerente Dr. Wagner Caçador Carvalho e da técnica Marinalva Muniz Rocha da pela confecção das microsoldas dos diodos nas bases cerâmicas.

A Superintendência do Instituto de Pesquisas Energéticas e Nucleares (IPENCNEN/SP) pelas facilidades proporcionadas durante o desenvolvimento deste trabalho.

Ao Centro de Tecnologia das Radiações (CTR) e a Divisão de Pesquisa e Desenvolvimento do IPEN-CNEN/SP nas pessoas da Dra Margarida Mizume Hamada e Dra Monica Beatriz Mathor pelo incentivo e infra-estrutura disponibilizada durante a realização deste trabalho.

A Gerência de Metrologia das Radiações (GMR) na pessoa da Prof ${ }^{\mathbf{a}}$. Dr ${ }^{\mathrm{a}}$ Linda Viola Ehlin Caldas pelas facilidades de uso do gerador de radiação X Pantak-Seifert instalado no Laboratório de Calibração de Instrumentos (LCI).

A Coordenação de Aperfeiçoamento de Pessoal de Nível Superior (CAPES), pela concessão de Bolsa de Estudos durante a realização deste trabalho.

Aos meus amigos do grupo de pesquisa: a Dr $^{\mathbf{a}}$ Thais Cavalheri dos Santos, pelo grande apoio, força e amizade desde meus primeiros momentos aqui em São Paulo, ao Dr. 
Danilo Cardenuto Ferreira por ter sempre uma palavra amiga e estar disposto a uma boa conversa, a doutoranda Kelly Cristina da Silva Pascoalino pela amizade, apoio e força e inúmeros conselhos e aos doutorandos Túlio Cearamicolini Vivaldini e Iara Batista de Lima pela amizade e pela constante disposição e alegria. Obrigada a todos por me apoiarem nos momentos difíceis e por me acompanharem nos momentos de alegria, são amizades como as de vocês que levarei comigo pelo resto da vida. 
"Um dia, quando olhares para trás, verás que os dias mais belos foram aqueles em que lutaste." 


\title{
Uso de Diodos Epitaxiais de Si em Dosimetria de Fótons
}

\author{
Lilian Nunes Pereira
}

\section{Resumo}

Neste trabalho são apresentados os resultados da caracterização dosimétrica de dois diodos especiais de silício, resistentes a danos de radiação, crescidos pelo método epitaxial com vistas a sua aplicação na monitoração em tempo real de feixes de fótons de qualidades de radiodiagnóstico convencional, mamografia e tomografia computadorizada, no intervalo de tensão de $28 \mathrm{kV}$ a $150 \mathrm{kV}$. Os dispositivos utilizados, um submetido à pré-dose de 200 kGy de raios gama do ${ }^{60}$ Co no Centro de Tecnologia das Radiações (CTR) do IPENCNEN/SP, e outro sem qualquer irradiação prévia, foram processados na Universidade de Hamburgo a partir de uma camada epitaxial com $50 \mu \mathrm{m}$ de espessura. Apenas para comparação, um diodo de Si crescido por fusão zonal padrão foi também estudado.

As irradiações foram realizadas no Laboratório de Calibração de Instrumentos (LCI) do IPEN/CNEN-SP, onde está instalado um gerador de radiação X, Pantak-Seifert, Isovolt $160 \mathrm{HS}$, cujas qualidades de radiação foram verificadas por câmaras de ionização padronizadas. Os diodos foram ligados a um eletrômetro Keithley 6517B em modo fotovoltaico, com a distância do ponto focal do gerador aos diodos mantida em $1 \mathrm{~m}$. Os principais parâmetros dosimétricos das amostras foram avaliados de acordo com a norma IEC61674. Os coeficientes de calibração dos diodos em termos do kerma no ar também foram determinados.

Os diodos apresentaram excelente estabilidade de resposta em curto prazo para as qualidades estudadas, com coeficientes de variação em corrente equivalentes e não superiores a $0,3 \%$. O comportamento das fotocorrentes em função da taxa de dose foi linear para os três dispositivos no intervalo de 0,8 a 77,2 $\mathrm{mGy} / \mathrm{min}$. As curvas carga-dose obtidas pela integração dos sinais de corrente tornaram evidente a ausência de dependência energética para feixes de mamografia e de radiodiagnóstico até $70 \mathrm{kV}$. O diodo epitaxial sem pré-dose apresentou maior sensibilidade em corrente e em carga em relação aos demais, com queda neste parâmetro de $8 \%$ após receber dose acumulada de 49 Gy. Até este limite de dose, as correntes de fuga dos dispositivos mantiveram-se estáveis em cerca de $0,4 \mathrm{pA}$ ao longo das irradiações, sendo menores por um fator até $10^{4}$ em relação às correntes em condição de irradiação. A variação da resposta direcional de ambos diodos para o intervalo de $\pm 5^{\circ}$ foi inferior a $0,1 \%$ e seus coeficientes de calibração para os feixes 
estudados foram determinados a partir dos padrões de referência do LCI. As alterações das características elétricas das amostras em função de danos de radiação foram também estudadas e não revelaram alteração significativa para tensão de polarização nula.

Com base nos resultados obtidos até o presente e considerando as recomendações da norma IEC 61674, pode-se afirmar que diodos epitaxiais sem pré-dose e com pré-dose podem ser empregados de forma confiável na dosimetria de feixes de radiação eletromagnética para imagens médicas até o limite de dose acumulada de 10 Gy e acima de $206 \mathrm{kGy}$, respectivamente. 


\title{
Use of Epitaxial Silicon Diodes in Photon Dosimetry
}

\author{
Lilian Nunes Pereira
}

\begin{abstract}
In this work we report on results obtained with two rad-hard epitaxial (EPI) silicon diodes as on-line dosimeter for diagnostic radiology, mammography and computed tomography, in the $28 \mathrm{kV}$ to $150 \mathrm{kV}$ range. The epitaxial diodes used were processed at University of Hamburg on $50 \mu \mathrm{m}$ thick epitaxial silicon layer. One sample was not irradiated before using as a dosimeter, while the other received a gamma pre-dose of 200 kGy from ${ }^{60} \mathrm{Co}$. For comparison, a standard float zone silicon diode was also studied.

The samples irradiation was performed using X-ray beams from a Pantak/Seifert generator, model Isovolt $160 \mathrm{HS}$, previously calibrated with standardized ionization chambers, located at Laboratório de Calibração de Instrumentos of IPEN-CNEN/SP. The diode was connected to an electrometer Keithley 6517B in the photovoltaic mode. Irradiations were carried out with the diodes positioned at $1 \mathrm{~m}$ from the X-ray tube (focal spot). The main dosimetric parameters of the EPI samples were evaluated in according to IEC 61674 norm. The calibration coefficients of the diode, in terms of air kerma, were also determined.

The repeatability was measured with photon beams of all qualities. The current signals induced showed the diodes are stable, characterized by coefficients of variation less than $0.3 \%$. The current response of the unirradiated EPI diode has been shown to be very linear with dose-rate in the range of 0.8 up to $77.2 \mathrm{mGy} / \mathrm{min}$. A linear relation between charge and dose in the whole energy range was observed for the three samples. It is important to notice that for EPI diodes non energy dependence was observed for mammography beams and until $70 \mathrm{kV}$ for radiodiagnostic qualities. The unirradiated diode presented sensitivity higher than the others, showing a decrease of $8 \%$ in this parameter after accumulated dose of $49.15 \mathrm{~Gy}$. The dark currents were stable about $0.4 \mathrm{pA}$ during the irradiations, value $10^{4}$ higher than the lowest photocurrents measured. The directional response of both diodes was $0.1 \%$ within an angle range of $\pm 5^{\circ}$. Based on these results, one can conclude that the unirradiated and pre-irradiated EPI diodes can be used as a reliable alternative choice to relative medical imaging photon dosimetry within $10 \mathrm{~Gy}$ and 206 kGy of accumulated dose, respectively.
\end{abstract}




\section{SUMÁRIO}

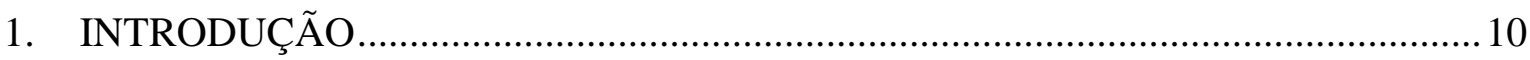

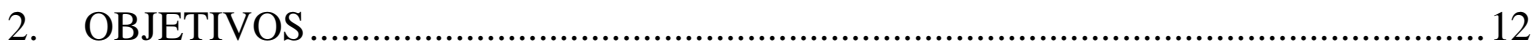

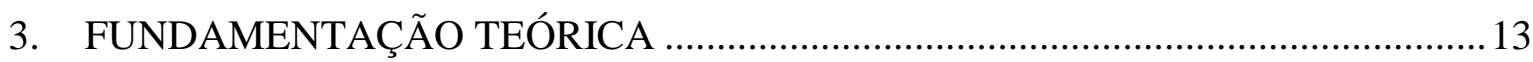

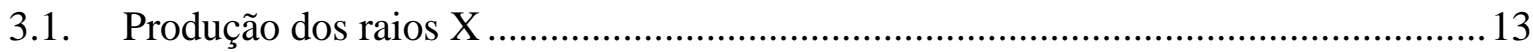

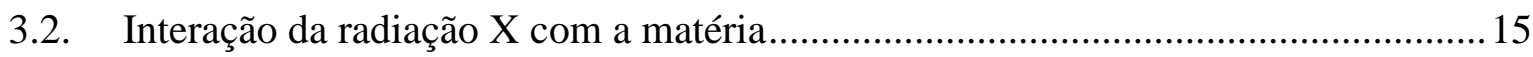

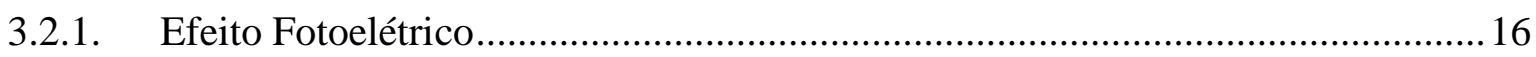

3.2.2. Espalhamento Compton .......................................................................... 17

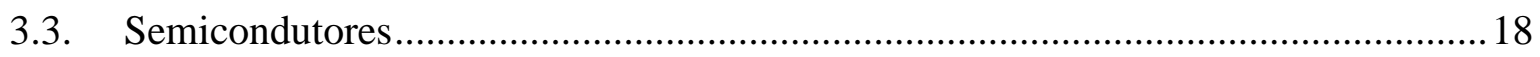

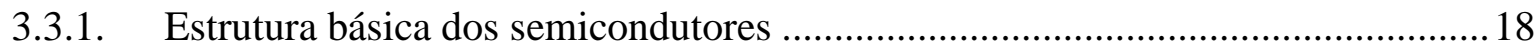

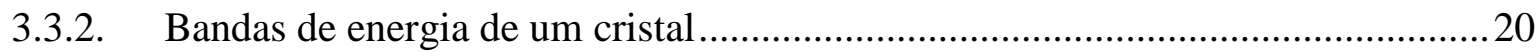

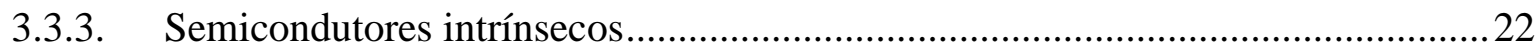

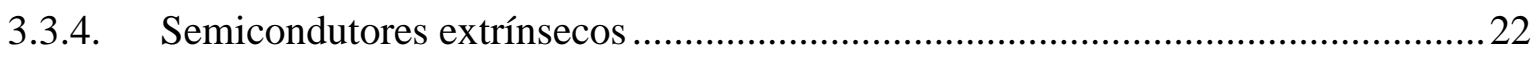

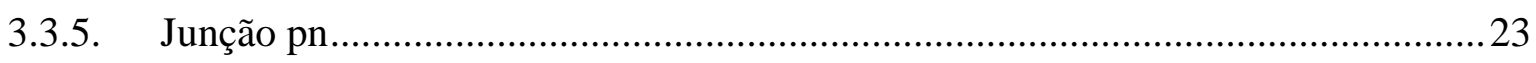

3.4. Princípio de funcionamento de diodos de Si como dosímetros de radiação.............24

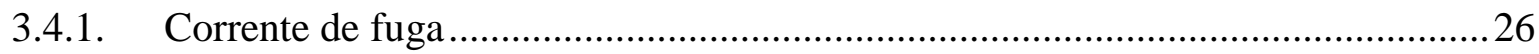

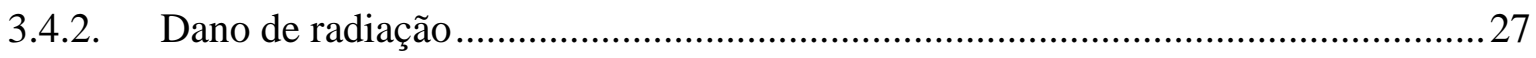

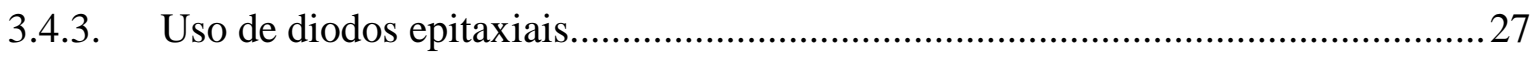

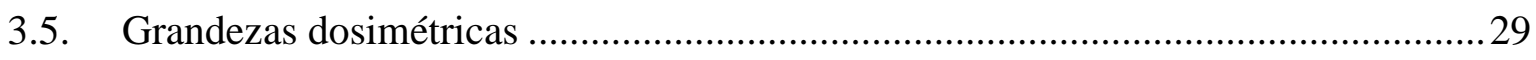

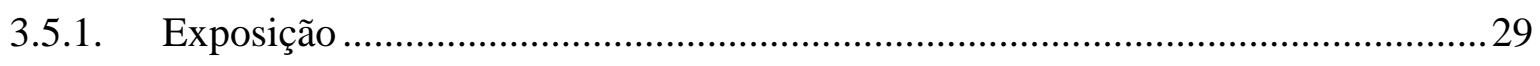

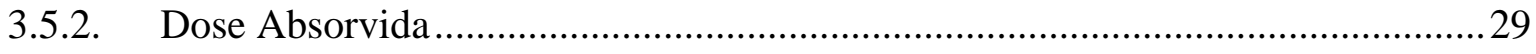

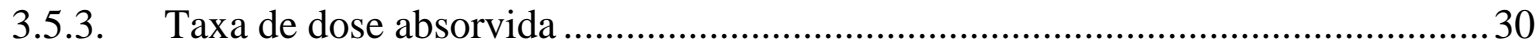

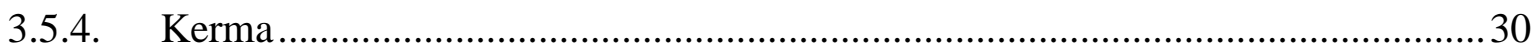

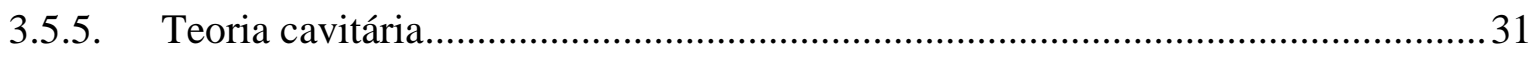

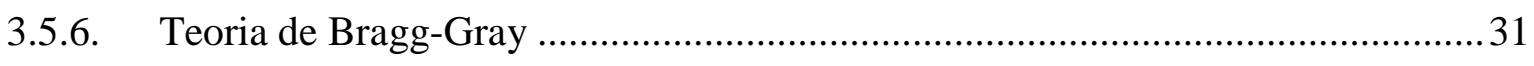

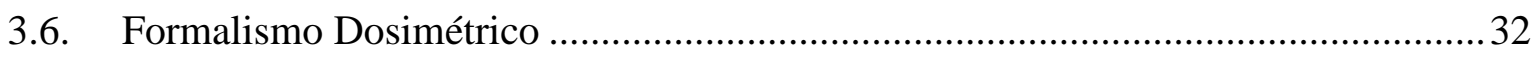

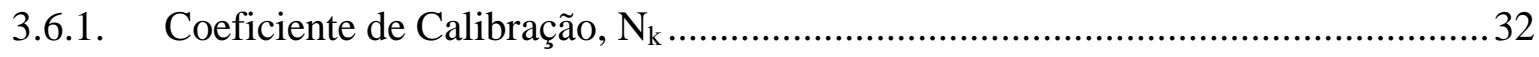

3.6.1.1. Fator de correção para a densidade do ar ............................................................ 33

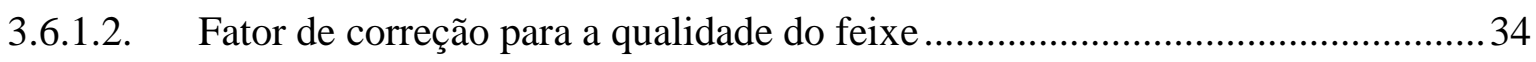

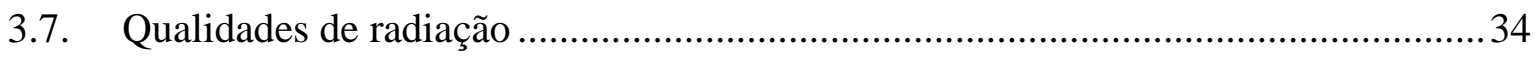

3.7.1. Qualidades de radiação implantadas em um tubo de raios $X$ convencional ..........34

3.7.1.1. Qualidade de radiação padrão de radiodiagnóstico feixes diretos (RQR).........35

3.7.1.2. Qualidade de radiação padrão RQA atenuados e RQT …………....................... 35

3.7.1.3. Qualidade de radiação padrão RQR-M e RQA-M .............................................35 


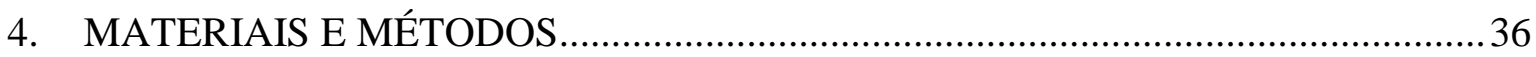

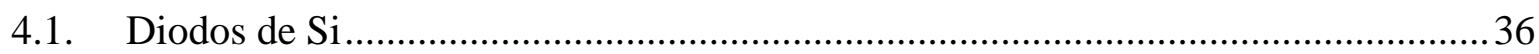

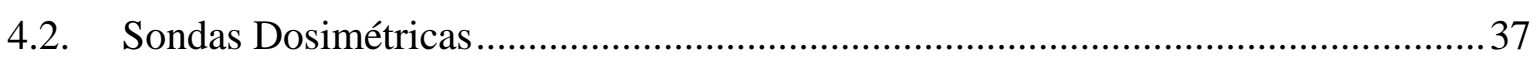

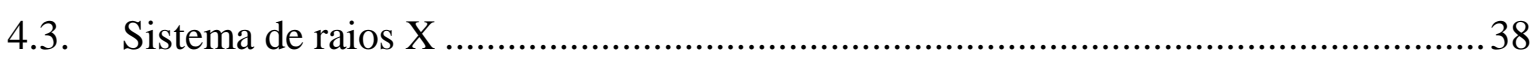

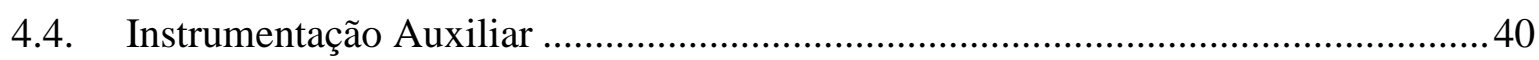

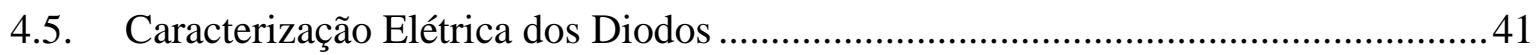

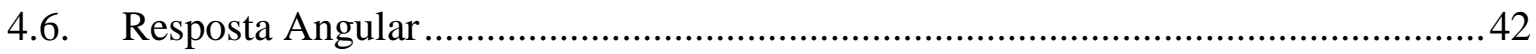

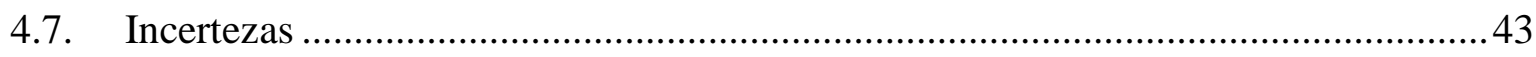

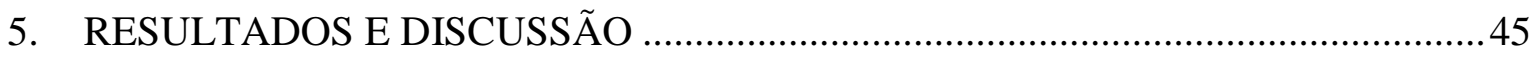

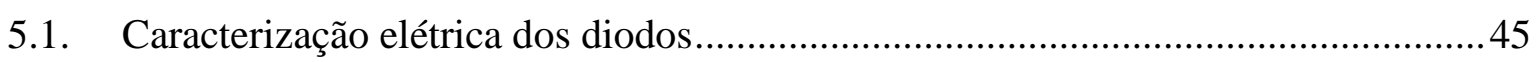

5.1.1. Corrente de fuga em função da tensão de polarização reversa (curva I-V) ...........45

5.1.2. Capacitância em função da tensão de polarização reversa (curva C-V) ................46

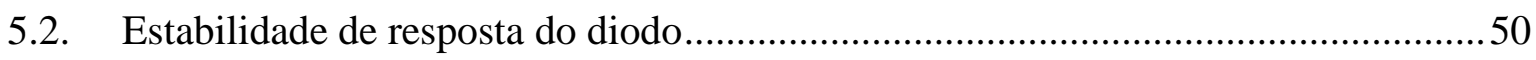

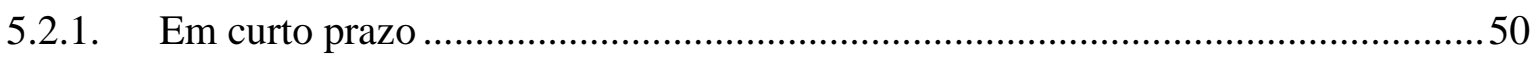

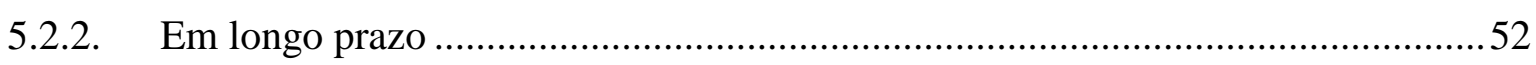

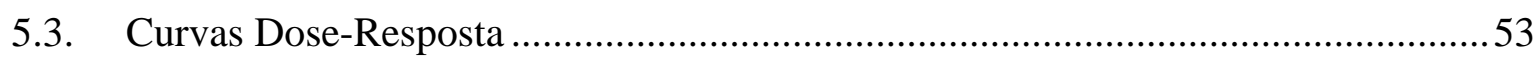

5.4. Linearidade de resposta com a dose para do diodo EPI\#46 …...............................63

5.5. Linearidade de resposta dos diodos com a taxa de Kerma ......................................64

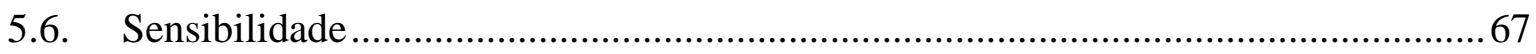

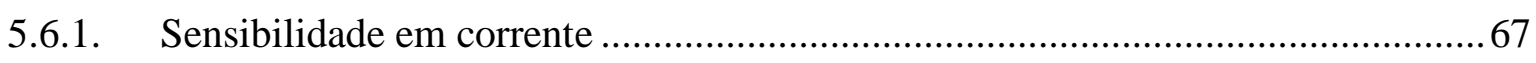

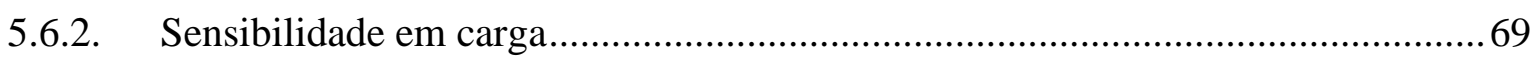

5.7. Modos de aquisição em corrente e em carga para o diodo EPI\#46 ..........................76

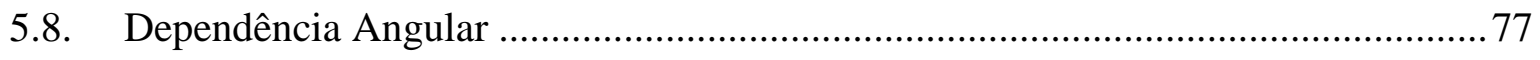

5.9. Cálculo dos coeficientes de calibração ..................................................................... 78

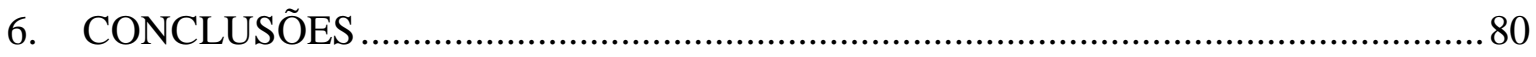

APÊNDICE A - Simulações dos espectros das qualidades de raios $\mathrm{X}$ utilizadas neste

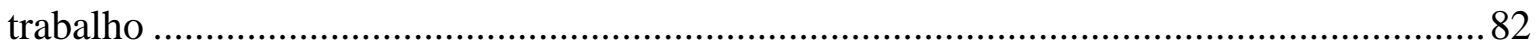

Qualidades de radiodiagnóstico com feixes diretos (RQR) ............................................. 82

Qualidades de radiodiagnóstico com feixes atenuados (RQA) ........................................ 83

Qualidades de mamografia com feixes atenuados e diretos (RQA/R 2/4M) ...................... 83

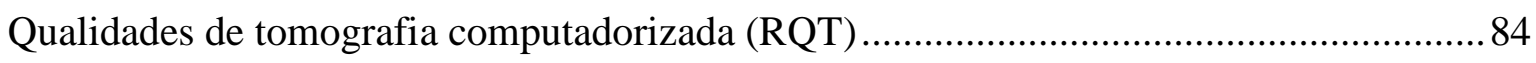

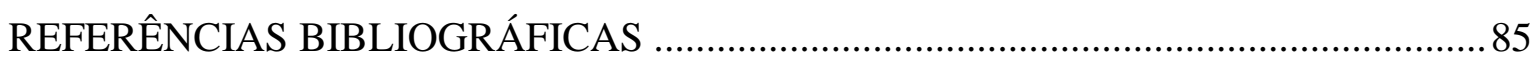




\section{LISTA DE TABELAS}

TABELA 1: Características elétricas e dimensões dos diodos utilizados neste trabalho. A numeração da amostra corresponde a sua posição na pastilha matriz durante seu processo de produção

TABELA 2: Qualidades dos feixes de raios X implantados no sistema Pantak-Seifert 160HS Isovolt e utilizados neste trabalho. Os feixes de referência de cada qualidade estudada estão assinalados em negrito.

TABELA 3: Energias nominal e média [54-57] das qualidades dos feixes estudados.........40

TABELA 4: Principais fontes de incertezas do tipo B associadas às medições, fornecidas pelos certificados de calibração e fabricante de equipamentos.

TABELA 5: Valores dos Coeficientes de Variação (CV) em corrente para os diodos EPI\#46, EPI\#45 e FZ\#04 com os feixes de referência estudados.

TABELA 6: Valores de dose de cada medição com intervalos de tempo de irradiação diferentes para o diodo EPI\#46.

TABELA 7: Sensibilidade em corrente do diodo EPI\#45 para os feixes de referência das qualidades estudadas neste trabalho.

TABELA 8: Sensibilidade em corrente do diodo EPI\#46 para os feixes de referência das qualidades estudadas neste trabalho.

TABELA 9: Sensibilidade em corrente do diodo FZ\#04 para os feixes de referência das qualidades estudadas neste trabalho.

TABELA 10: Sensibilidade em carga dos diodos EPI\#45, \#46 e FZ\#04 para os feixes de mamografia, radiodiagnóstico e tomografia.

TABELA 11: Comparação dos valores da carga medida com o diodo EPI\#46 nos modos de aquisição em carga e em corrente com o eletrômetro Keithley 6517B.

TABELA 12: Coeficientes de calibração e fatores de correção para os diodos EPI\#46, \#45

e FZ\#04 utilizando as qualidades estudadas neste trabalho. 


\section{LISTA DE FIGURAS}

FIGURA 1: Ilustração do esquema de um tubo de raios X convencional [36] ...................13

FIGURA 2: Ilustração do efeito Bremsstrahlung [36]....................................................... 14

FIGURA 3: ilustração do mecanismo de produção dos raios $\mathrm{X}$ característicos [36].......... 15

FIGURA 4: Coeficiente de atenuação mássico no silício em função da energia do fóton

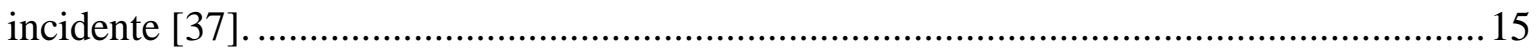

FIGURA 5: Ilustração do processo de interação fotoelétrica [38]. ..................................... 16

FIGURA 6: Ilustração do processo de interação por espalhamento Compton [38]. ............17 FIGURA 7:a) Rede cúbica simples. b) Rede cúbica de corpo centrado. c) Rede cúbica de

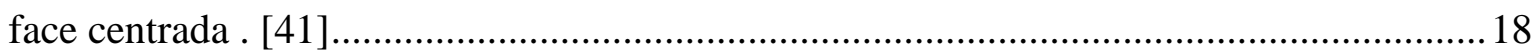

FIGURA 8: Ilustração das posições atômicas na célula cúbica da estrutura do diamante

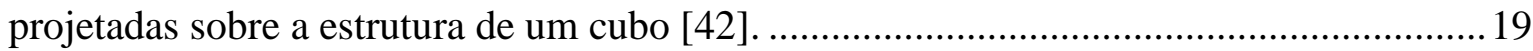

FIGURA 9: Ilustração de uma rede com átomos tetravalentes [43]....................................19

FIGURA 10: Influência da temperatura em um cristal gerando um elétron de condução

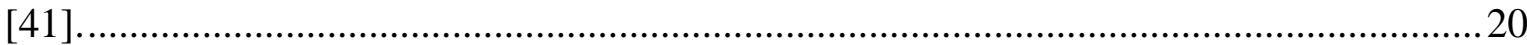

FIGURA 11: Diagrama das bandas de energia em um cristal semicondutor [43]. .............21

FIGURA 12: Estrutura das bandas de energia de um (a) isolante, (b) semicondutor, (c) condutores onde a banda de valência e a de condução se sobrepõem (d) banda de condução

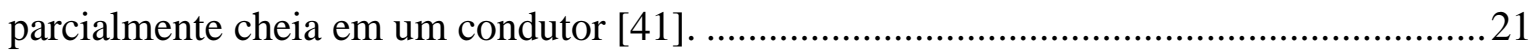

FIGURA 13: Ilustração da inserção de um átomo de arsênio (As) na estrutura do silício

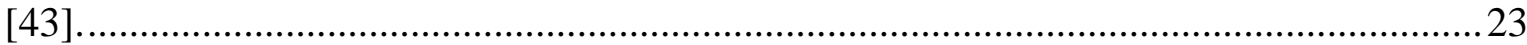

FIGURA 14: Ilustração da inserção de um átomo de boro (B) na estrutura do silício [43].23 FIGURA 15: (a) semicondutor do tipo p homogeneamente dopado, eletricamente neutro e em equilíbrio térmico com elétrons e lacunas distribuídas igualmente. (b) difusão de elétrons para a região $\mathrm{p}$ e lacunas para a região $\mathrm{n}$ gerando um excedente de carga elétrica

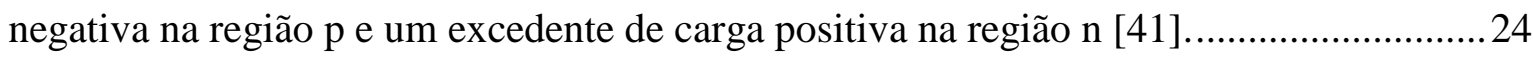

FIGURA 16: Ilustração do processo de interação da radiação com um diodo [45]............ 25 FIGURA 17: a) Base cerâmica com contatos em ouro; b) diodo epitaxial fixado na base cerâmica com a face $\mathrm{p}^{+}$micro soldada; $\mathrm{c}$ ) sonda dosimétrica aberta; d) sonda dosimétrica

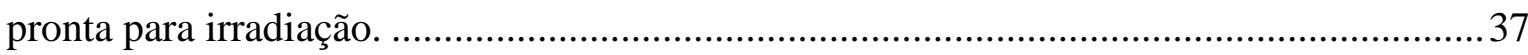

FIGURA 18: Equipamento de radiação X Pantak/Seifert instalado no LCI do IPENCNEN/SP com a sonda dosimétrica posicionada com auxílio de feixes de lasers de He-Ne.

FIGURA 19: Diagrama de blocos ilustrando do arranjo experimental para a construção das curvas I-V e C-V.

FIGURA 20: Vista frontal a) e traseira b) da sonda dosimétrica fixada ao goniômetro com

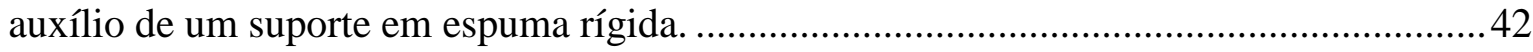

FIGURA 21: Vista superior do arranjo para estudo da resposta direcional dos diodos......43 FIGURA 22: Corrente de fuga em função da tensão de polarização reversa (I-V) para o diodo EPI\#46 (sem pré-dose) a 0 Gy e a 49,15 Gy (as incertezas associadas às medições são menores que as dimensões dos pontos).

FIGURA 23: Corrente de fuga em função da tensão de polarização reversa (I-V) para o diodo EPI\#45 (pré-irradiado) a 0 Gy e a 6,3 Gy (as incertezas associadas às medições são menores que as dimensões dos pontos). 
FIGURA 24: Corrente de fuga em função da tensão de polarização reversa (I-V) para o diodo FZ\#04 a 0 Gy e a 36 Gy (as incertezas associadas às medições são menores que as dimensões dos pontos).

FIGURA 25: Curvas da capacitância em função da tensão de polarização reversa para o diodo EPI\#46 (sem pré-dose) em 0 Gy e em 49,15 Gy (as incertezas associadas às medições são menores que as dimensões dos pontos).

FIGURA 26: Curvas da capacitância em função da tensão de polarização reversa para o diodo EPI\#45 (com pré-dose) em 0 Gy e em 6,3 Gy (as incertezas associadas às medições são menores que as dimensões dos pontos).

FIGURA 27: Curvas da capacitância em função da tensão de polarização reversa para o diodo FZ\#04 em 0 Gy e em 36 Gy (as incertezas associadas às medições são menores que as dimensões dos pontos).

FIGURA 28: Curva da espessura da zona de depleção para o diodo EPI\#46 em função da tensão de polarização reversa (as incertezas associadas à medida são menores que as dimensões dos pontos).

FIGURA 29: Curva da espessura da zona de depleção para o diodo EPI\#45 em função da tensão de polarização reversa (as incertezas associadas à medida são menores que as dimensões dos pontos).

FIGURA 30: Curva da espessura da zona de depleção para o diodo FZ\#04 em função da tensão de polarização reversa (as incertezas associadas às medições são menores que as dimensões dos pontos).

FIGURA 31: Corrente para o diodo EPI\#46 em função do tempo de irradiação para cada feixe de referência das qualidades estudadas: RQR5, RQA5, RQR-2M e RQT9. As incertezas associadas são menores que as dimensões dos pontos do gráfico.

FIGURA 32: Corrente para o diodo EPI\#45 em função do tempo de irradiação para cada feixe de referência das qualidades estudadas: RQR5, RQA5, RQR-2M e RQT9. As incertezas associadas são menores que as dimensões dos pontos do gráfico.

FIGURA 33: Corrente para o diodo FZ\#04 em função do tempo de irradiação para cada feixe de referência das qualidades estudadas: RQR5, RQA5, RQR-2M e RQT9. As incertezas associadas são menores que as dimensões dos pontos do gráfico.

FIGURA 34: Curva dose-resposta do diodo EPI\#46 para as qualidades de mamografia com

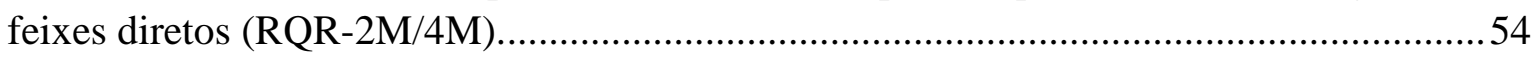
FIGURA 35: Curva dose-resposta do diodo EPI\#46 para as qualidades de mamografia com feixes atenuados (RQA-2M/4M).

FIGURA 36: Curva carga dose para todas as qualidades de mamografia, feixes diretos e

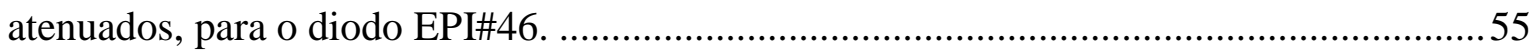

FIGURA 37: Curva dose-resposta do diodo EPI\#46 para as qualidades RQR. .................55 FIGURA 38: Curva dose-resposta do diodo EPI\#46 para as qualidades de radiodiagnóstico,

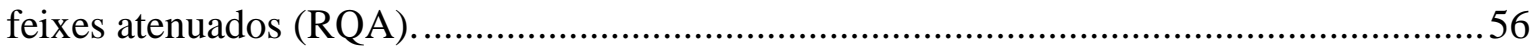

FIGURA 39: Curva dose-resposta do diodo EPI\#46 para as qualidades de tomografia

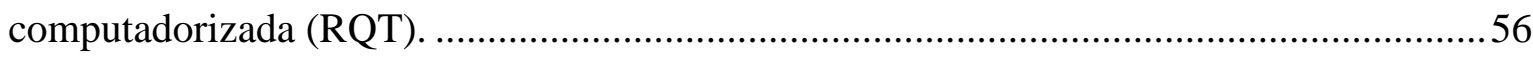
FIGURA 40: Curva dose-resposta do diodo EPI\#45 para sa qualidades de mamografia com

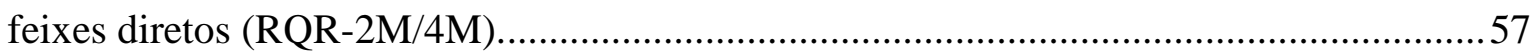
FIGURA 41: Curva dose-resposta do diodo EPI\#45 para as qualidades de mamografia com feixes atenuados (RQA-2M/4M). 
FIGURA 42: Curva carga dose para todas as qualidades de mamografia, feixes diretos e atenuados, para o diodo EPI\#45.

FIGURA 43: Curva dose-resposta do diodo EPI\#45 para as qualidades de radiodiagnóstico, feixes diretos (RQR).

FIGURA 44: Curva dose-resposta do diodo EPI\#45 para as qualidades de radiodiagnóstico,

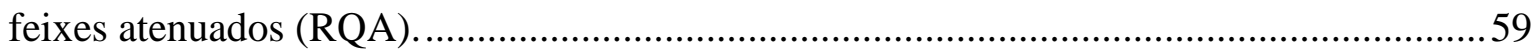

Figura 45: Curva dose-resposta do diodo EPI\#45 para as qualidades de tomografia computadorizada (RQT).

FIGURA 46: Curva dose-resposta do diodo FZ\#04 para as qualidades de mamografia com feixes diretos (RQR-2M/4M).

FIGURA 47: Curva dose-resposta do diodo FZ\#04 para as qualidades de mamografia com feixes atenuados (RQA-2M/4M).

FIGURA 48: Curva carga dose para todas as qualidades de mamografia, feixes diretos e atenuados, para o diodo FZ\#04.

FIGURA 49: Curva dose-resposta do diodo FZ\#04 para as qualidades de radiodiagnóstico,

feixes diretos (RQR).

FIGURA 50: Curva dose-resposta do diodo FZ\#04 para as qualidades de radiodiagnóstico,

feixes atenuados (RQA).

FIGURA 51: Curva dose-resposta do diodo FZ\#04 para as qualidades de tomografia computadorizada (RQT).

FIGURA 52: Corrente em função do tempo do diodo EPI\#46 para diferentes intervalos de tempo de irradiação nas qualidades RQR2M, RQR5 e RQT9.

FIGURA 53: Curvas da dose em função dos tempos de irradiação do diodo EPI\#46 para as qualidades RQR2M, RQR5 e RQT9.

FIGURA 54: Curva da corrente em função da taxa de Kerma para o diodo EPI\#46 com os

feixes de referência das qualidades estudadas.

FIGURA 55: Curva da corrente em função da taxa de Kerma para diodo FZ\#04 com os feixes de referência das qualidades estudadas.

Figura 56: Curva da corrente em função da Taxa de Kerma para diodo EPI\#45 com os feixes de referência das qualidades estudadas.

FIGURA 57: Corrente volumétrica dos diodos EPI\#46 e FZ\#04 em função da taxa de

Kerma para as qualidades RQR5 e RQT9.

FIGURA 58: Corrente volumétrica dos diodos EPI\#46 e FZ\#04 em função da taxa de Kerma para as qualidades RQA5 e RQR2M.

FIGURA 59: Sensibilidade em corrente do diodo EPI\#45 para os feixes RQR5 e RQT9.

Valores de sensibilidade normalizados para os valores de referência destas qualidades...66 FIGURA 60: Sensibilidade em corrente do diodo EPI\#46 para os feixes de referência das qualidades RQR5 e RQT9. Valores de sensibilidade normalizados para os valores de referência destas qualidades.

FIGURA 61: Sensibilidade em corrente do diodo FZ\#04 para os feixes de referência das qualidades RQR5 e RQT9. Valores de sensibilidade normalizados para os valores de referência destas qualidades.

FIGURA 62: Sensibilidade em carga dos diodos EPI\#46, \#45 e FZ\#04 em função da energia efetiva do feixe para as qualidades de mamografia com feixes atenuados.

FIGURA 63: Sensibilidade em carga dos diodos EPI\#46, \#45 e FZ\#04 em função da energia efetiva do feixe para as qualidades de mamografia com feixes diretos. 
FIGURA 64: Sensibilidade em carga dos diodos EPI\#46, \#45 e FZ\#04 em função da energia efetiva do feixe para as qualidades de radiodiagnóstico com feixes diretos.

FIGURA 65: Sensibilidade em carga dos diodos EPI\#46, \#45 e FZ\#04 em função da energia efetiva do feixe para as qualidades de radiodiagnóstico com feixes atenuados......72 FIGURA 66: Sensibilidade em carga dos diodos EPI\#46, \#45 e FZ\#04 em função da energia efetiva do feixe para as qualidades de tomografia. .

FIGURA 67: Sensibilidade em carga do diodo EPI\#45 em função da taxa de Kerma para as qualidades de mamografia, tomografia e radiodiagnóstico feixes diretos (valores normalizados para o feixe de referência).

FIGURA 68: Sensibilidade em carga do diodo EPI\#45 em função da taxa de Kerma para a qualidade radiodiagnóstico feixes atenuados (valores normalizados para o feixe de referência).

FIGURA 69: Sensibilidade em carga do diodo EPI\#46 em função da taxa de Kerma para as qualidades de mamografia, tomografia e radiodiagnóstico feixes diretos (valores normalizados para o feixe de referência).

FIGURA 70: Sensibilidade em carga do diodo EPI\#46 em função da taxa de Kerma para a qualidade radiodiagnóstico feixes atenuados (valores normalizados para o feixe de referência).

Figura 71: Sensibilidade em carga do diodo FZ\#04 em função da taxa de Kerma para as qualidades de mamografia, tomografia e radiodiagnóstico feixes diretos (valores normalizados para o feixe de referência).

FIGURA 72: Sensibilidade em carga do diodo FZ\#04 em função da taxa de Kerma para a qualidade radiodiagnóstico feixes atenuados (valores normalizados para o feixe de referência).

FIGURA 73: Carga acumulada pelo diodo EPI\#46 em função do tempo de irradiação para o feixe de qualidade RQR5....

FIGURA 74: Corrente medida pelo diodo EPI\#46 em função do tempo de irradiação para o feixe de qualidade RQR5.

FIGURA 75: Dependência angular do diodo EPI\#46 para as qualidades de feixe RQR5, RQA5 e RQR2M e do diodo EPI\#45 para as qualidades de feixe RQR2M.

Figura 76: Espectros de energia para as qualidades de radiodiagnóstico com feixes diretos (RQR).

FIGURA 77: Espectros de energia para as qualidades de radiodiagnóstico com feixes atenuados (RQA).

FIGURA 78: Espectros de energia para as qualidades de mamografia com feixes diretos e atenuados (RQA/R 2/4M)

FIGURA 79: Espectros de energia para as qualidades de tomografia computadorizada (RQT). 


\section{INTRODUÇÃO}

Diodos de silício ( $\mathrm{Si}$ ) têm sido amplamente empregados em rotinas de dosimetria na área médica, principalmente em aplicações que exigem pequenos campos de radiação, elevada resolução espacial e alta sensibilidade para diagnóstico e tratamentos de radioterapia [1-8]. Para garantir a qualidade destes tratamentos é necessário monitorar a dose recebida pelo paciente [9]. Os dosímetros de $\mathrm{Si}$ atendem esta exigência, pois fornecem resposta em tempo real durante as irradiações, possibilitando correções de dose em pacientes nos tratamentos in vivo [10]. No entanto, a maior restrição ao uso destes dispositivos na dosimetria de radiação eletromagnética está relacionada a danos induzidos pela radiação na estrutura cristalina do $\mathrm{Si}$, conduzindo a queda de sensibilidade com o acumulo da dose [11-12], o aumento da corrente de fuga, o aumento da tensão total de depleção do dispositivo e a redução da eficiência de coleta de cargas proveniente do armadilhamento de elétrons e lacunas [13-20].

A solução destes problemas associados aos danos de radiação produzidos em detectores semicondutores, cujas intensidades crescem com a dose e tipo de radiação, representa também um desafio para utilização destes detectores em experiências na área da Física de Altas Energias (FAE) que demandam, além da rapidez de resposta do detector, elevada resistência aos danos de radiação [21,22]. Para conciliar estas exigências, surgiram colaborações, como a RD50 [23-28], ligadas aos projetos de pesquisa do Centro Europeu de Pesquisas Nucleares (CERN), destinadas ao aperfeiçoamento dos métodos de crescimento dos cristais e das técnicas de fabricação de detectores semicondutores resistentes a danos de radiação [12]. Destes diodos tem merecido destaque, mais recentemente, os dispositivos crescidos pelo método epitaxial (EPI). Estes diodos constituem os candidatos favoritos a utilização no Grande Colisor de Hádrons (LHC) pelo enorme aumento de sua resistência a danos de radiação em comparação aos demais dispositivos [29-33]. Esta característica dos diodos EPI tem sido atribuída principalmente a um efeito de compensação entre a geração de aceitadores e a criação de doadores de carga, única em materiais epitaxiais, tendo sido relatada uma queda na eficiência de coleta de cargas de apenas $20 \%$ para irradiações em alto fluxo $\left(6.10^{15} \mathrm{~cm}^{-2}\right)$. 
Em recente visita ao Laboratório de Desenvolvimento de Novos Tipos de Detectores de Radiação do CTR no IPEN-CNEN/SP, a Dra. Ioana Pintilie, do Instituto Nacional de Física de Materiais da Romênia, respeitada especialista em danos de radiação em semicondutores, forneceu para testes alguns diodos de Si crescidos pelo método epitaxial (EPI). As vantagens de elevada resistência a danos de radiação e a excepcional estabilidade dos sinais de corrente apresentadas pelos dispositivos EPI motivaram o seu uso neste trabalho na confecção de sondas dosimétricas utilizadas na monitoração de feixes de radiodiagnóstico convencional, tomografia computadorizada e mamografia.

No entanto, apesar do desempenho dos sistemas dosimétricos desenvolvidos até o presente indicar grande potencial para a monitoração de processos de irradiação para medidas diretas de taxas de dose e da dose absorvida, é importante salientar que a sua utilização rotineira em hospitais requer a introdução de procedimentos de calibração no tocante a função resposta do dispositivo, sua repetibilidade e reprodutibilidade, faixa operacional de dose e precisão exigidas pelas práticas padronizadas por normas da International Eletrotechical Commission 61647 (IEC 61647) [34] e da International Atomic Energy Agency (TRS 457) [35].

Por estas razões, os dosímetros baseados em diodos de Si que desempenham a função de monitorar em tempo real a estabilidade do processo mediante a medida da corrente gerada pela radiação no volume sensível do dispositivo, são mais adequados que os sistemas dosimétricos estáticos com filmes. De fato, um sistema de monitoração em tempo real com a indicação e armazenamento contínuo de dose e tensão do acelerador, bem como a possibilidade de medida da dose total pela integração dos sinais de corrente registrados em função do tempo de irradiação, é o mais preciso e o que melhor atende às exigências de tratamentos hospitalares. Além disso, as pequenas variações de energia do feixe, com a consequente mudança na taxa de Kerma, são instantaneamente identificadas nos sinais de corrente, permitindo a correção do procedimento de forma a garantir o controle preciso das doses que devem ser ministradas aos pacientes, de acordo com o procedimento previamente estabelecido.

Com o propósito de realizar a caracterização dosimétrica de diodos EPI foram realizadas irradiações no aparelho de raios X Pantak-Seifert, modelo Isovolt $160 \mathrm{HS}$, instalado no Laboratório de Calibração de Instrumentos (LCI) do IPEN/CNEN-SP. Por ser o LCI um laboratório de referência, foi possível também proceder à calibração dos diodos epitaxiais para as qualidades de radiação estudadas neste trabalho. 


\section{OBJETIVOS}

Os objetivos deste trabalho contemplam:

- desenvolvimento de sondas dosimétricas baseadas em diodos de Si epitaxiais, resistentes a danos de radiação, para o uso em dosimetria de feixes de fótons para diagnóstico médico.

- estudo de possíveis danos provocados pela radiação eletromagnética nos diodos de Si e materiais estruturais usados nas sondas dosimétricas. 


\section{FUNDAMENTAÇÃO TEÓRICA}

\subsection{Produção dos raios $X$}

Após sua descoberta por Röntgen em 1895, os raios X foram estudados em diversas áreas, viabilizando exames e tratamentos na área médica.

De uma forma simplificada, um tubo de raios $\mathrm{X}$ convencional é constituído por um eletrodo negativo (catodo) e outro positivo (anodo), ambos dispostos no interior de uma ampola de vidro selada em alto vácuo (FIG.1). O catodo é constituído por um filamento de tungstênio, que emite elétrons por emissão termiônica. O anodo é constituído por uma haste de cobre e tungstênio ou outro elemento de número atômico alto, como o ródio ou molibdênio. Quando alta tensão é aplicada entre o catodo e o anodo, os elétrons emitidos pelo filamento são acelerados para o anodo, alcançando velocidades elevadas ao atingirem o alvo. No catodo, os elétrons sofrem colisões com átomos do meio, determinando processos de ionização e excitação; além disso, estão sujeitos a deflexões de suas trajetórias devido à ação das forças coulombianas sendo acelerados e emitindo energia na forma de radiação eletromagnética (radiação de freamento ou Bremsstrahlung) com espectro contínuo, consequentemente, perdendo sua energia cinética. A FIG. 2 ilustra este processo.

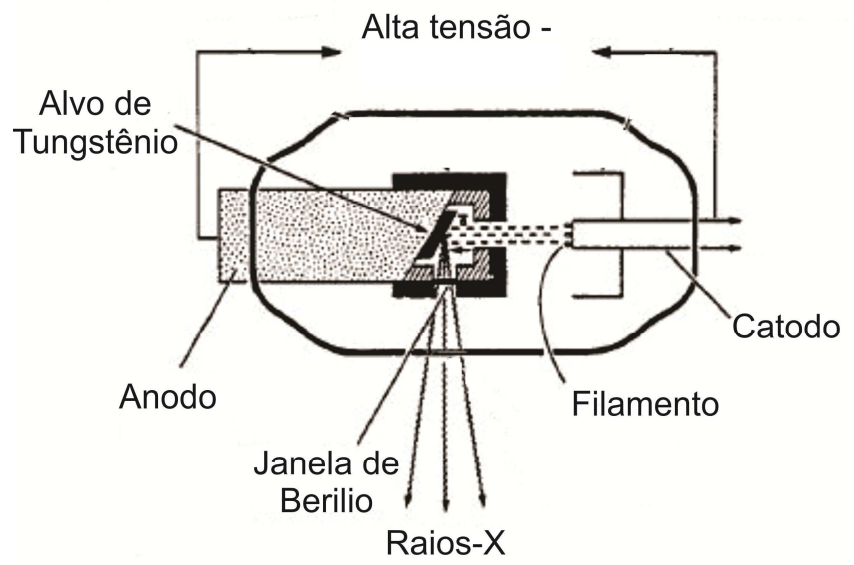

FIGURA 1: Ilustração do esquema de um tubo de raios X convencional [36]. 


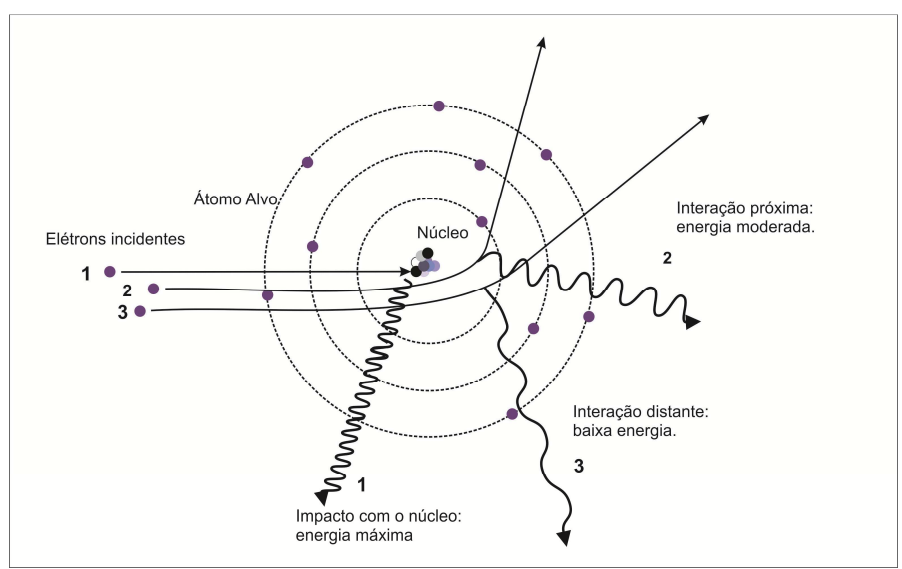

FIGURA 2: Ilustração do efeito Bremsstrahlung [36].

Como a perda de energia do elétron por átomo depende do quadrado do número atômico do alvo $\left(Z^{2}\right)$, podemos dizer que a probabilidade de produção de fótons por Bremsstrahlung varia de acordo com o material do alvo. A eficiência é definida como a razão entre a energia de saída emitida como raios X e a energia de entrada depositada pelos elétrons. A EQ. 1 define a eficiência [36]:

$$
\text { Eficiência }=9 \times 10^{-10} \mathrm{ZV}
$$

onde $V$ é a tensão aplicada no tubo, em volts. Através da EQ. 1 podemos estimar a eficiência, por exemplo, da produção de raios $X$ em um alvo de tungstênio $(Z=74)$, com elétrons acelerados a $100 \mathrm{kV}$ como sendo inferior a $1 \%$; o restante da energia (99\%) aparece na forma de calor.

Quando os elétrons incidem sobre o alvo há também a produção de raios $\mathrm{X}$ característicos (FIG. 3), que ocorre quando o elétron incidente no alvo ioniza átomos do meio e o subsequente preenchimento destas lacunas (geralmente nos orbitais mais internos do átomo) é acompanhada da emissão de radiação eletromagnética de energia bem definida.

Por exemplo, se o elétron realiza a transição entre os orbitais L para o K, então o fóton emitido terá energia igual a $h v=E_{K}-E_{L}$, onde $E_{K}$ e $E_{L}$ são os módulos das energias de ligação da camada $\mathrm{K}$ e L, respectivamente. 


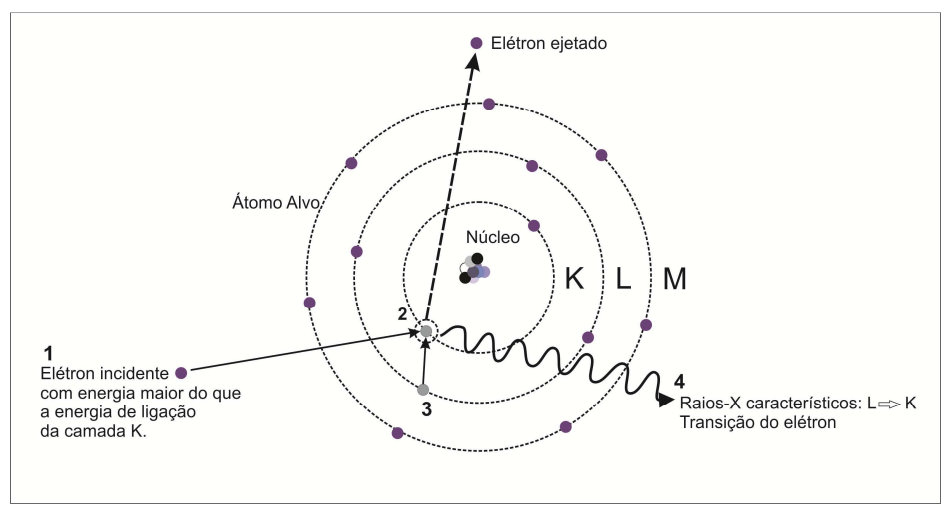

FIGURA 3: ilustração do mecanismo de produção dos raios X característicos [36].

\subsection{Interação da radiação $X$ com a matéria}

Neste trabalho utilizaremos a radiação $\mathrm{X}$ proveniente de uma ampola de raios $\mathrm{X}$, com espectro heterogêneo e tensão nominal no intervalo de $28 \mathrm{kV}$ a $150 \mathrm{kV}$. Levando em conta estes valores de energia da radiação eletromagnética incidente e a seção de choque total de interação no $\mathrm{Si}$, traduzida pelo seu coeficiente de atenuação mássico (FIG.4), podemos concluir que os mecanismos de interação da radiação $X$ com a matéria preponderantes para este trabalho são o efeito fotoelétrico (majoritário para energias até 55 $\mathrm{keV}$ ) e o espalhamento Compton (significativo para energias maiores que $60 \mathrm{keV}$ ).

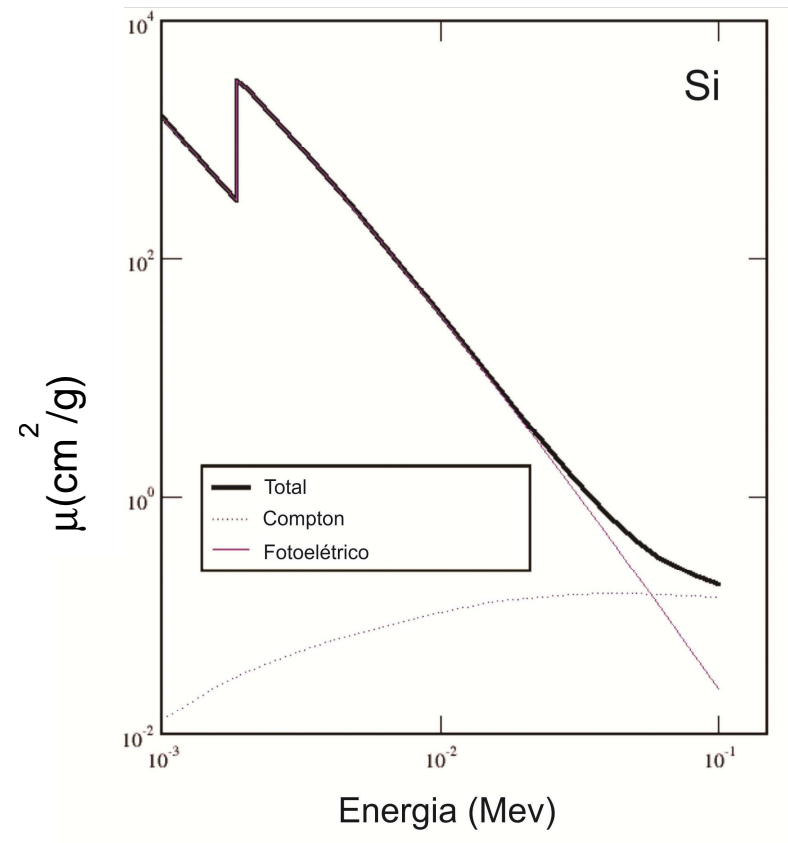

FIGURA 4: Coeficiente de atenuação mássico no silício em função da energia do fóton incidente [37]. 
Por esta razão serão descritos resumidamente apenas estes dois processos de interação da radiação eletromagnética com a matéria.

\subsubsection{Efeito Fotoelétrico}

O efeito fotoelétrico ocorre quando um fóton, de energia hv, é absorvido por um átomo do meio e como resultado desta interação sua energia é convertida em energia cinética de um elétron, que é ejetado do átomo a um ângulo $\theta$ em relação à direção de incidência do fóton. A FIG.5 ilustra a interação fotoelétrica.

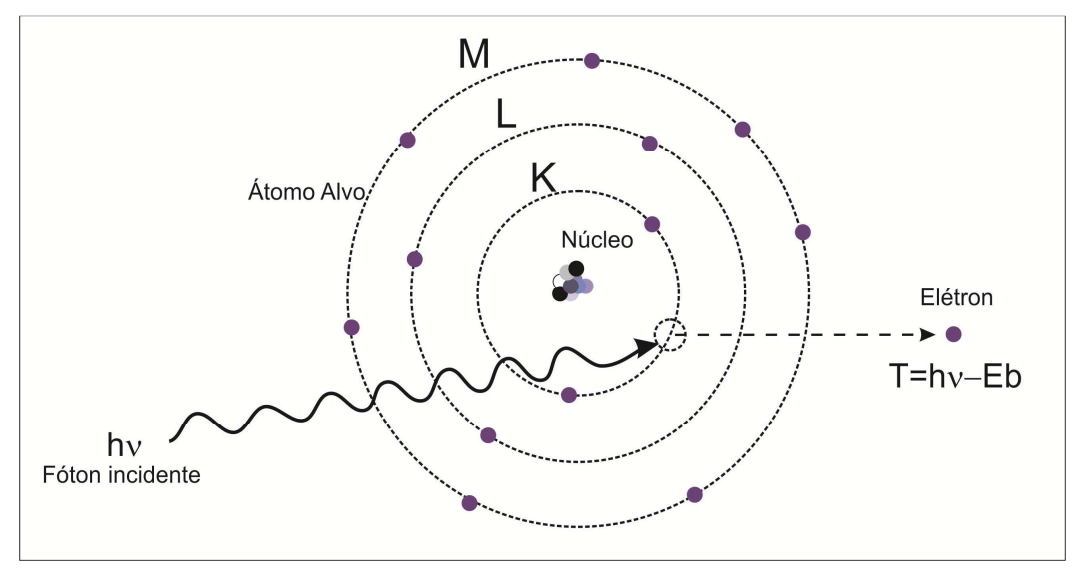

FIGURA 5: Ilustração do processo de interação fotoelétrica [38].

A energia cinética adquirida pelo elétron pode ser escrita como:

$$
\mathrm{T}=\mathrm{h} v-\mathrm{E}_{\mathrm{b}}
$$

onde $\mathrm{h} v$ é a energia do fóton incidente, $\mathrm{E}_{\mathrm{b}}$ a energia de ligação do elétron no átomo.

A seção de choque para o efeito fotoelétrico diminui à medida que a energia do fóton incidente aumenta e é proporcional a $\mathrm{Z}^{4}$, sendo assim temos a EQ.3 que descreve a seção de choque por átomo [39]:

$$
{ }_{\mathrm{a}} \sigma \propto \frac{\mathrm{Z}^{4}}{(\mathrm{~h} v)^{3}}
$$

onde $\mathrm{Z}$ é o número atômico do absorvedor e hv é a energia do fóton incidente. 


\subsubsection{Espalhamento Compton}

O espalhamento Compton ocorre quando um fóton da radiação $\mathrm{X}$ incide em um elétron do absorvedor. No espalhamento, a interação do fóton incidente faz com que um elétron do alvo seja defletido em um ângulo $\phi$ em relação à direção de incidência. A energia do fóton é transportada para o elétron, sendo que um fóton de menor energia é espalhado em um ângulo $\theta$. A FIG.6 ilustra o processo de interação por espalhamento Compton.

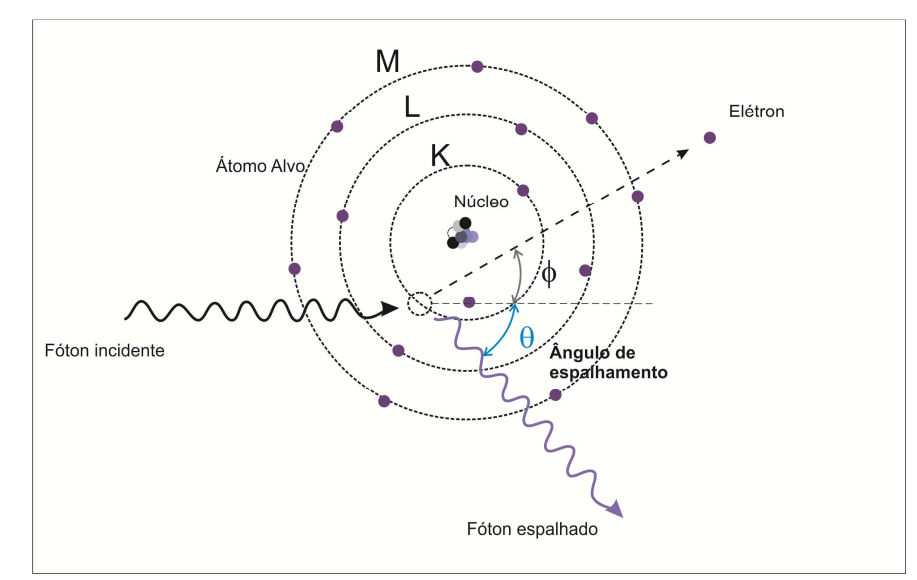

FIGURA 6: Ilustração do processo de interação por espalhamento Compton [38].

Para exprimir a relação entre a energia fornecida para o elétron e o ângulo do fóton espalhado, deve-se relacionar simultaneamente equações de conservação de energia e momento. Daí pode-se escrever as equações que descrevem a transferência de energia:

$$
\begin{gathered}
E^{\prime}=\frac{E}{1+\left[\frac{E}{m_{0} \cdot c^{2}} \cdot(1-\cos \theta)\right]} \\
T=E-E^{\prime}
\end{gathered}
$$

onde , E' a energia do fóton espalhado, $\mathrm{E}=\mathrm{h} v$ a energia do fóton incidente, $\mathrm{m}_{0} \cdot \mathrm{c}^{2}$ representa a energia de repouso do elétron e T a energia cinética do elétron espalhado. 
A probabilidade de interação dos raios X com a matéria por espalhamento Compton varia linearmente com o número atômico $\mathrm{Z}$ do meio de interação do fóton incidente, e predomina entre energias de 0,1 e $5 \mathrm{MeV}$.

\subsection{Semicondutores}

A pesquisa sobre os semicondutores teve início no século XIX e desde então diversos materiais foram estudados. Os semicondutores são compostos atômicos únicos, tais como o silício ( $\mathrm{Si}$ ) e o germânio (Ge), encontrados na coluna IV da Tabela Periódica [40]. No início da década de 50 o germânio foi um dos principais semicondutores e, com o passar dos anos, no início da década de 60, o silício tornou-se seu substituto mais prático. Essa substituição ocorreu pelo fato do silício possuir melhores propriedades à temperatura ambiente e custo reduzido. Outro fator provém da abundância do silício na superfície terrestre, sendo o segundo composto mais encontrado no planeta. No entanto, o silício encontrado na natureza é na forma de $\mathrm{SiO}_{2}$, sendo necessária a sua conversão para silício monocristalino para que seja possível seu uso na construção de componentes eletrônicos.

\subsubsection{Estrutura básica dos semicondutores}

Os materiais semicondutores são sólidos organizados de maneira periódica em uma estrutura tridimensional, ou rede. Este arranjo é submetido constantemente a vibrações térmicas. A célula unitária representa toda a estrutura cristalina, repetindo-se ao longo do cristal formando assim a rede cristalina. A FIG. 7 ilustra três tipos de células unitárias.

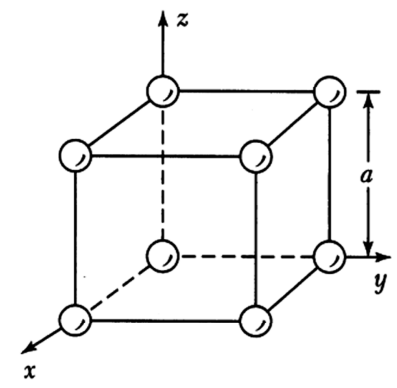

(a)

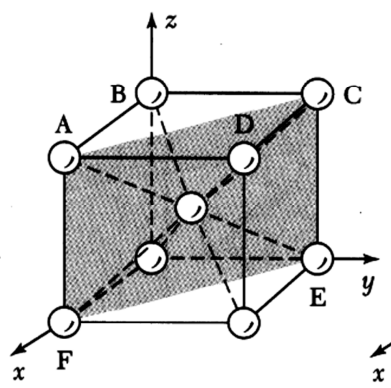

(b)

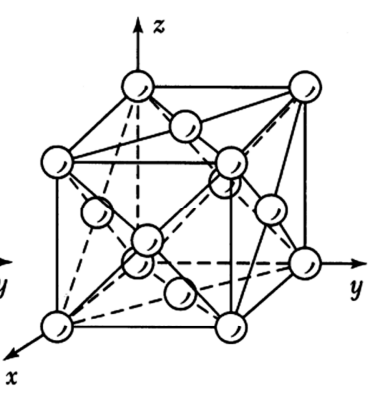

(c)

FIGURA 7:a) Rede cúbica simples. b) Rede cúbica de corpo centrado. c) Rede cúbica de face centrada . [41] 
Elementos semicondutores como o silício e o germânio possuem rede cristalina similar a dos diamantes (FIG.7). Esta estrutura é chamada de cúbica de face centrada (fcc) que pode ser vista como uma sub-rede fcc que intercepta outra sub-rede deslocadas uma da outra por um quarto da distância ao longo da diagonal do cubo, isto é $a \sqrt{3 / 4}$ [41]. A FIG.8 ilustra as posições atômicas na célula cúbica da estrutura do diamante projetadas sobre a estrutura de um cubo, sendo que para uma rede espacial fcc, a base consiste em dois átomos iguais situados em $(0,0,0)$ e $(1 / 4,1 / 4,1 / 4)$. Esta estrutura apresenta a disposição cristalina dos materiais semicondutores Ge (germânio) e Si (silício).

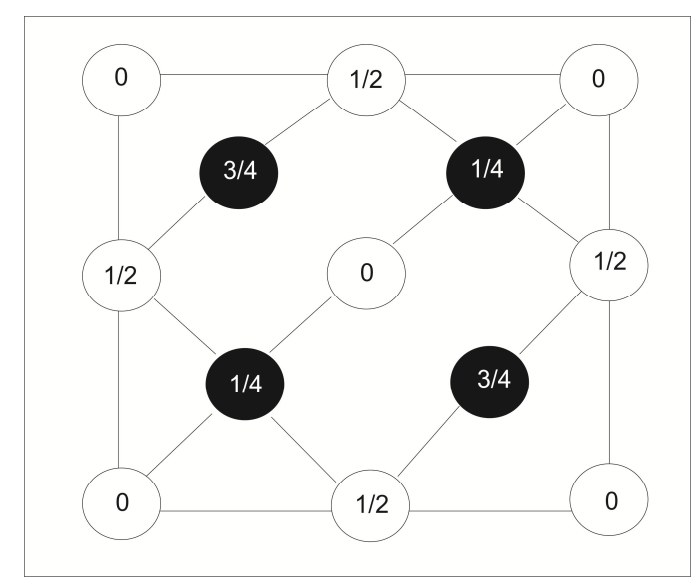

FIGURA 8: Ilustração das posições atômicas na célula cúbica da estrutura do diamante projetadas sobre a estrutura de um cubo [42].

Como citado anteriormente, as ligações do Si e do Ge são similares a de um diamante possuindo em sua rede átomos tetravalentes, como mostra a FIG.9. Cada átomo possui quatro elétrons em sua camada de valência, podendo assim compartilhá-los com seus vizinhos, através de ligações covalentes.

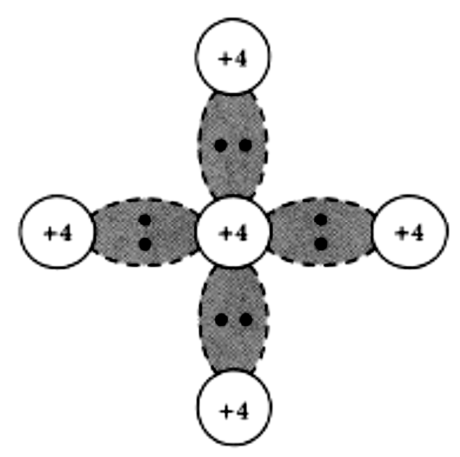

FIGURA 9: Ilustração de uma rede com átomos tetravalentes [43]. 
Do ponto de vista da condutividade, os materiais semicondutores são sensíveis à temperatura e, quando submetidos a temperaturas muito baixas, próximas do zero absoluto, temos a situação onde todos os elétrons estão presos na rede e não podem conduzir. Quando submetemos o cristal a temperaturas mais elevadas, as vibrações térmicas podem quebrar as ligações covalentes, gerando assim elétrons livres que podem contribuir para a condução da corrente, como ilustra a FIG.10. A ausência de elétrons gera uma vacância, ou lacuna como é chamada, que pode ser suprida com elétrons. As lacunas possuem carga positiva e quando submetidas a um campo elétrico externo se movimentam em direção oposta a dos elétrons. Consequentemente, tanto elétrons como as lacunas contribuem para a corrente elétrica total gerada no cristal [43].

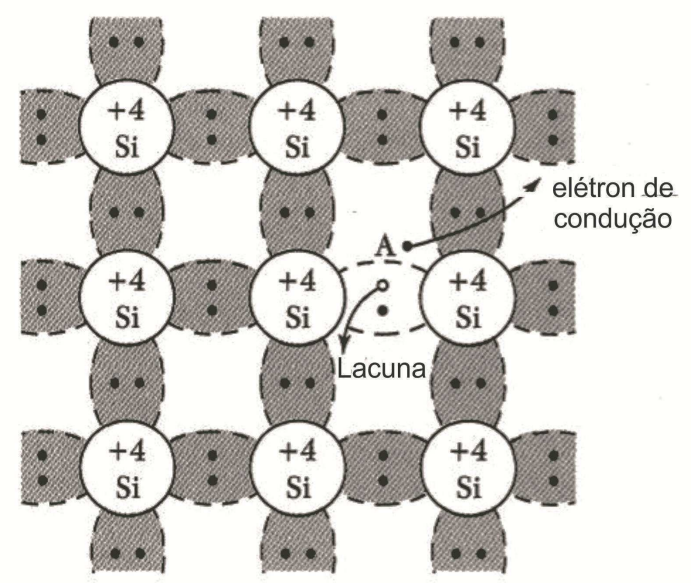

FIGURA 10: Influência da temperatura em um cristal gerando um elétron de condução [41].

\subsubsection{Bandas de energia de um cristal}

Se um cristal for formado por $\mathrm{N}$ átomos, energeticamente ele possuirá também $\mathrm{N}$ níveis de energia associados aos elétrons de valência. Energeticamente falando, a diferença entre níveis mais elevados e mais baixos é de alguns elétrons-volts, sendo que a energia entre níveis energéticos vizinhos é da ordem de $10^{-22} \mathrm{eV}$. Como este valor é muito pequeno, pode-se considerar que os níveis de energia não são discretos e sim contínuos. Para cada nível de energia haverá intervalos de energias proibidas e permitidas, os quais podem ser chamados de bandas proibidas ou bandas permitidas. A FIG.11 Ilustra um diagrama esquemático da formação de um cristal de silício a partir de $\mathrm{N}$ átomos isolados. À temperatura de zero absoluto os elétrons ocupam os estados mais baixos de energia, de 
modo que a banda de valência fica completamente cheia e a banda de condução completamente vazia. Para que um elétron alcance a banda de condução ele deverá possuir uma energia igual ou maior que $\mathrm{E}_{\mathrm{G}}$, a energia da banda proibida. Fisicamente, $\mathrm{E}_{\mathrm{G}}$, é a energia necessária para quebrar uma ligação no semicondutor e gerar um elétron livre para a banda de condução deixando assim uma lacuna na banda de valência [43].

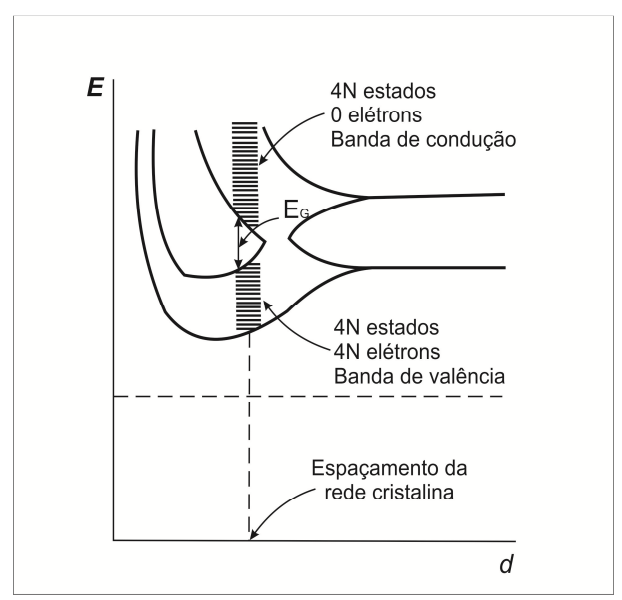

FIGURA 11: Diagrama das bandas de energia em um cristal semicondutor [43].

Do ponto de vista dos níveis de energia das bandas dos materiais podemos traçar um paralelo entre a condutividade dos mesmos e o valor energético da sua banda proibida. A estrutura das bandas de energia de um material isolante pode ser observada na FIG.12 (a), pois a banda proibida é muito extensa e a probabilidade de condução é zero. Os materiais semicondutores, como o nome sugere, possuem as bandas de energia em uma posição intermediária (FIG.12 (b)). Já, os condutores possuem as bandas de valência e condução sobrepostas (FIG.12 (c)), ou a banda de condução parcialmente cheia (FIG.12 (d)).

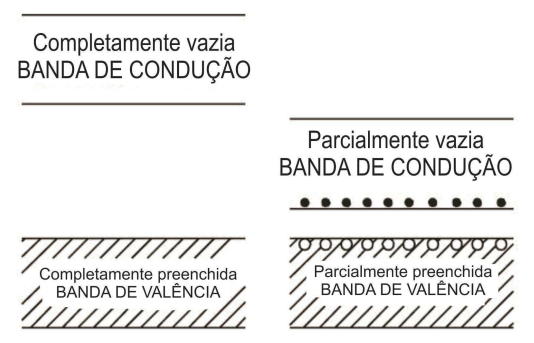

a)

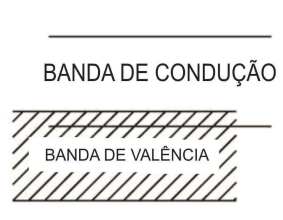

c)
Parcialmente preechida BANDA DE CONDUÇÃO IIIIIIIIIT

d)

FIGURA 12: Estrutura das bandas de energia de um (a) isolante, (b) semicondutor, (c) condutores onde a banda de valência e a de condução se sobrepõem (d) banda de condução parcialmente cheia em um condutor [41]. 
Os materiais semicondutores classificam-se ainda em intrínsecos ou extrínsecos devido à quantidade de impurezas presentes em sua estrutura.

\subsubsection{Semicondutores intrínsecos}

Um semicondutor intrínseco é definido como aquele onde a maioria de seus portadores de carga livres, elétrons e lacunas, originam-se de seus próprios átomos [44], de modo que, quando um elétron recebe energia térmica suficiente para ser transferido da banda de valência para banda de condução, cada lacuna deixada na banda de valência corresponderá a um elétron na banda de condução. Dessa forma podemos afirmar que a concentração de elétrons de condução será exatamente igual à concentração de lacunas na banda de valência:

$$
\mathrm{n}_{\mathrm{i}}=\mathrm{p}_{\mathrm{i}}
$$

onde $n_{i}$ e $p_{i}$ representam a concentração de elétrons e lacunas em um cristal intrínseco.

\subsubsection{Semicondutores extrínsecos}

Na indústria o silício utilizado possui alto grau de pureza, no entanto pode-se inserir de maneira controlada impurezas que alterem as suas propriedades elétricas. Este procedimento é denominado dopagem e geralmente é realizado através da inserção de elementos químicos trivalentes, como o boro, ou pentavalentes, tais como o fósforo ou arsênio. A FIG.13 ilustra um cristal de Si com estrutura de ligação covalente. Neste caso, cada átomo de Si possui quatro elétrons na sua camada de valência. A FIG.13 ilustra a inserção de um elemento pentavalente (arsênio (As)). Este material é denominado semicondutor do tipo $n$ por possuir elétrons em excesso. Este dopante inserido na estrutura do Si, o arsênio (As), é denominado doador [43].

Ao inserir no $\mathrm{Si}$ impurezas trivalentes, teremos uma deficiência no número de elétrons, deixando assim vacâncias na banda de valência. Neste caso, o processo de condução é realizado pelas lacunas geradas e o semicondutor será do tipo $p$. A FIG.14 mostra a inserção de boro (B) na estrutura cristalina do Si, esses dopantes são denominados aceitadores [43]. 


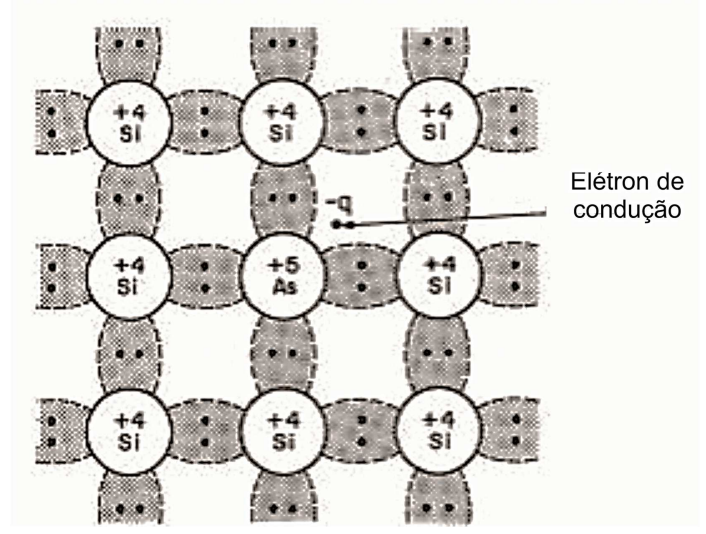

FIGURA 13: Ilustração da inserção de um átomo de arsênio (As) na estrutura do silício [43].

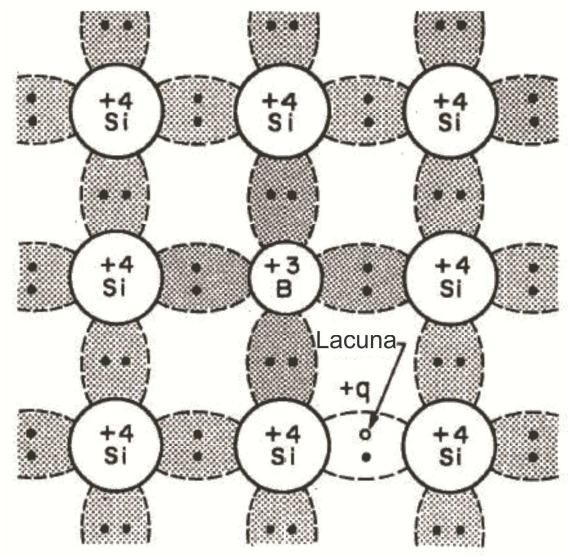

FIGURA 14: Ilustração da inserção de um átomo de boro (B) na estrutura do silício [43].

\subsubsection{Junção pn}

Uma das estruturas eletrônicas mais importantes é a junção pn, obtida pela junção de dois semicondutores extrínsecos de dopagens opostas [43].

A operação dos detectores semicondutores depende da formação de uma junção semicondutora, ou junção pn, conhecida em eletrônica como diodo retificador (embora os detectores semicondutores não sejam utilizados desta forma).

A formação da junção pn ocorre pela justaposição de um semicondutor do tipo $p$ com um do tipo n, através de técnicas especiais como difusão em temperatura elevada ou 
implantação iônica. $\mathrm{Na}$ região da interface entre os dois tipos de materiais surge uma região com características apropriadas para a detecção de radiação, como veremos a seguir.

Partindo-se de um cristal extrínseco do tipo p, eletricamente neutro e em equilíbrio térmico (FIG. 15(a)), quando este é colocado "em contato" com um cristal do tipo n (FIG.15(b)), pela diferença de concentração de portadores majoritários dos dois lados da junção, haverá difusão destes portadores em ambos os materiais: elétrons do lado n para o lado p e lacunas do lado p para o lado n.

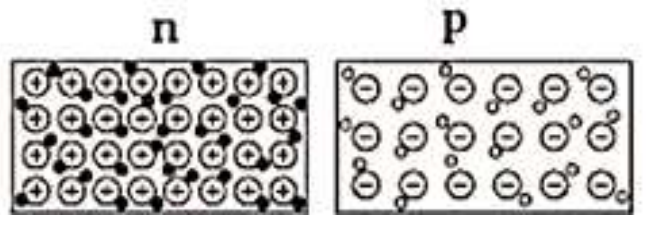

a)

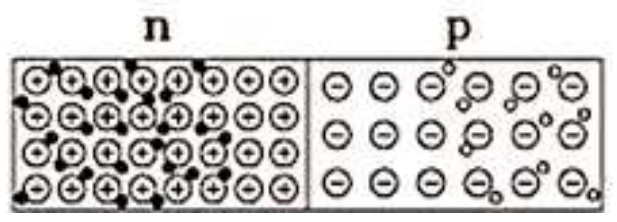

b)

FIGURA 15: (a) semicondutor do tipo p homogeneamente dopado, eletricamente neutro e em equilíbrio térmico com elétrons e lacunas distribuídas igualmente. (b) difusão de elétrons para a região $\mathrm{p}$ e lacunas para a região n gerando um excedente de carga elétrica negativa na região $\mathrm{p}$ e um excedente de carga positiva na região $\mathrm{n}$ [41].

Os elétrons preencherão as lacunas do lado p e as lacunas irão capturar elétrons do lado n. Esta recombinação dá origem ao crescimento de carga espacial em ambos os lados da junção, criando um campo elétrico nesta região capaz de barrar a difusão futura dos portadores majoritários. Este campo elétrico estabelece uma diferença de potencial na junção, chamado potencial de contato, $\mathrm{V}_{\mathrm{C}}$ (para o $\mathrm{Si} \mathrm{V}_{\mathrm{C}} \cong 1 \mathrm{~V}$ ), que promove a remoção dos portadores majoritários desta interface, dando origem a uma região depletada de portadores livres de carga ou zona de depleção, cujas propriedades elétricas são essenciais para a detecção da radiação.

\subsection{Princípio de funcionamento de diodos de Si como dosímetros de radiação}

Quando consideramos a incidência de radiação em uma junção pn, de fato, os pares elétron-lacuna produzidos pela radiação ionizante nesta região serão separados pelo campo elétrico aí existente; se contatos elétricos apropriados forem colocados nas extremidades da 
junção, uma corrente proporcional à ionização produzida será gerada, permitindo a sua detecção (FIG.16).

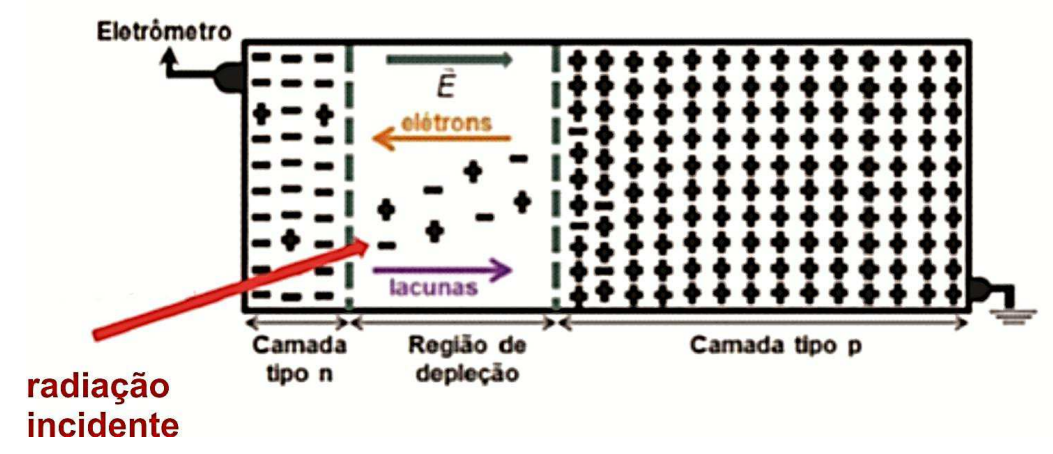

FIGURA 16: Ilustração do processo de interação da radiação com um diodo [45].

Devido à elevada resistividade da zona de depleção, esta pode ser considerada equivalente a um capacitor plano de placas paralelas e sua capacitância dada por:

$$
\mathrm{C}=\mathrm{k} \cdot \varepsilon_{0} \cdot \frac{\mathrm{A}}{\mathrm{d}}
$$

onde $k=11,9$ é a constante dielétrica ou permissividade relativa do $\mathrm{Si}, \varepsilon_{0}$ é a permissividade dielétrica no vácuo, $A$ é a área útil do dispositivo e $d$ a espessura da sua região de depleção.

Em aplicações onde se deseja aumentar a eficiência de coleta de pares elétronlacuna, polariza-se a junção pn reversamente, de modo que a tensão aplicada se superponha ao potencial de contato. Como consequência, há um aumento da extensão da região de depleção com decréscimo da sua capacitância e aumento do volume sensível de detecção.

Entretanto, juntamente com essas vantagens, verifica-se um aumento da corrente de fuga na junção decorrente do aumento da deriva de portadores minoritários nesta região. Portanto, deve existir um compromisso entre a aplicação que se deseja e a corrente de fuga máxima em que o detector pode operar.

No modo fotovoltaico, a corrente gerada pela incidência de radiação, como vimos anteriormente, será devida à coleta dos pares elétron-lacuna produzidos por ação apenas do potencial de contato na junção e também dos portadores minoritários existentes fora dela, que acabam se difundindo para seu interior, contribuindo também para a corrente total [1]. A largura total da região sensível do diodo, $\mathrm{d}_{\mathrm{S}}$, pode então ser definida pela EQ. [8]: 


$$
\mathrm{d}_{\mathrm{S}}=\mathrm{L}_{\mathrm{n}}+\mathrm{L}_{\mathrm{p}}+\mathrm{d}
$$

onde d, $\mathrm{L}_{\mathrm{n}}$ e $\mathrm{L}_{\mathrm{p}}$ representam, respectivamente, a largura da região de depleção, a extensão da difusão dos elétrons da região tipo p e a extensão da difusão das lacunas da região tipo n.

Admitindo-se uma irradiação homogênea no diodo e operando-o em modo fotovoltaico [43], a densidade de corrente induzida pela radiação pode ser escrita como sendo [43]:

$$
\mathrm{J}_{\mathrm{CC}}=-\mathrm{q} \cdot \mathrm{G}_{\mathrm{L}} \cdot\left(\mathrm{L}_{\mathrm{n}}+\mathrm{L}_{\mathrm{p}}+\mathrm{d}\right)
$$

onde q e $\mathrm{G}_{\mathrm{L}}$ representam, respectivamente, a carga gerada na irradiação e a taxa de geração de portadores por unidade de volume.

Como a densidade de corrente, EQ. 9, está diretamente ligada ao volume sensível do detector, pode-se também escrever a equação para a determinação da corrente medida. De acordo com a EQ. 10 [1] temos:

$$
I_{C C}=-q \cdot A \cdot G_{L} \cdot\left(L_{n}+L_{p}+d\right)
$$

onde A representa a área do detector.

Espera-se, portanto, que a fotocorrente gerada pelos processos de interação da radiação no detector seja proporcional ao seu volume sensível e à taxa de dose, parâmetro importante para dosimetria.

\subsubsection{Corrente de fuga}

Embora em ausência de radiação um diodo usado como detector seja considerado idealmente como não condutor, há sempre uma pequena corrente que flui através da junção pn, que aumenta com eventual tensão reversa aplicada ao diodo. Esta corrente, que aparece como ruído para o sistema de detecção, limita a menor corrente devida à radiação incidente que pode ser medida e tem como causas principais três fatores: a) movimento de 
portadores minoritários ao longo da junção pn; b) geração térmica de portadores de carga a partir de centros de recombinação e armadilhas no cristal e c) corrente de fuga pelos canais superficiais do cristal.

Em nossas medidas a contribuição desta corrente foi minimizada mediante operação dos diodos sem tensão de polarização externa e uso em ambiente com temperatura controlada, relativa às condições de calibração exigidas pela norma IEC 61674.

\subsubsection{Dano de radiação}

Uma das restrições mais importantes ao uso de detectores semicondutores na área médica está relacionada aos danos impostos na estrutura do cristal pela radiação incidente, devidos a defeitos pontuais causados pelo deslocamento de átomos de suas posições usuais que ocorrem pela interação de partículas carregadas com a rede cristalina. Estes defeitos estruturais dão origem a níveis de energia discretos na banda proibida do cristal, os quais atuam como armadilhas e centros de recombinação, reduzindo o número de portadores de carga disponíveis para formação de um sinal elétrico.

Os principais efeitos decorrentes dos danos de radiação, cuja intensidade varia com o tipo, energia e taxa de incidência da radiação, se traduzem em queda de sensibilidade do detector com a dose acumulada, aumento da corrente de fuga e da tensão total de depleção do dispositivo, bem como a redução da eficiência de coleta de cargas proveniente do armadilhamento de elétrons e lacunas [13-20]. A intensidade destes defeitos é, portanto, fator determinante da máxima fluência de radiação a que um detector pode estar exposto sem que haja comprometimento da qualidade de sua resposta para as diferentes aplicações.

\subsubsection{Uso de diodos epitaxiais}

Com a finalidade de transpor a principal desvantagem do uso de diodos de Si na dosimetria de fótons e elétrons, caracterizada pela queda de sensibilidade com aumento da dose acumulada causada pelos danos de radiação citados, muito tem sido feito no sentido de aumentar a resistência dos diodos a esses danos utilizando técnicas de dopagem especiais com oxigênio e platina, bem como submetendo diodos comerciais a uma etapa de 
pré-irradiação com feixes de elétrons ou fótons a doses da ordem de $10 \mathrm{kGy}$ [46]. Este procedimento, que visa saturar os dispositivos em termos de danos em sua estrutura, faz com que os diodos apresentem menor sensibilidade, porém, com maior estabilidade de resposta; entretanto, observa-se um decréscimo, ainda que menos pronunciado, na sensibilidade dos diodos pré-irradiados que no caso de aplicações médicas determina frequentes recalibrações.

Como visto anteriormente (EQ. 10), os dosímetros que operam no modo fotovoltaico apresentam sensibilidade proporcional ao volume sensível de detecção, o qual é determinado fundamentalmente pelo comprimento de difusão (L) dos portadores minoritários de carga. A degradação de resposta dos diodos está diretamente vinculada à diminuição do tempo de vida destes portadores devido à criação de centros de recombinação pela incidência de radiação (dose). Como o comprimento de difusão é proporcional ao tempo de vida dos portadores minoritários, esses danos pontuais provocam a diminuição do volume sensível do dosímetro e em consequência, de sua sensibilidade.

Uma inovação que tem determinado avanço significativo na direção de mitigar esses danos de radiação em detectores semicondutores foi proposta recentemente [29,32,33]. Trata-se de limitar o volume sensível de detecção mediante a implantação da junção semicondutora em uma fina camada epitaxial, cuja área é definida pelo uso de anéis de guarda incorporados na estrutura do diodo. Esta técnica, que utiliza materiais e técnicas de processamento bem conhecidas, permite a produção de sensores únicos ou segmentados cuja sensibilidade tem se mostrado independente da dose acumulada. A razão desta estabilização de resposta dos diodos epitaxiais, com sensibilidades adequadas para uso em dosimetria de radiação, baseia-se no fato de que ao limitar a espessura ativa dos dispositivos a valores $(\cong 50 \mu \mathrm{m})$ menores que o comprimento de difusão dos portadores minoritários (mesmo em condição de máxima dose de operação), estando sua área fixa pelos anéis de guarda, consegue-se manter o volume sensível do dosímetro praticamente inalterado e independente da dose acumulada. Além disso, esses diodos apresentam menor zona morta quando comparados aos diodos de fusão zonal (mais comumente empregados em dosimetria) contribuindo para o aumento de sensibilidade em baixas energias. $\mathrm{O}$ uso bem sucedido deste tipo de diodo na dosimetria de feixes de radioterapia [47,48], inclusive no grupo de detectores semicondutores do Centro de Tecnologia das Radiações do IPENCNEN/SP [49], nos incentivou a estudar as características de resposta destes diodos para feixes de radiação eletromagnética de menor energia, na área de diagnóstico médico. 


\subsection{Grandezas dosimétricas}

\subsubsection{Exposição}

Historicamente a exposição é grandeza mais antiga e foi definida em 1928 pela ICRU [50] com a unidade Roentgen (R). Por convenção define-se exposição somente para raios X e Gama [39].

A dosimetria utiliza a ionização no ar como referência por muitos anos devido a parâmetros físicos favoráveis, que provém do fato do ar possuir um número atômico semelhante ao do tecido mole (pele), ficando assim mais fácil correlacionar os efeitos biológicos causados pelos raios $\mathrm{X}$ e raios gama e a energia requerida para produzir um par de íons no ar (w).

De acordo com a ICRU (1980) [51], a exposição, X, é o quociente de $d Q$ por $d m$, onde $d Q$ é o valor absoluto da carga total dos íons de um sinal produzidos no ar quando todos os elétrons liberados pelos fótons em uma massa $d m$ no ar são completamente freados. Assim podemos escrever [39]:

$$
X=\frac{d Q}{d m}
$$

A unidade de Exposição é o C.kg-1 (Coulomb por kilograma), que anteriormente era chamada de R (Röntgen), no SI é denotada como $\mathrm{R}=2,58 \times 10^{-4} \mathrm{C}_{\mathrm{kg}} \mathrm{kg}^{-1}$ [39].

\subsubsection{Dose Absorvida}

A dose absorvida é uma grandeza relevante para todos os tipos de campos de radiação ionizante, bem como qualquer fonte de radiação ionizante distribuída em um meio absorvedor. A energia absorvida por unidade de massa é a grandeza mais importante que correlaciona os efeitos dessas radiações.

De acordo com o ICRU (1998) [52] a dose absorvida é dada por $\mathrm{d} \overline{\mathrm{E}} / \mathrm{dm}$, onde $\mathrm{d} \overline{\mathrm{E}}$ representa a energia média depositada pela radiação ionizante em uma quantidade de massa dm: 


$$
\mathrm{D}=\frac{\mathrm{d} \overline{\mathrm{E}}}{\mathrm{dm}}
$$

A unidade da dose absorvida é o gray (Gy), que equivale a 1 Joule por kilograma $\left(\mathrm{J}_{\mathrm{kg}}{ }^{-1}\right)$.

\subsubsection{Taxa de dose absorvida}

A taxa de dose absorvida é simplesmente o quociente $\mathrm{dD}$ por $\mathrm{dt}$, onde $\mathrm{dD}$ é o incremento de dose absorvida no intervalo de tempo dt.

$$
\dot{\mathrm{D}}=\frac{\mathrm{dD}}{\mathrm{dt}}=\frac{\mathrm{d}}{\mathrm{dt}}\left(\frac{\mathrm{d} \overline{\mathrm{E}}}{\mathrm{dm}}\right)
$$

A unidade da taxa de dose absorvida é o Gy.s. ${ }^{-1}$.

\subsubsection{Kerma}

A grandeza kerma está diretamente ligada com a Exposição, sendo que conceitualmente elas são muito próximas. Formalmente, pela ICRU, o Kerma, K, é o quociente $\mathrm{dE}_{\mathrm{tr}} / \mathrm{dm}$, onde $\mathrm{dE}_{\mathrm{tr}}$ é a soma da energia cinética inicial de todas as partículas ionizantes e carregadas liberadas por radiação ionizante (sem carga) em uma determinada quantidade de massa dm [39]:

$$
\mathrm{K}=\frac{\mathrm{dE}_{\mathrm{tr}}}{\mathrm{dm}}
$$

A unidade do Kerma é a mesma para dose absorvida, i.e. J.kg-1 (Gy) [SI]. O Kerma se aplica sempre para radiação indiretamente ionizante (fótons e nêutrons). Em condições onde a radiação de freamento for desprezível e se estabelecer equilíbrio eletrônico, o Kerma será igual a dose absorvida no ar (ICRU 1980) [51]. 


\subsubsection{Teoria cavitária}

Para que se possa medir a dose absorvida em um meio, faz-se necessário a inserção de um dispositivo sensível à radiação, ou um dosímetro. Geralmente o meio sensível do dosímetro não será igual ao do material em que o mesmo é incorporado. Dessa maneira, segundo Bragg, a Teoria Cavitária relaciona a dose absorvida no meio sensível do dosímetro (cavidade) com a dose absorvida no meio circundante que contém a cavidade. De acordo com a teoria de Bragg-Gray, este meio pode ser um gás, um líquido ou um sólido, e é referida de uma maneira geral como uma cavidade. De uma forma geral, a cavidade pode ser pequena média ou grande, quando comparada com o alcance das partículas carregadas produzidas por fótons no meio [39].

\subsubsection{Teoria de Bragg-Gray}

Em 1929, Gray, foi o primeiro a enunciar o princípio cavitário, embora Bragg em 1912 já tivesse discutido o assunto. O desenvolvimento dado por Gray à teoria cavitária foi baseado na ionização do ar provocada pela radiação gama.

Considerando-se o meio uniformemente irradiado e existindo equilíbrio eletrônico, a energia depositada por elétrons secundários num elemento de volume é igual à energia perdida por fótons por meio de interações. Desta forma, o princípio da equivalência enunciado por Gray, diz que: a energia perdida pelos elétrons na cavidade por unidade de volume é $1 / \rho$ vezes a energia perdida pela radiação gama por unidade de volume do sólido, sendo $\rho$ a densidade volumétrica do meio. Assim pode-se escrever a relação de Bragg-Gray como [39]:

$$
\mathrm{D}_{\text {meio }}=\mathrm{D}_{\text {cavidade }} \cdot \mathrm{mS}_{\text {cavidade }}^{\text {meio }}
$$

onde $\mathrm{D}_{\text {meio }} \mathrm{e} \mathrm{D}_{\text {cavidade }}$ representam a dose absorvida no meio e na cavidade, respectivamente, e $\mathrm{mS}_{\text {cavidade }}^{\text {meio }}$ a razão entre os poderes de freamento mássico médio do meio e da cavidade.

A relação de Bragg-Gray é um modelo de perda contínua de radiação, pois não leva em consideração a produção dos raios delta que depositam energia fora do volume de interesse, mas, considera que toda energia perdida pelos elétrons é dissipada localmente. 


\subsection{Formalismo Dosimétrico}

A Technical Reports Series No. 457 (TRS 457) [35] recomenda o formalismo dosimétrico empregado para a dosimetria em processos de radiodiagnóstico, sendo similares à recomendação para a determinação da dose absorvida na água em radioterapia regidas pela Technical Reports Series No. 398 (TRS 398). A TRS 398 tem seu formalismo baseado em termos da dose absorvida na água, já a TRS 457 baseia-se em padrões de Kerma no ar. $\mathrm{O}$ coeficiente de calibração, $\mathrm{N}_{\mathrm{k}}$, é baseado nestes formalismos implantados por meio deste. Neste tópico vamos discutir a definição do coeficiente de calibração e os fatores de correção aplicados na sua obtenção no presente trabalho.

\subsubsection{Coeficiente de Calibração, $\mathbf{N}_{k}$}

O coeficiente de calibração refere-se às condições usadas no laboratório expressando a razão entre o valor convencional da quantidade medida pelo valor indicado. A EQ.16 apresenta o cálculo para o coeficiente de calibração [35]:

$$
\mathrm{N}_{\mathrm{k}, \mathrm{Q}_{0}}=\frac{\mathrm{K}_{\mathrm{a}}}{\left(\mathrm{M}_{\mathrm{Q}_{0}}-\mathrm{M}_{0}\right)}
$$

onde $\mathrm{K}_{\mathrm{a}}$ é o Kerma no ar, em um ponto de referência (no ar) para um feixe com a qualidade de referência $\mathrm{Q}_{0} ; \mathrm{M}_{\mathrm{Q}_{0}}$ é a leitura do dosímetro sob condições de referência utilizadas em um laboratório; $\mathrm{M}_{0}$ é a leitura do dosímetro na ausência do feixe (leitura zero); e finalmente $\mathrm{N}_{\mathrm{k}, \mathrm{Q}_{0}}$ é o coeficiente de calibração em termos do kerma no ar obtido no laboratório padrão. A EQ.16 representa uma forma genérica para a determinação do coeficiente de calibração, sendo necessária a definição de alguns fatores de correção, tais como os de temperatura e pressão ambientais para câmaras de ionização não seladas.

As condições de referência englobam um conjunto de valores de grandezas de influência onde o coeficiente de calibração é valido sem correções. Essas grandezas de influência para calibrações em termos de Kerma no ar são a qualidade do feixe, a temperatura ambiente, a pressão do ar e a umidade relativa do ar. Como as condições de medição normalmente não são coincidentes com as de referência utilizadas em laboratórios padrão faz-se necessário o uso de correções. 
As grandezas de influência podem ser definidas como quantidades que não são objeto de medição, porém influenciam no resultado da medição. Estas grandezas podem ser de naturezas diferentes como temperatura e pressão, ou estarem relacionadas com o campo de radiação. As grandezas de influência podem ter diferentes efeitos em diferentes tipos de dosímetro, como por exemplo, a resposta de um dosímetro semicondutor, ao contrário de uma câmara de ionização, normalmente não é influenciada por alterações da pressão atmosférica.

Assumindo que as grandezas de influência agem de forma independente uma da outra podemos fazer o produto dos fatores de correção, $\mathrm{k}_{\mathrm{i}}$, e aplicando na EQ.17 com o kerma no ar K, no feixe de qualidade $\mathrm{Q}$, podemos escrever [35]:

$$
\mathrm{K}=\left(\mathrm{M}_{\mathrm{Q}}-\mathrm{M}_{0}\right) \mathrm{N}_{\mathrm{K}, \mathrm{Q}_{0}} \prod_{\mathrm{i}} \mathrm{k}_{\mathrm{i}}
$$

onde $\mathrm{M}_{\mathrm{Q}}$ é a leitura do instrumento para a qualidade do feixe $Q$, e os fatores $k_{i}$ representam a correção para os efeitos das i-ésimas grandezas de influência. Os fatores de correção podem ser aplicados aos coeficientes de calibração. Por definição $\mathrm{k}_{\mathrm{i}}$ é igual a 1 onda as grandezas de influência assumem os valores de referência.

Em aplicações onde a leitura de fundo é muito pequena quando comparada com a leitura do dosímetro, $\mathrm{M}_{0}$ poderá ser desconsiderada, uma vez que sua magnitude é insignificante quando comparada com $\mathrm{M}_{\mathrm{Q}}$. A EQ. 18 pode ser reescrita como [35]:

$$
\mathrm{K}=\mathrm{M}_{\mathrm{Q}} \mathrm{N}_{\mathrm{K}, \mathrm{Q}_{0}} \prod_{\mathrm{i}} \mathrm{k}_{\mathrm{i}}
$$

Para os dosímetros calibrados neste trabalho os fatores de correção mais relevantes que foram utilizados foram o de densidade do ar e o de correção para as qualidades do feixe, os quais serão discutidos a seguir.

\subsubsection{Fator de correção para a densidade do ar}

Um fator de correção que muitas vezes é aplicado em medições, tanto em câmaras de ionização quanto em dispositivos semicondutores, é o que corrige as alterações devidas à densidade do ar pelas variações da temperatura ambiente e pressão. Relacionando estes parâmetros podemos escrever a EQ. 19 [35]: 


$$
\mathrm{k}_{\rho}=\left(\frac{273,2+\mathrm{T}}{273,2+\mathrm{T}_{0}}\right)\left(\frac{\mathrm{P}_{0}}{\mathrm{P}}\right)
$$

onde $\mathrm{P}_{0}$ e $\mathrm{T}_{0}$ correspondem à pressão e temperatura de referência, respectivamente.

A norma TRS 457 recomenda que sejam utilizados os valores de referência de pressão $\left(\mathrm{P}_{0}=101,3 \mathrm{kPa}\right)$ e temperatura $\left(\mathrm{T}_{0}=20{ }^{\circ} \mathrm{C}\right)$ para que o fator de correção $\mathrm{k}_{\rho}$ seja definido. Para a umidade relativa do ar, a norma também recomenda um fator de correção específico, porém se a umidade estiver entre $30 \%$ e $80 \%$ esta correção poderá ser desconsiderada.

\subsubsection{Fator de correção para a qualidade do feixe}

O coeficiente de calibração é calculado primariamente em função da qualidade do feixe utilizado como referência, $\mathrm{Q}_{0}$. Assumindo que as outras grandezas de influência sejam mantidas nos valores de referência e o kerma no ar de uma qualidade Q, diferindo do kerma da qualidade $\mathrm{Q}_{0}$, deve-se utilizar a correção [35]:

$$
\mathrm{k}_{\mathrm{Q}, \mathrm{Q}_{0}}=\frac{K_{Q}}{\mathrm{M}_{\mathrm{Q}} \mathrm{N}_{\mathrm{K}, \mathrm{Q}_{0}}}
$$

onde o fator $\mathrm{k}_{\mathrm{Q}_{\text {, }}}$ corrige a diferença entre o feixe da qualidade referência $\mathrm{Q}_{0}$ e o feixe de qualidade Q.

\subsection{Qualidades de radiação}

\subsubsection{Qualidades de radiação implantadas em um tubo de raios X convencional}

Ao estabelecer qualidades de feixes de radiação em um tubo de raios $\mathrm{X}$ deve-se atentar principalmente para as normas e recomendações internacionais, tais como a IEC 61267 [53], para estabelecer com segurança que não haja ambiguidade na definição das qualidades de radiação. 


\subsubsection{Qualidade de radiação padrão de radiodiagnóstico feixes diretos (RQR)}

Geralmente a qualidade de radiodiagnóstico feixes diretos, RQR, é estabelecida em um tubo convencional de raios $\mathrm{X}$ com alvo de tungstênio.

O processo de implantação desta qualidade inicia-se com o estabelecimento das tensões no tubo e suas incertezas. Logo em seguida é necessária a determinação da quantidade necessária de filtração para que a qualidade corresponda a RQR. Este processo é feito através de uma curva de atenuação com camadas de alumínio[35].

\subsubsection{Qualidade de radiação padrão RQA atenuados e RQT}

As qualidades de radiação da série RQA (feixes atenuados) representam simulações do campo de radiação por trás de um paciente, enquanto que a série RQT simula feixes não atenuados usados em tomografia computadorizada (CT). Uma vez estabelecidas em um tubo de raios $\mathrm{X}$ as qualidades RQR, as qualidades RQA e RQT são facilmente obtidas com a adição de filtrações adicionais previstas na norma IEC 61267. Para estabelecer a qualidade RQA é necessária a adição de filtros de alumínio, enquanto a qualidade RQT é obtida adicionando-se filtrações de alumínio e cobre, também em concordância com a norma (IEC 61267).

\subsubsection{Qualidade de radiação padrão $R Q R-M$ e RQA-M}

Para as qualidades de mamografia, RQR-M, é necessário que o tubo de raios $\mathrm{X}$ possua anodo de molibdênio; se esta condição não puder ser satisfeita, deve-se inserir uma filtração adicional de molibdênio para que a qualidade seja implantada. Já para as qualidades RQA-M, que simulam campos de radiação atrás do paciente, assim como a RQA em relação à RQR, deve-se inserir filtros adicionais de alumínio (Al) para que os valores de Kerma estejam em concordância com a norma.

As simulações das diferentes qualidades de raios $\mathrm{X}$ utilizadas neste trabalho utilizando o código de Monte Carlo disponível para uso livre no sítio da Siemens® [54-57] encontram-se no APÊNDICE A desta dissertação. 


\section{MATERIAIS E MÉTODOS}

\subsection{Diodos de Si}

Neste trabalho foram empregados como dosímetros três diodos: dois crescidos pelo método epitaxial (EPI) e o terceiro crescido pelo método de Fusão Zonal Padrão (FZ). Os diodos epitaxiais utilizados foram fabricados com uma fina camada epitaxial de $50 \mu \mathrm{m}$ crescida sobre um substrato de $300 \mu \mathrm{m}$ de Si do tipo n, processados pelo Instituto de Física Experimental (IFE) da Universidade de Hamburgo, Alemanha; o diodo FZ possui um substrato único de $300 \mu \mathrm{m}$ crescido pelo método de fusão zonal padrão e foi produzido no Centro de Microeletrônica da Universidade Tecnológica de Helsinque, Finlândia. Estes dispositivos foram gentilmente doados no âmbito de colaborações entre os referidos laboratórios e o Laboratório de Desenvolvimento de Novos Tipos de Detectores de Radiação do CTR no IPEN-CNEN/SP.

Dentre as amostras estudadas, apenas o diodo EPI\#45 foi submetido a um processo de pré-irradiação com $200 \mathrm{kGy}$ de raios gama do ${ }^{60} \mathrm{Co}$, realizado no irradiador do tipo Gammacell, Nordion modelo 220, do Centro de Tecnologia das Radiações (CTR) do IPEN/CNEN-SP. Esta conduta descrita por alguns autores [33, 49, 58, 59] é usada para atingir a condição de estabilidade de resposta do dosímetro em termos de sensibilidade. Por esta razão, este diodo foi usado como referência para o estudo comparativo com os diodos sem irradiação prévia.

As características dos diodos utilizados como tensão de depleção total $\left(\mathrm{V}_{\mathrm{fd}}\right)$, corrente de fuga para tensão de depleção total a zero volts $\left(\mathrm{I}_{\text {fuga } 0 \mathrm{~V}}\right)$, área útil $(\mathrm{A})$, volume sensível (V), espessura (d) e resistividade ( $\rho$ ) estão resumidas na TAB. 1, segundo dados dos fabricantes. Os números atribuídos às amostras pelos respectivos fabricantes correspondem às posições ocupadas pelos diodos na pastilha matriz. 
TABELA 1: Características elétricas e dimensões dos diodos utilizados neste trabalho. A numeração da amostra corresponde a sua posição na pastilha matriz durante seu processo de produção.

\begin{tabular}{ccccccc}
\hline Diodo & $\mathrm{V}_{\mathrm{fd}}(\mathrm{V})$ & $\mathrm{I}_{\text {fuga } 0 \mathrm{~V}}(\mathrm{nA})$ & $\mathrm{A}\left(\mathrm{mm}^{2}\right)$ & $\mathrm{V}\left(\mathrm{mm}^{3}\right)$ & $\mathrm{d}(\mu \mathrm{m})$ & $\rho(\Omega . \mathrm{cm})$ \\
\hline EPI\#45 & 124,45 & 0,027 & 25 & 1,25 & 50 & 50 \\
EPI\#46 & 120,13 & 0,026 & 25 & 1,25 & 50 & 50 \\
FZ\#04 & 14,00 & 30,000 & 25 & 7,5 & 300 & $10^{4}$ \\
\hline
\end{tabular}

\subsection{Sondas Dosimétricas}

Para serem empregados como dosímetros de feixes clínicos, os diodos tiveram sua face $\mathrm{n}^{+}$(backplane) fixada com cola epóxi condutora em uma base cerâmica com terminais em ouro (também desenvolvida pelo IFE/Universidade de Hamburgo) (FIG. 17a), enquanto a face $\mathrm{p}^{+}$(eletrodo para a extração dos sinais) foi micro-soldada em um dos terminais desta base (FIG. 17b). Estas etapas foram realizadas no Centro de Tecnologia da Informação Renato Archer, em Campinas.

A seguir, cada diodo foi acondicionado em uma sonda de acrílico (PMMA) preto medindo $25 \mathrm{~mm} \times 10 \mathrm{~mm}$ x $50 \mathrm{~mm}$, com janela de papel de $8,3 \mathrm{~g} / \mathrm{cm}^{2}$ de espessura (FIG. 17c), projetada de modo a fornecer resistência mecânica e proteção contra a luz ambiente e poeira (FIG. 17d).

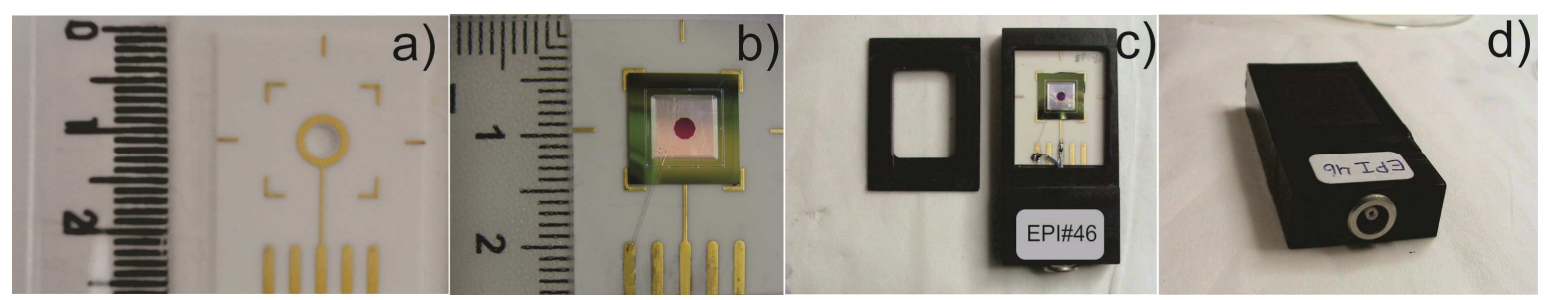

FIGURA 17: a) Base cerâmica com contatos em ouro; b) diodo epitaxial fixado na base cerâmica com a face $\mathrm{p}^{+}$micro soldada; c) sonda dosimétrica aberta; d) sonda dosimétrica pronta para irradiação.

Os diodos de Si foram ligados em modo fotovoltaico, com seu eletrodo de extração de sinais (face $\mathrm{p}^{+}$) conectado diretamente a um eletrômetro Keithley ${ }^{\circledR}$, modelo 6517B. As leituras das fotocorrentes produzidas pela incidência da radiação foram armazenadas no eletrômetro e transferidas para um computador portátil através de uma plataforma desenvolvida em $\mathrm{LabView}^{\circledR}$, fornecida pelo fabricante, com o auxílio de uma interface GPIB-USB. 


\subsection{Sistema de raios $X$}

As irradiações com feixes de fótons clínicos foram realizadas no Laboratório de Calibração de Instrumentos (LCI) do IPEN/CNEN-SP, considerado de referência, onde está instalado um gerador de radiação X industrial, Pantak-Seifert, modelo Isovolt 160 HS $(5 \mathrm{kV}-160 \mathrm{kV})$ de potencial constante, com alvo de tungstênio e filtração inerente de 0,8 mm Be (FIG. 18). Neste sistema foram implantadas qualidades de feixe de radiação específicas para radiodiagnóstico convencional, mamografia e tomografia computadorizada de acordo com a norma IEC 61267 [53]. As qualidades dos feixes foram certificadas com câmaras de ionização Radcal modelos RC3CT série 8769 (tomografia), RC6 série 16675 (radiodiagnóstico convencional) e RC6M de série 9231(mamografia), calibradas no Physikalisch-Technische Bundesanstalt (PTB) na Alemanha.

As filtrações adicionais (roda de filtros) empregadas nos feixes atenuados foram posicionadas na saída do tubo (em contato com a blindagem), assim como a filtração de molibdênio utilizada para as qualidades mamográficas. A saída do feixe de raios $\mathrm{X}$ era controlada pelo usuário através da abertura e fechamento de um obturador. A FIG.18 ilustra a montagem para a caracterização dosimétrica dos diodos.

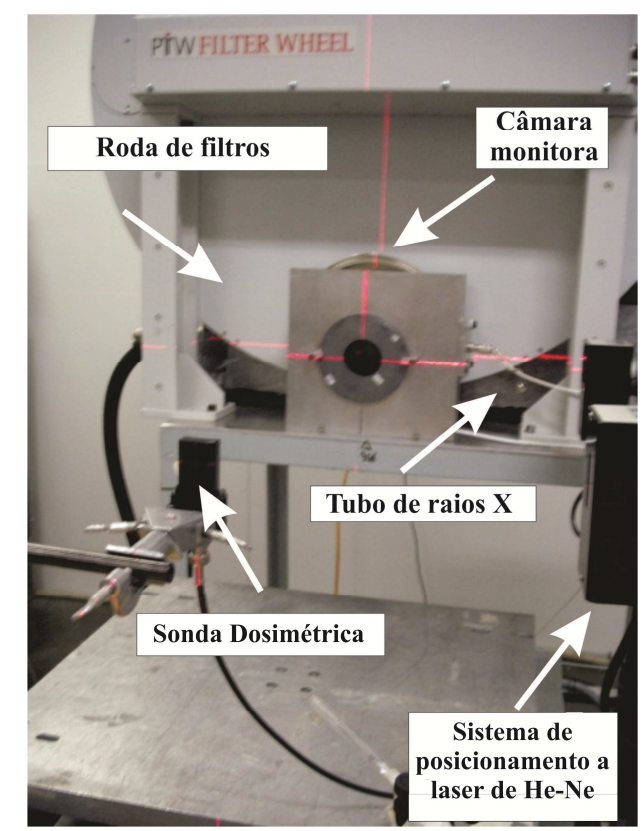

FIGURA 18: Equipamento de radiação X Pantak/Seifert instalado no LCI do IPENCNEN/SP com a sonda dosimétrica posicionada com auxílio de feixes de lasers de He-Ne. 
$\mathrm{Na}$ TAB.2 são apresentadas as qualidades de raios $\mathrm{X}$ clínicos implantadas no sistema Pantak-Seifert e utilizadas neste trabalho, onde os feixes de referência de cada qualidade estudada estão assinalados em negrito. E a TAB. 3 apresenta os intervalos de energias nominal e média [54-57] dos feixes.

TABELA 2: Qualidades dos feixes de raios $\mathrm{X}$ implantados no sistema Pantak-Seifert 160HS Isovolt e utilizados neste trabalho. Os feixes de referência de cada qualidade estudada estão assinalados em negrito.

\begin{tabular}{|c|c|c|c|}
\hline \multicolumn{4}{|c|}{ Qualidades de mamografia (feixes diretos) } \\
\hline Qualidade & $\mathrm{kV} \quad \mathrm{mA}$ & Filtração (mm) & Taxa de Kerma no ar (mGy/min) \\
\hline RQR-2M & 2810 & 0,07 Mo & $13,0(3)$ \\
\hline RQR-4M & 35 & 0,07 Mo & $19,2(4)$ \\
\hline \multicolumn{4}{|c|}{ Qualidades de mamografia (feixes atenuados) } \\
\hline Qualidade & $\mathrm{kV} \quad \mathrm{mA}$ & Filtração (mm) & Taxa de Kerma no ar (mGy/min) \\
\hline RQA-2M & $28 \quad 10$ & $0,07 \mathrm{Mo}+2,0 \mathrm{Al}$ & $0,68(1)$ \\
\hline RQA-4M & $35 \quad 10$ & $0,07 \mathrm{Mo}+2,0 \mathrm{Al}$ & $1,48(3)$ \\
\hline \multicolumn{4}{|c|}{ Qualidades de Tomografia } \\
\hline Qualidade & $\mathrm{kV} \quad \mathrm{mA}$ & Filtração (mm) & Taxa de Kerma no ar (mGy/min) \\
\hline RQT8 & $100 \quad 10$ & $3,2 \mathrm{Al}+0, \mathrm{Cu}$ & $22,0(7)$ \\
\hline RQT9 & 12010 & 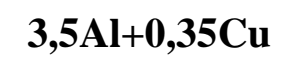 & $34,0(1)$ \\
\hline RQT10 & $150 \quad 10$ & $4,2 \mathrm{Al}+0,35 \mathrm{Cu}$ & $57,0(2)$ \\
\hline
\end{tabular}

Qualidades de radiodiagnóstico (feixes diretos)

\begin{tabular}{ccccc}
\hline Qualidade & kV & mA & Filtração (mmAl) & Taxa de Kerma no ar (mGy/min) \\
\hline RQR3 & 50 & 10 & 2,4 & $22,4(2)$ \\
RQR5 & $\mathbf{7 0}$ & $\mathbf{1 0}$ & $\mathbf{2 , 8}$ & $\mathbf{3 8 , 6 ( 3 )}$ \\
RQR8 & 100 & 10 & 3,2 & $69,3(5)$ \\
RQR10 & 150 & 10 & 4,2 & $120(1)$ \\
\hline
\end{tabular}

Qualidades de radiodiagnóstico (feixes atenuados)

\begin{tabular}{ccccc}
\hline Qualidade & $\mathrm{kV}$ & $\mathrm{mA}$ & Filtração $(\mathrm{mm})$ & Taxa de Kerma no ar (mGy/min) \\
\hline RQA3 & 50 & 10 & 12,4 & $1,63(1)$ \\
RQA5 & $\mathbf{7 0}$ & $\mathbf{1 0}$ & $\mathbf{2 3 , 8}$ & $\mathbf{1 , 5 6 ( 1 )}$ \\
RQA8 & 100 & 10 & 37,2 & $2,55(2)$ \\
RQA10 & 150 & 10 & 49,2 & $5,65(4)$ \\
\hline
\end{tabular}


TABELA 3: Energias nominal e média [54-57] das qualidades dos feixes estudados.

\begin{tabular}{ccc}
\hline Qualidades de radiação & Tensão nominal $(\mathrm{kV})$ & Energia Média $(\mathrm{keV})$ \\
\hline RQA2M & 28 & 19,4 \\
RQA4M & 35 & 25,7 \\
RQR2M & 28 & 17,1 \\
RQR4M & 35 & 19,2 \\
\hline RQR3 & 50 & 33,5 \\
RQR5 & 70 & 41,8 \\
RQR8 & 100 & 52,1 \\
RQR10 & 150 & 62,5 \\
RQA3 & 50 & 38,7 \\
RQA5 & 70 & 51,8 \\
RQA8 & 100 & 67,0 \\
RQA10 & 150 & 93,2 \\
\hline RQT8 & 100 & 60,0 \\
RQT9 & 120 & 66,6 \\
RQT10 & 150 & 74,7 \\
\hline
\end{tabular}

Em todas as medições deste trabalho a distância entre a sonda dosimétrica e o ponto focal do tubo de raios $\mathrm{X}$ foi mantida em 1 metro, em acordo com a condição de calibração do sistema realizada com câmaras de ionização padronizadas.

\subsection{Instrumentação Auxiliar}

Durante as irradiações, estavam disponíveis no LCI, além de sistemas de arcondicionado e desumidificadores, um termômetro (marca Hart Scientific ${ }^{\circledR}$, modelo ChubE4 1529), higrômetro (marca Extech Instruments ${ }^{\circledR}$ modelo 445702) e um barômetro (GE Industrial Sensing, modelo DPI 147) que permitiram monitorar as condições ambientais da sala onde está instalado o gerador de raios X. Nas medições realizadas neste trabalho, a temperatura e a umidade relativa do ar foram mantidas em $20^{\circ} \mathrm{C}$ e $50 \%$, respectivamente. 
Para o posicionamento das sondas dosimétricas um sistema de feixes de laser de He-Ne foi utilizado.

\subsection{Caracterização Elétrica dos Diodos}

A presença dos possíveis danos de radiação nos diodos estudados foi feita mediante a avaliação das alterações das propriedades elétricas dos dispositivos utilizando um circuito projetado e construído [60] com base no amplificador operacional OPA665U (Texas Instruments), o qual permitia a medição da corrente de fuga e capacitância do diodo em função da tensão reversa (FIG.19).

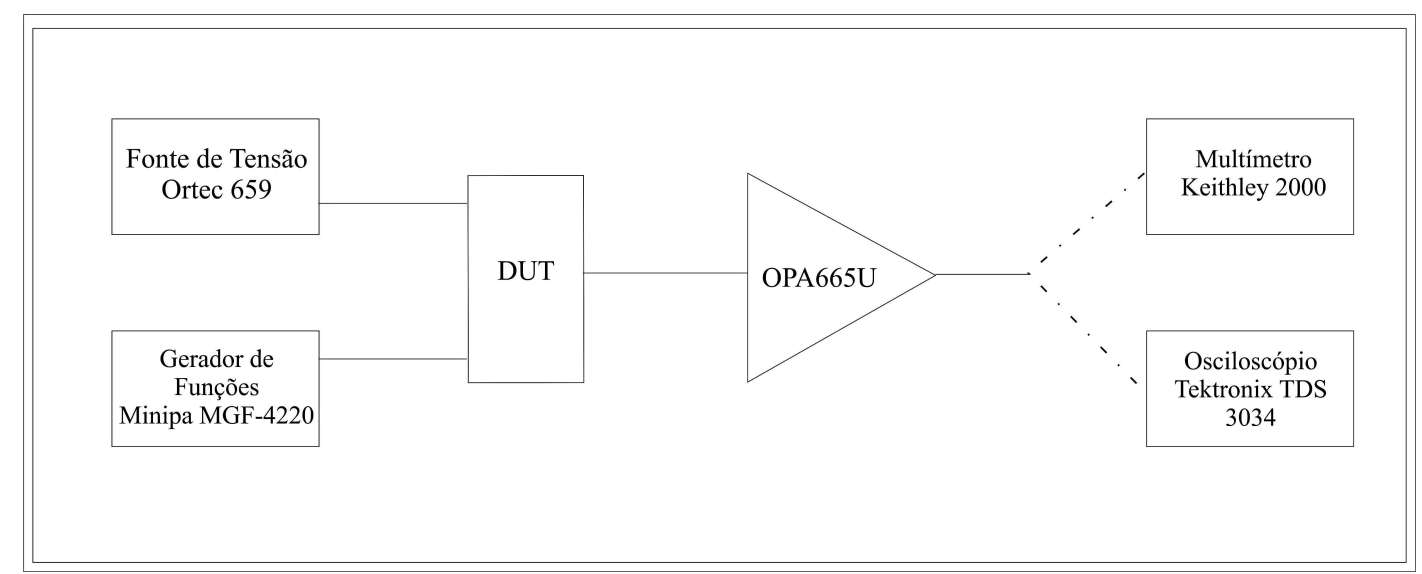

FIGURA 19: Diagrama de blocos ilustrando do arranjo experimental para a construção das curvas I-V e C-V.

No arranjo experimental utilizado nestas medidas, onde para uma dada tensão reversa aplicada nos diodos, a sua corrente de fuga era convertida no amplificador operacional em um sinal de tensão, medido por um multímetro (Keithley® 2000) e que pode ser expresso através da lei de Ohm (EQ. 21):

$$
\mathrm{I}_{\mathrm{f}}=\frac{\mathrm{V}_{\mathrm{DC}}}{\mathrm{R}}
$$

onde $V_{D C}$ e R representam, respectivamente, a tensão contínua e a resistência interna do circuito.

Para monitorar as formas de onda na entrada e saída do circuito foi utilizado um osciloscópio digital (Tektronix, modelo TDS3034). A medida das capacitâncias 
correspondentes foi feita de modo indireto, mediante amplificação de um sinal de tensão AC proveniente de um oscilador externo, cujo ganho é função da reatância capacitiva do diodo EQ.22:

$$
\mathrm{C}=\frac{\mathrm{V}_{\mathrm{OUT}}}{\mathrm{R} \cdot 2 \cdot \pi \cdot \mathrm{f}_{\mathrm{in}} \cdot \mathrm{V}_{\mathrm{in}}}
$$

onde $V_{\text {OUT }}, R, f_{\text {in }}$ e $V_{\text {in }}$ representam, respectivamente, a amplitude do sinal na saída do circuito, a resistência interna do circuito, a frequência e a amplitude do sinal injetado na entrada do circuito.

\subsection{Resposta Angular}

A resposta direcional dos diodos foi estudada com auxílio de um goniômetro da marca Optron ${ }^{\circledR}$, modelo GN1-200, graduado de $0^{\circ}$ a $180^{\circ}$. Os diodos foram fixados ao eixo articulado do goniômetro através de uma base de acrílico de espuma rígida como ilustra a FIG. 20. A FIG. 21 ilustra o esquema de posicionamento que permitia a rotação dos dispositivos em relação ao feixe de raios $\mathrm{X}$.

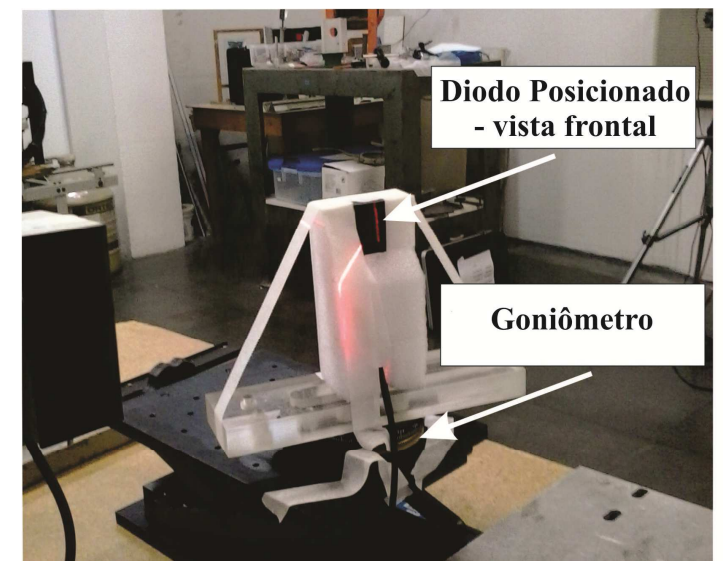

a)

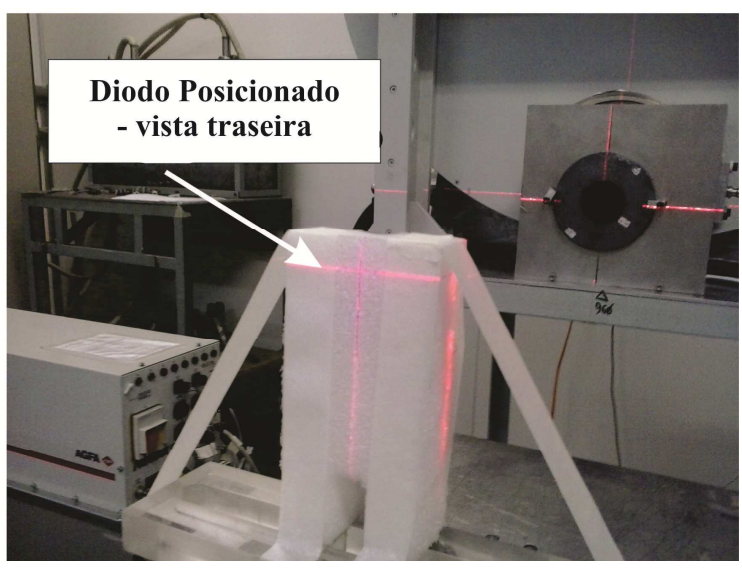

b)

FIGURA 20: Vista frontal a) e traseira b) da sonda dosimétrica fixada ao goniômetro com auxílio de um suporte em espuma rígida. 


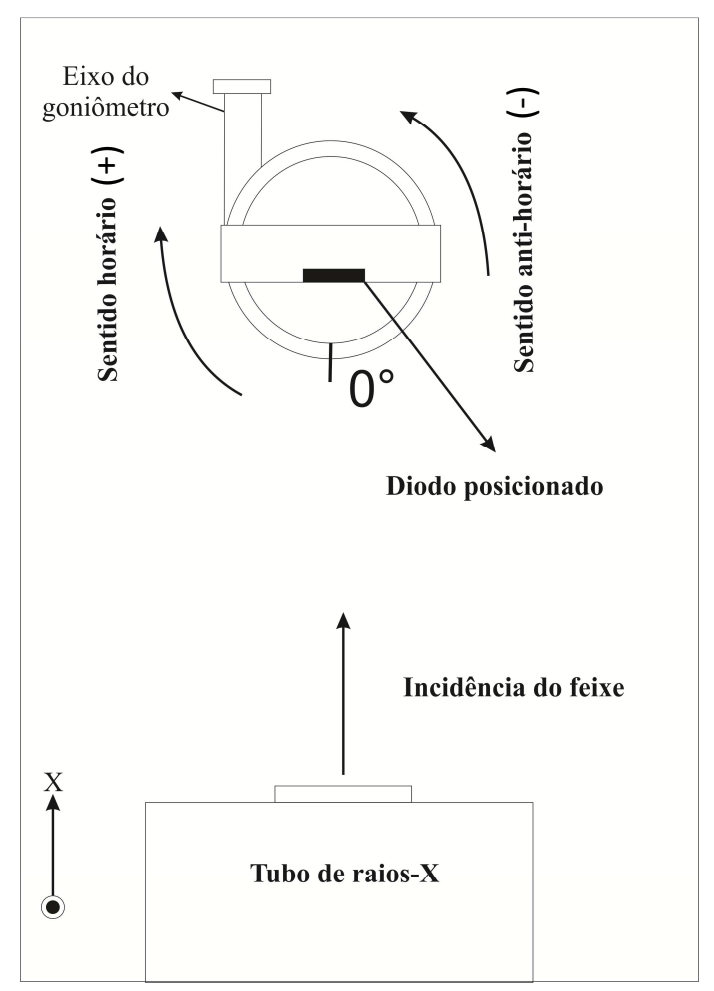

FIGURA 21: Vista superior do arranjo para estudo da resposta direcional dos diodos.

\subsection{Incertezas}

As incertezas neste trabalho foram estimadas de acordo com a norma ISO [61], que classificam as incertezas em tipo A e tipo B.

As incertezas do tipo A são aquelas associadas à análise estatística de uma série de observações [61]. Aqui foram utilizadas médias aritméticas das séries de medições $(\bar{x})$ em mesmas condições e desvios padrões experimentais da média $\left(\sigma_{\bar{x}}\right)$, de modo que o resultado de cada medição fica dado por $\overline{\mathrm{x}} \pm \sigma_{\bar{x}}$, onde:

$$
\overline{\mathrm{x}}=\frac{1}{\mathrm{~N}} \sum_{\mathrm{i}=1}^{\mathrm{N}} \mathrm{x}_{\mathrm{i}}
$$

e

$$
\sigma_{\overline{\mathrm{x}}}=\sqrt{\frac{1}{\mathrm{~N}(\mathrm{~N}-1)} \sum_{\mathrm{i}=1}^{\mathrm{N}}\left(\mathrm{x}_{\mathrm{i}}-\overline{\mathrm{X}}\right)^{2}}
$$

As incertezas do tipo B são aquelas não associadas à análise estatística [61], sendo atribuídas a equipamentos de medidas, dados fornecidos em certificados de calibração, especificações dos fabricantes, entre outros. 
As incertezas do tipo A e B devem ser correlacionadas e representadas pela incerteza combinada, obtida pela soma quadrática dessas incertezas, ou seja:

$$
\sigma_{C}=\sqrt{\sigma_{A}^{2}+\sigma_{B}^{2}}
$$

A partir da incerteza combinada, devemos ainda estimar a incerteza expandida, a qual fornecerá o intervalo de confiança de nossas medições. A incerteza expandida (U) é dada pela EQ.26, onde k é ao fator de abrangência, que reflete o nível de confiança de uma dada medição.

$$
\mathrm{U}=\mathrm{k} \cdot \sigma_{\mathrm{C}}
$$

No presente trabalho foi utilizada a incerteza combinada expandida, considerando as incertezas do tipo A e $\mathrm{B}, \operatorname{com} k=2$, correspondendo a um nível de confiança de 95,4\%.

As principais fontes de incertezas do tipo $\mathrm{B}$ associadas às nossas medidas são apresentadas na TAB.4.

TABELA 4: Principais fontes de incertezas do tipo $\mathrm{B}$ associadas às medições, fornecidas pelos certificados de calibração e fabricante de equipamentos.

\begin{tabular}{c|c}
\hline Fontes de incertezas tipo B & Incertezas \% \\
\hline Calibração da câmara de ionização de referência - RQT & 1,5 \\
Calibração da câmara de ionização de referência - RQR/RQA & 0,77 \\
Calibração da câmara de ionização de referência - RQR/A-2M/4M & 0,96 \\
Eletrômetro (escala de 200pA) & 1 \\
Termômetro (fabricante) & 0,01 \\
Distância fonte-detector & 0,05 \\
\hline
\end{tabular}




\section{RESULTADOS E DISCUSSÃO}

\subsection{Caracterização elétrica dos diodos}

\subsubsection{Corrente de fuga em função da tensão de polarização reversa (curva I-V)}

As curvas I-V para os diodos EPI\#46, \#45 e FZ\#04 são mostradas nas FIG.22-24, onde se observa em todas as amostras um aumento da corrente de fuga com a dose absorvida nos dispositivos. Este efeito está diretamente relacionado com a quantidade de defeitos gerados na estrutura do cristal que permitem a emissão de elétrons e lacunas, contribuindo para o aumento da corrente de fuga dos dispositivos.

Durante as medições, a dose total absorvida no diodo EPI\#46 foi de 49,15 Gy. Para o diodo EPI\#45 a medida considerada a "0 Gy" inclui a pré-dose descrita de $200 \mathrm{kGy}$, sendo que no presente trabalho ele acumulou uma dose de 6,3 Gy, enquanto para o diodo FZ\#04 a dose acumulada foi de $36 \mathrm{~Gy}$. Os resultados confirmam que o uso dos diodos no modo fotovoltaico (tensão reversa nula) é o que garante menor contribuição da corrente de fuga, mesmo para doses acumuladas mais elevadas, possibilitando ampliação do limite operacional dos dispositivos.

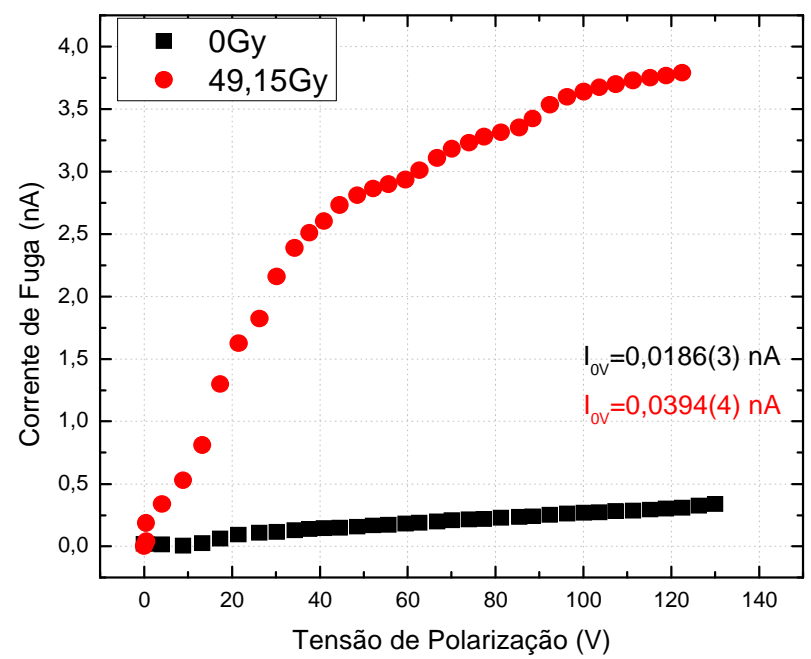

FIGURA 22: Corrente de fuga em função da tensão de polarização reversa (I-V) para o diodo EPI\#46 (sem pré-dose) a 0 Gy e a 49,15 Gy (as incertezas associadas às medições são menores que as dimensões dos pontos). 


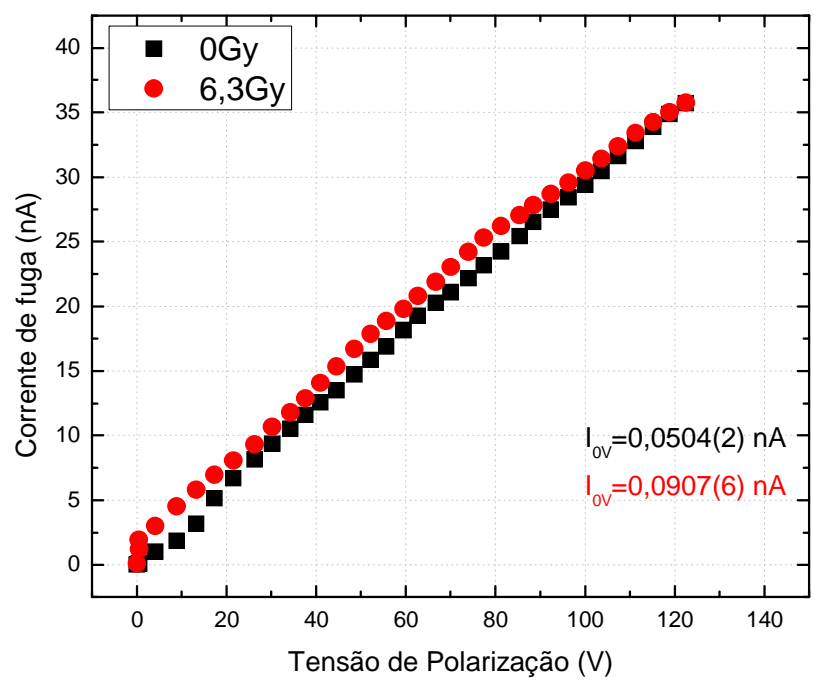

FIGURA 23: Corrente de fuga em função da tensão de polarização reversa (I-V) para o diodo EPI\#45 (pré-irradiado) a 0 Gy e a 6,3 Gy (as incertezas associadas às medições são menores que as dimensões dos pontos).

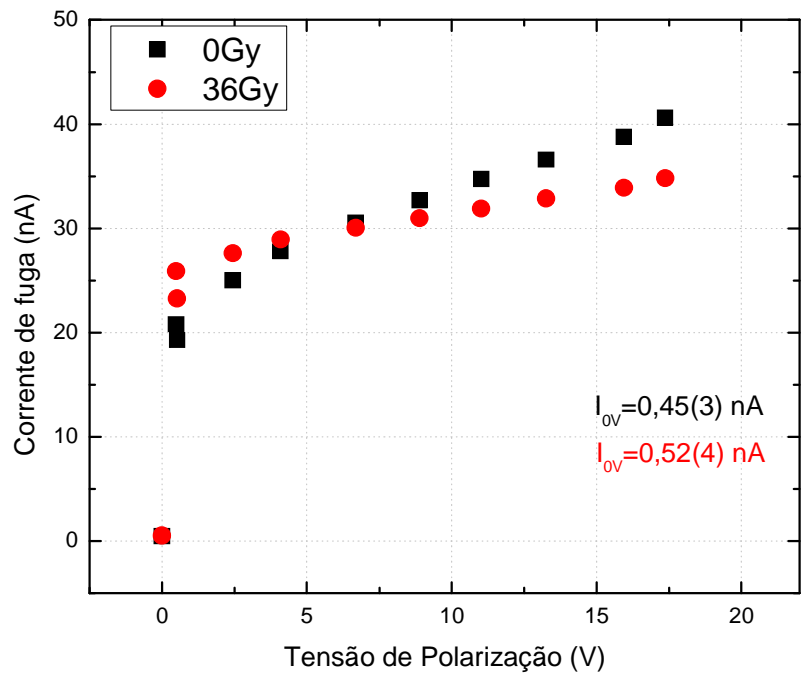

FIGURA 24: Corrente de fuga em função da tensão de polarização reversa (I-V) para o diodo FZ\#04 a 0 Gy e a 36 Gy (as incertezas associadas às medições são menores que as dimensões dos pontos).

\subsubsection{Capacitância em função da tensão de polarização reversa (curva $C-V$ )}

As curvas da capacitância dos diodos em função da tensão de polarização reversa empregando sinais senoidais com frequência de $1 \mathrm{kHz}$ são apresentadas nas FIG. 25 e 26 para os diodos EPI\#46 e EPI\#45 e na FIG. 27, com frequência de $10 \mathrm{kHz}$, para o diodo FZ\#04. 


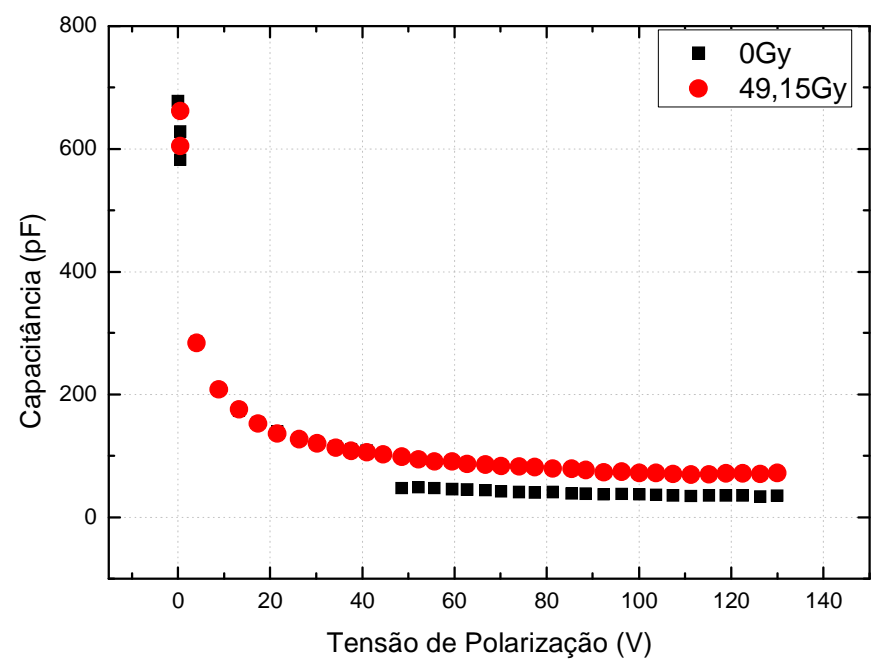

FIGURA 25: Curvas da capacitância em função da tensão de polarização reversa para o diodo EPI\#46 (sem pré-dose) em 0 Gy e em 49,15 Gy (as incertezas associadas às medições são menores que as dimensões dos pontos).

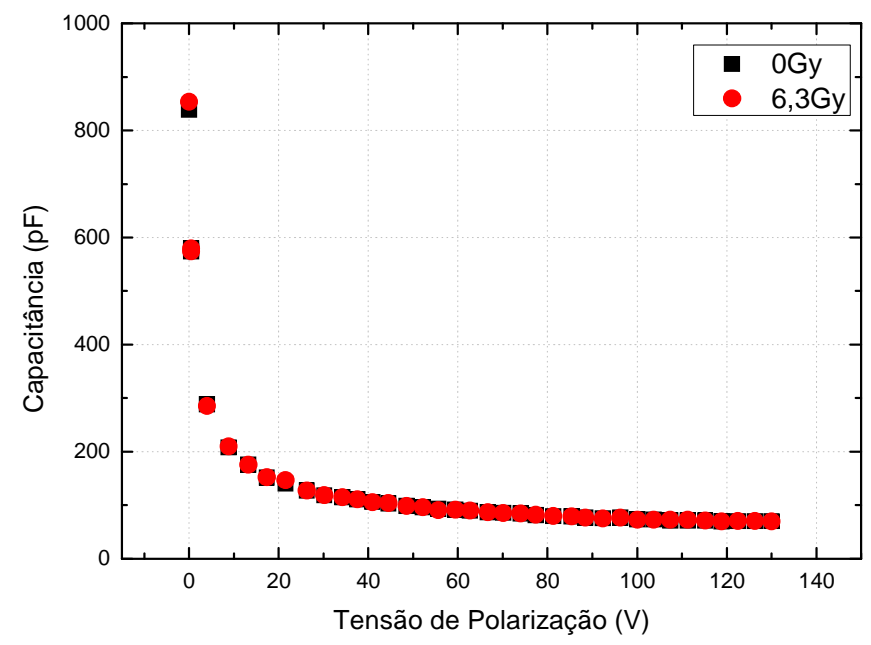

FIGURA 26: Curvas da capacitância em função da tensão de polarização reversa para o diodo EPI\#45 (com pré-dose) em 0 Gy e em 6,3 Gy (as incertezas associadas às medições são menores que as dimensões dos pontos).

Na FIG. 25 a curva a 0 Gy para o diodo EPI\#46 apresenta uma descontinuidade isto ocorreu pois a 0 Gy o diodo foi caracterizado com $10 \mathrm{kHz}$. Já na FIG.26 temos uma sobreposição das curvas $\mathrm{C}-\mathrm{V}$ mostrando que mesmo para uma dada dose absorvida a característica da capacitância não foi alterada. Na FIG.27 temos um ponto que não acompanha a linha de tendência para os valores de capacitância e que pode ser devido a um parâmetro do circuito que não foi avaliado. 


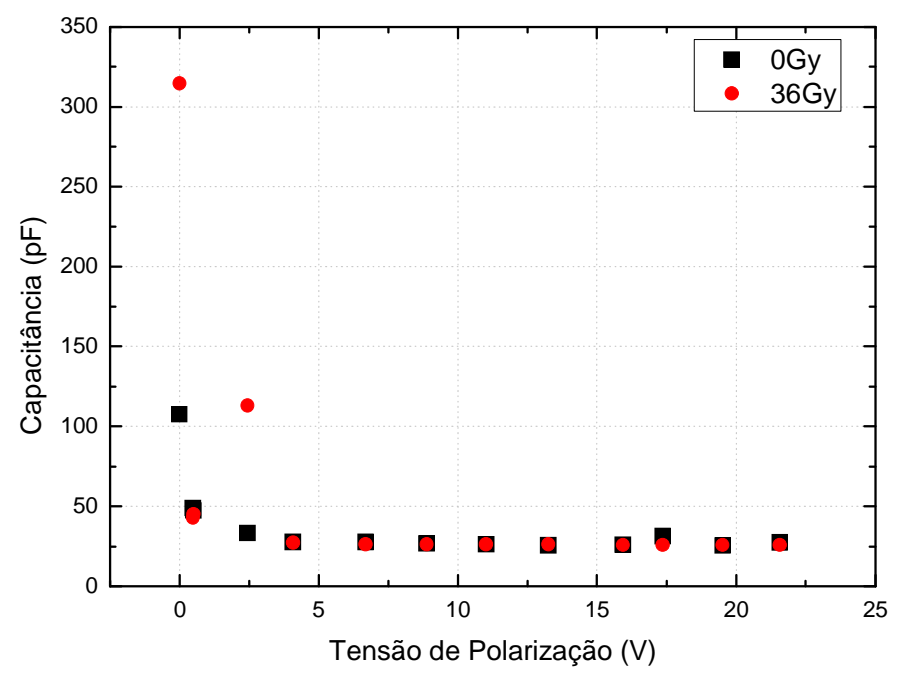

FIGURA 27: Curvas da capacitância em função da tensão de polarização reversa para o diodo FZ\#04 em 0 Gy e em 36 Gy (as incertezas associadas às medições são menores que as dimensões dos pontos).

As curvas $\mathrm{C}-\mathrm{V}$ apresentam para as três amostras comportamento esperado de diminuição da capacitância com aumento da tensão de polarização reversa, compatível com o efeito expansão da zona depletada, como será visto a seguir. Não foram verificadas alterações significativas nas capacitâncias dos diodos com aumento da dose absorvida.

As medidas de capacitância permitiram a construção da curva da espessura da zona de depleção em função da tensão de polarização para cada diodo, considerando-se que a junção se comporta como um capacitor de placas paralelas, cuja capacitância é dada pela EQ. 7 na Seção 4. As curvas da espessura da zona depletada para os diodos EPI\#46, EPI\#45 e FZ\#04 são apresentadas nas FIG.28 a 30 para as irradiações iniciais (0 Gy).

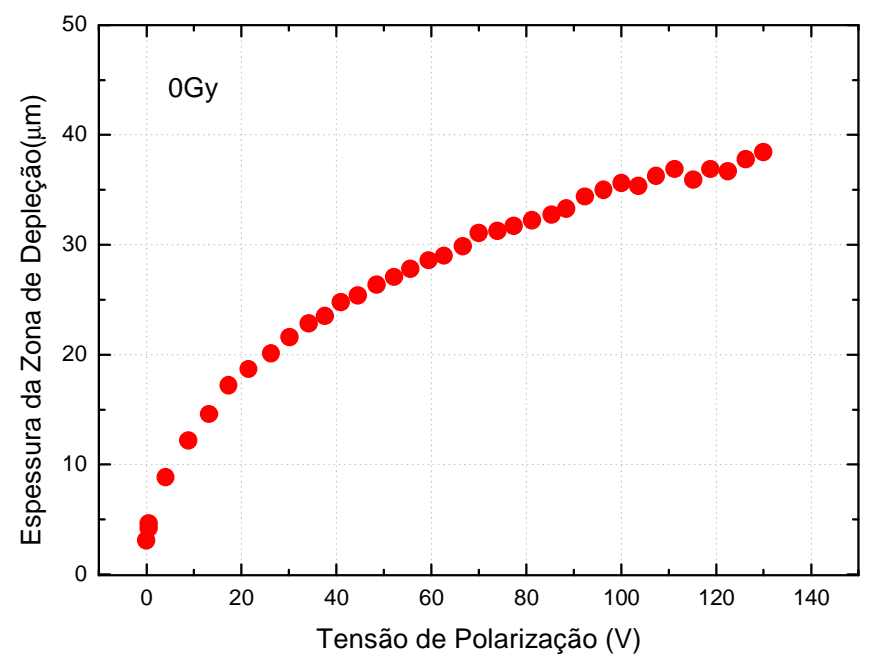

FIGURA 28: Curva da espessura da zona de depleção para o diodo EPI\#46 em função da tensão de polarização reversa (as incertezas associadas à medida são menores que as dimensões dos pontos). 


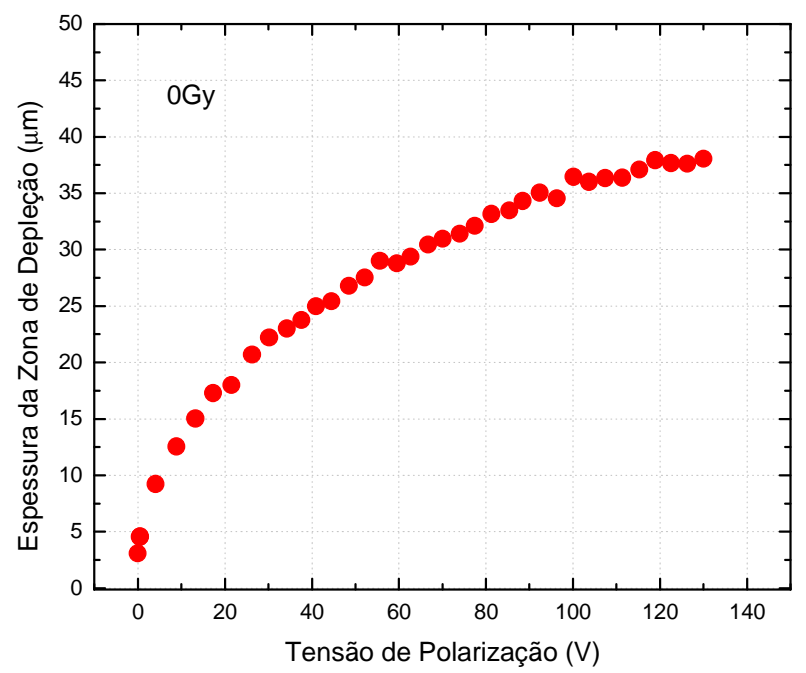

FIGURA 29: Curva da espessura da zona de depleção para o diodo EPI\#45 em função da tensão de polarização reversa (as incertezas associadas à medida são menores que as dimensões dos pontos).

O valor da espessura da zona depleção do diodo EPI\#46 para máxima tensão de

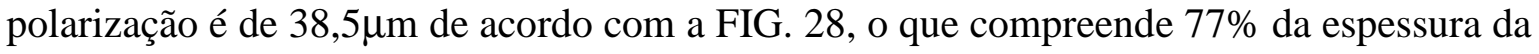
camada epitaxial do dispositivo (TAB.2). Da mesma forma, pode-se afirmar que para o diodo EPI\#45 a largura da zona depletada é de aproximadamente $40 \mu \mathrm{m}$ enquanto para o FZ\#04 chega apenas a $100 \mu \mathrm{m}$, ou cerca de 1/3 da espessura da pastilha de Si. Este resultado confirma a diferença na estrutura desses diodos, com os epitaxiais apresentando janela de entrada mais fina que o FZ e, portanto, possuindo maior sensibilidade para radiações de menor energia.

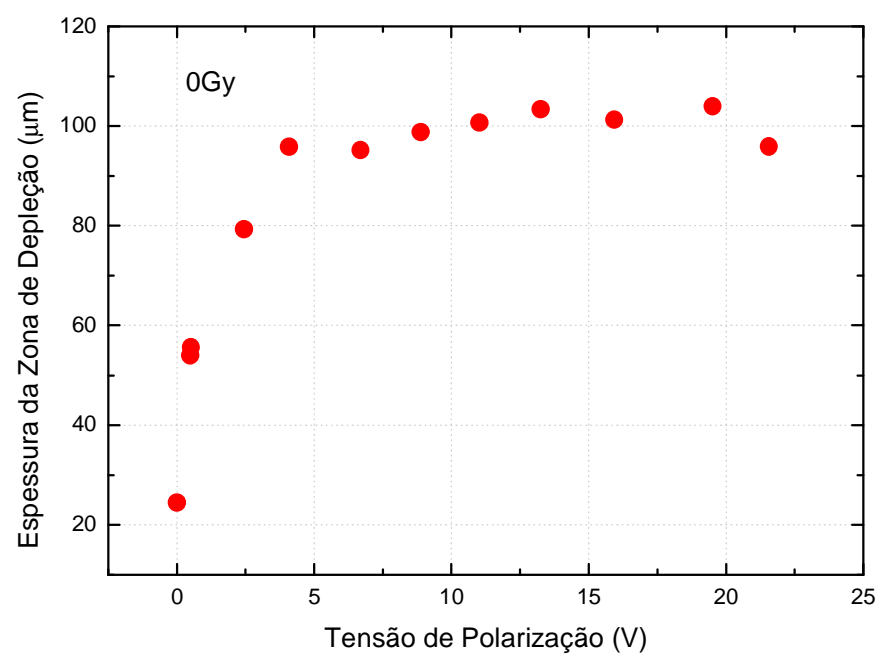

FIGURA 30: Curva da espessura da zona de depleção para o diodo FZ\#04 em função da tensão de polarização reversa (as incertezas associadas às medições são menores que as dimensões dos pontos). 


\subsection{Estabilidade de resposta do diodo}

\subsubsection{Em curto prazo}

A repetibilidade de resposta dos diodos epitaxiais e de fusão zonal foi estudada através de 10 medições consecutivas (com duração de 60s cada uma) da corrente produzida nos dispositivos quando expostos a radiação X. Para o diodo EPI\#45 foram realizadas apenas 5 medições de 60 s cada uma. Nas FIG. 31 a 33 são apresentadas as curvas das fotocorrentes em função do tempo obtidas para esses diodos com os feixes de referência das qualidades estudadas.

Os valores médios encontrados para as correntes de fundo dos dispositivos EPI\#46, EPI\#45 e FZ\#04 durante os intervalos de tempo em que o obturador permaneceu fechado não ultrapassaram 0,30 pA, 0,41 pA e 20,3 pA, respectivamente. No pior caso para o diodo EPI\#46, com a qualidade de feixe RQA5, as fotocorrentes medidas foram cerca de $10^{4}$ vezes maiores em relação à corrente de fundo.

A avaliação da repetibilidade em corrente dos diodos foi feita mediante determinação do coeficiente de variação (CV) dos dispositivos, definido [62] como o desvio padrão de uma medição (com duração de $60 \mathrm{~s}$ cada uma) expresso em termos de porcentagem do valor médio das leituras de corrente neste intervalo de tempo, ou seja:

$$
\mathrm{CV} \%=\frac{\sigma_{\mathrm{n}-1}}{\overline{\mathrm{x}}} \times 100
$$

onde $\sigma_{\mathrm{n}-1}$ é o desvio padrão e $\overline{\mathrm{x}}$ é o valor médio da medida, dados por:

$$
\begin{aligned}
& \sigma_{n-1}^{2}=\frac{\left(x_{i}-\bar{x}\right)^{2}}{n-1} \\
& \bar{x}=\frac{1}{n} \sum_{i=1}^{n} x_{i}
\end{aligned}
$$

A norma IEC 61674 [34] recomenda que o valor do coeficiente de variação (CV) da corrente medida não ultrapasse o limite de 3\%. Na TAB.5 são apresentados os valores dos 
coeficientes de variação para os diodos EPI\#46, EPI\#45 e FZ\#04 com os feixes de referência, comprovando a excelente estabilidade de resposta dos diodos.

TABELA 5: Valores dos Coeficientes de Variação (CV) em corrente para os diodos EPI\#46, EPI\#45 e FZ\#04 com os feixes de referência estudados.

\begin{tabular}{lccc}
\hline & EPI\#46 & EPI\#45 & FZ\#04 \\
\hline $\begin{array}{c}\text { Qualidade da } \\
\text { radiação }\end{array}$ & $\mathrm{CV}(\%)$ & $\mathrm{CV}(\%)$ & $\mathrm{CV}(\%)$ \\
\hline RQR2M 28kV & 0,26 & 0,27 & 0,22 \\
RQR5 70kV & 0,23 & 0,26 & 0,21 \\
RQA5 70kV & 0,27 & 0,28 & 0,32 \\
RQT9 120kV & 0,25 & 0,27 & 0,21 \\
\hline
\end{tabular}

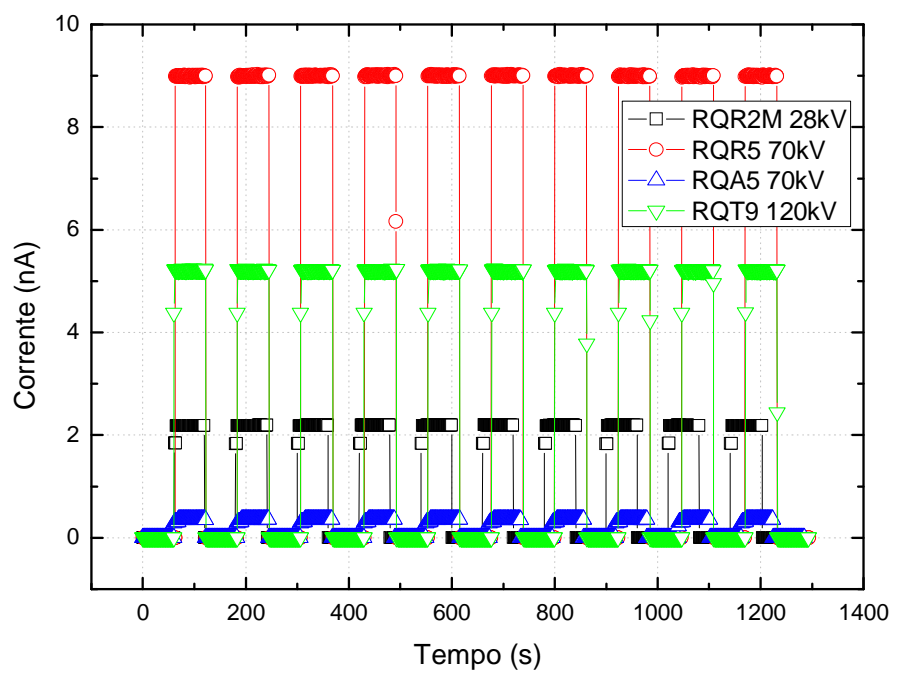

FIGURA 31: Corrente para o diodo EPI\#46 em função do tempo de irradiação para cada feixe de referência das qualidades estudadas: RQR5, RQA5, RQR-2M e RQT9. As incertezas associadas são menores que as dimensões dos pontos do gráfico.

Os resultados mostraram (FIG. 31 a 33) que os três diodos possuem estabilidade de resposta similar; particularmente, entre os diodos epitaxiais, notou-se que a pré-dose não interferiu no comportamento deste parâmetro dentro dos limites de dose analisados.

As correntes obtidas com o diodo FZ\#04 são cerca de vinte vezes maiores do que as obtidas com os diodos epitaxiais, consequência do seu maior volume sensível. Como era esperado, o diodo EPI\#45, por ter sido pré-irradiado, apresenta menor sensibilidade comparada a do EPI\#46, traduzida aqui em menores fotocorrentes para mesma qualidade de radiação incidente. 


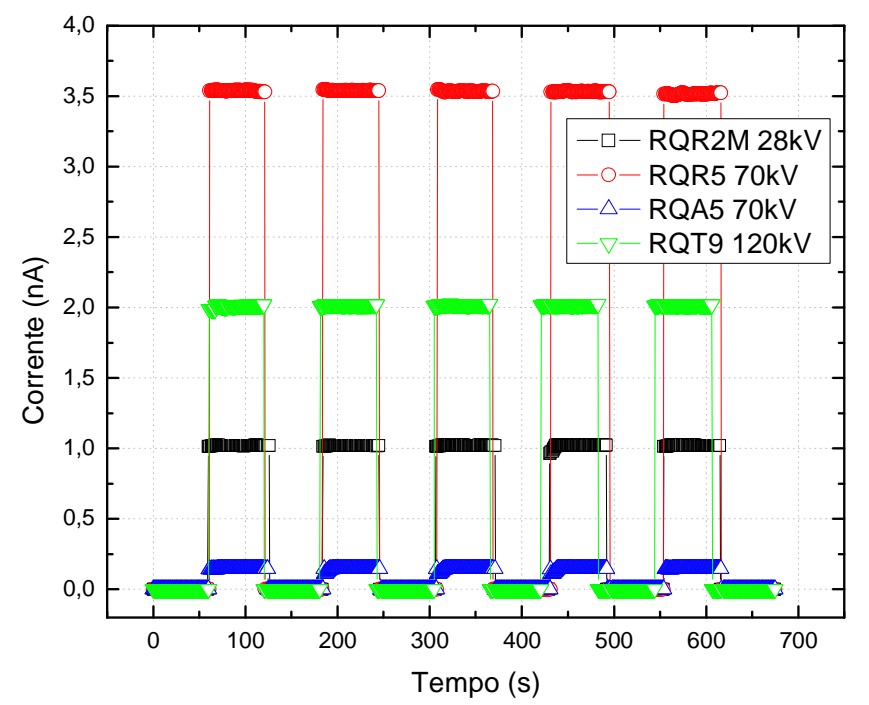

FIGURA 32: Corrente para o diodo EPI\#45 em função do tempo de irradiação para cada feixe de referência das qualidades estudadas: RQR5, RQA5, RQR-2M e RQT9. As incertezas associadas são menores que as dimensões dos pontos do gráfico.

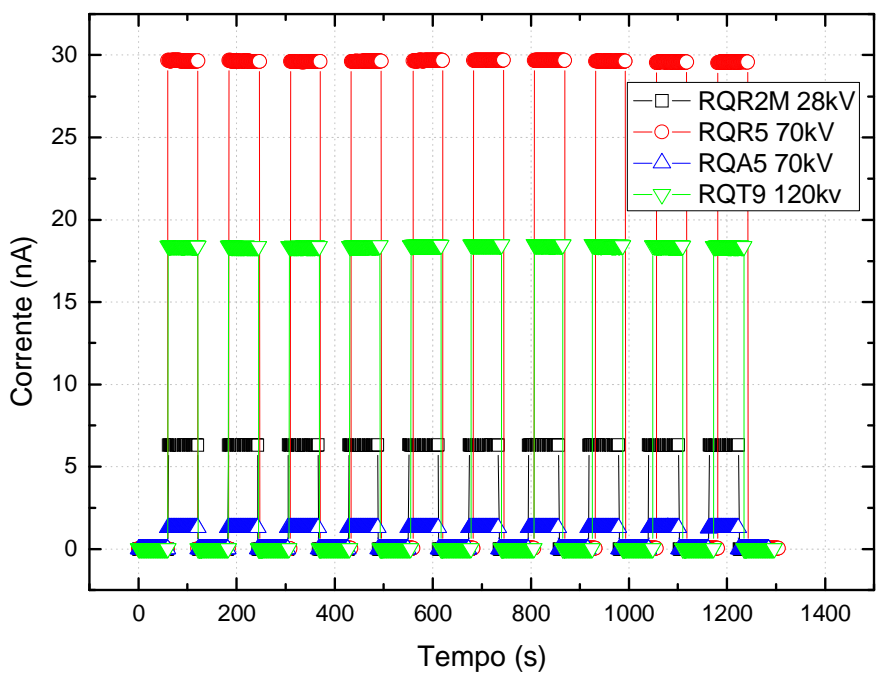

FIGURA 33: Corrente para o diodo FZ\#04 em função do tempo de irradiação para cada feixe de referência das qualidades estudadas: RQR5, RQA5, RQR-2M e RQT9. As incertezas associadas são menores que as dimensões dos pontos do gráfico.

\subsubsection{Em longo prazo}

A norma IEC 61674 [34] recomenda que as medidas de estabilidade em longo prazo sejam realizadas em um intervalo de 30 dias durante seis meses, as quais extrapoladas para o período de um ano não excedam o limite de variação de $\pm 2 \%$. Devido 
a grande demanda de calibrações no LCI, bem como período de manutenção não programada, não foi possível cumprirmos este cronograma. Mantendo-se as mesmas condições experimentais, realizou-se 8 séries de medidas durante seis meses para cada feixe de referência das diferentes qualidades estudadas, irradiando-se os diodos em 5 intervalos de 60 s cada um. Na região de doses absorvidas entre 10 Gy e 40 Gy o diodo foi irradiado com feixes de radioterapia, sob diferentes taxas de kerma, como parte integrante de outro trabalho de mestrado do grupo de detectores semicondutores do Centro de Tecnologia das Radiações do IPEN-CNEN/SP [63].

Os resultados indicam até o presente que para dose acumulada de 10 Gy a resposta em corrente do diodo EPI\#46 sofreu um decréscimo percentual de $2 \%$, estando dentro do limite estabelecido pela norma IEC 61674. Para dose absorvida superior e até o limite de 49,15 Gy abrangido por este trabalho, a queda na corrente chegou a $8 \%$. Para o diodo préirradiado a diminuição percentual na resposta em corrente foi de apenas $0,08 \%$ para dose acumulada de 6,5 Gy o que, dentro do erro experimental e valores de CV correspondentes, indica que a sensibilidade deste diodo, apesar de inferior à do diodo EPI\#46, permaneceu constante neste intervalo.

\subsection{Curvas Dose-Resposta}

Como o parâmetro dosimétrico fornecido pelo diodo de Si é a corrente gerada em seu volume sensível devido à incidência da radiação, a carga por ele coletada foi obtida por meio da integração destes sinais durante o tempo de irradiação com auxílio de um programa gráfico. O comportamento da carga em função da dose absorvida (em termos de Kerma no ar, em nosso caso) correspondente é chamado de curva dose-resposta de um dosímetro. Nas FIG.34 a 39 são apresentadas para o diodo EPI\#46 as curvas dose-resposta para qualidades de mamografia, radiodiagnóstico e tomografia computadorizada, o mesmo acontecendo nas FIG. 40 a 45 para o diodo EPI\#45 e nas FIG.46 a 51 para o diodo FZ\#04.

Na FIG.42 é apresentada a curva carga dose para todas as qualidades de mamografia; o coeficiente de correlação obtido, $\mathrm{R}^{2}=0,9998$, indica dependência energética desprezível no intervalo de energia de 28 a $35 \mathrm{kV}$. Os resultados obtidos mostram que para os três diodos até tensõess de feixe de $70 \mathrm{kV}$ a dependência energética é desprezível, tornando-se significativa para feixes de energias superiores e, principalmente, aqueles 


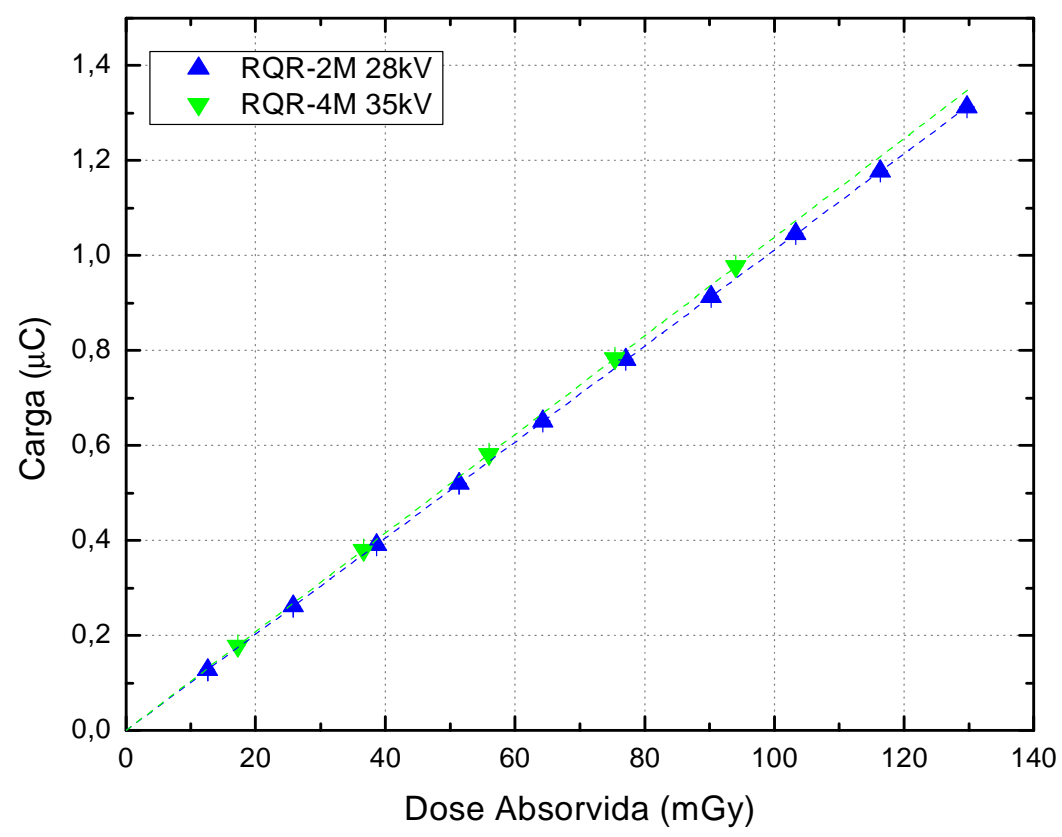

FIGURA 34: Curva dose-resposta do diodo EPI\#46 para as qualidades de mamografia com feixes diretos (RQR-2M/4M).

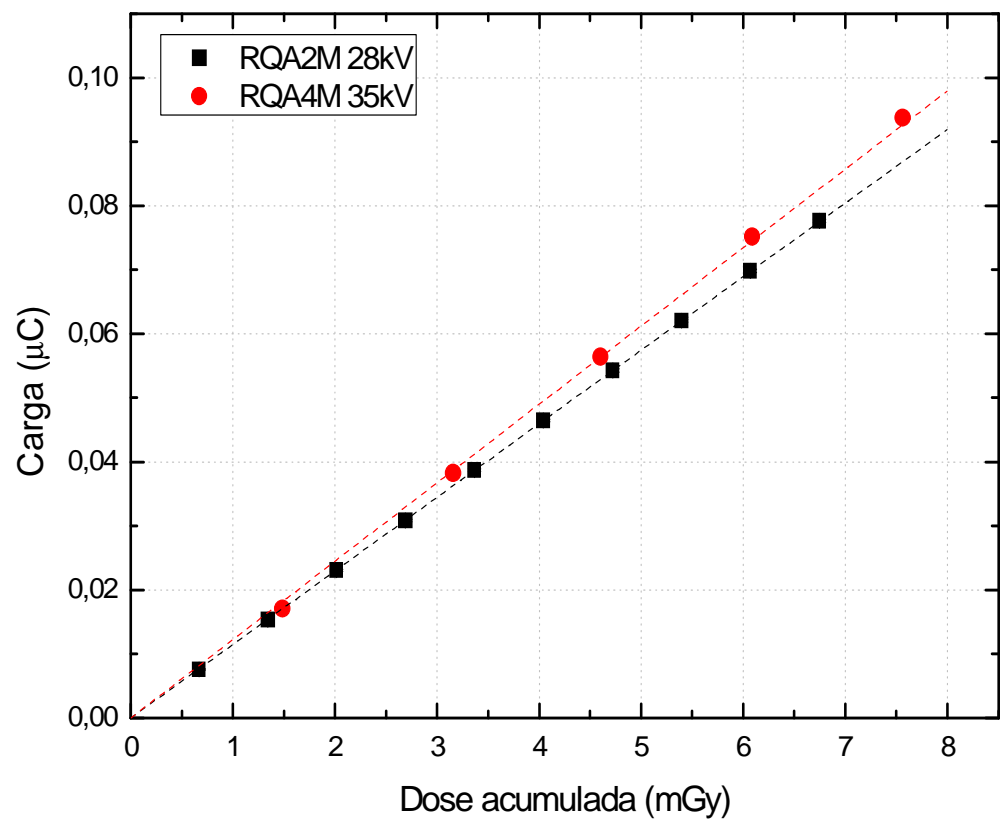

FIGURA 35: Curva dose-resposta do diodo EPI\#46 para as qualidades de mamografia com feixes atenuados (RQA-2M/4M). 


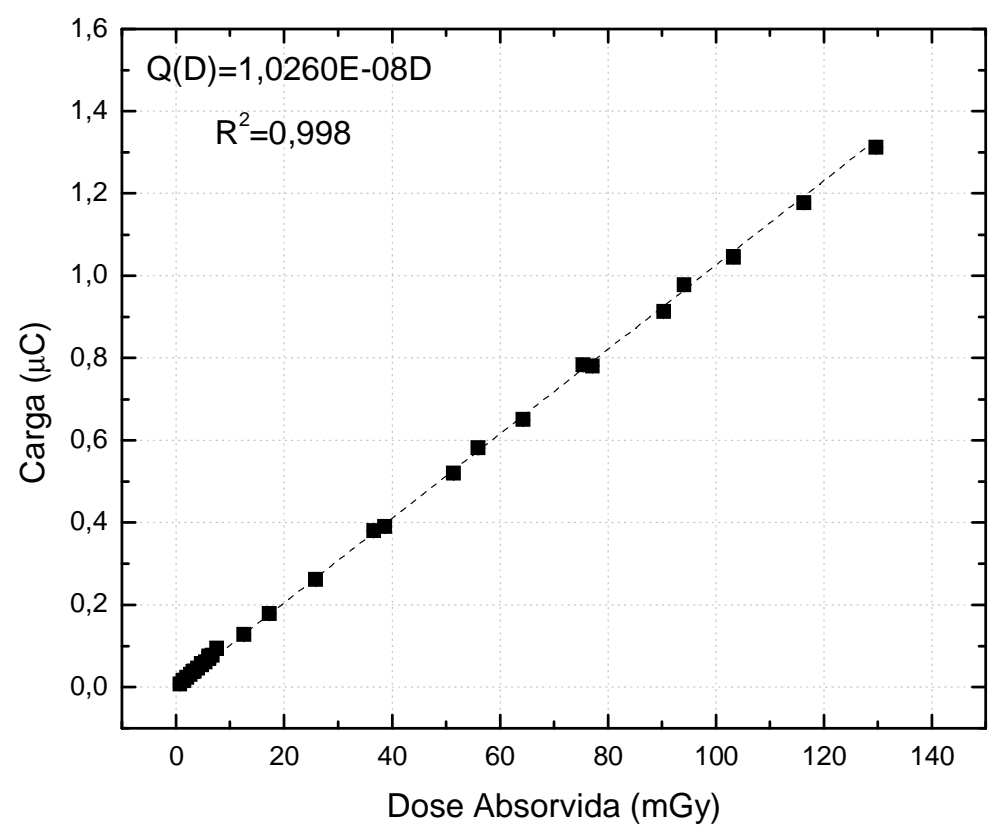

FIGURA 36: Curva carga dose para todas as qualidades de mamografia, feixes diretos e atenuados, para o diodo EPI\#46.

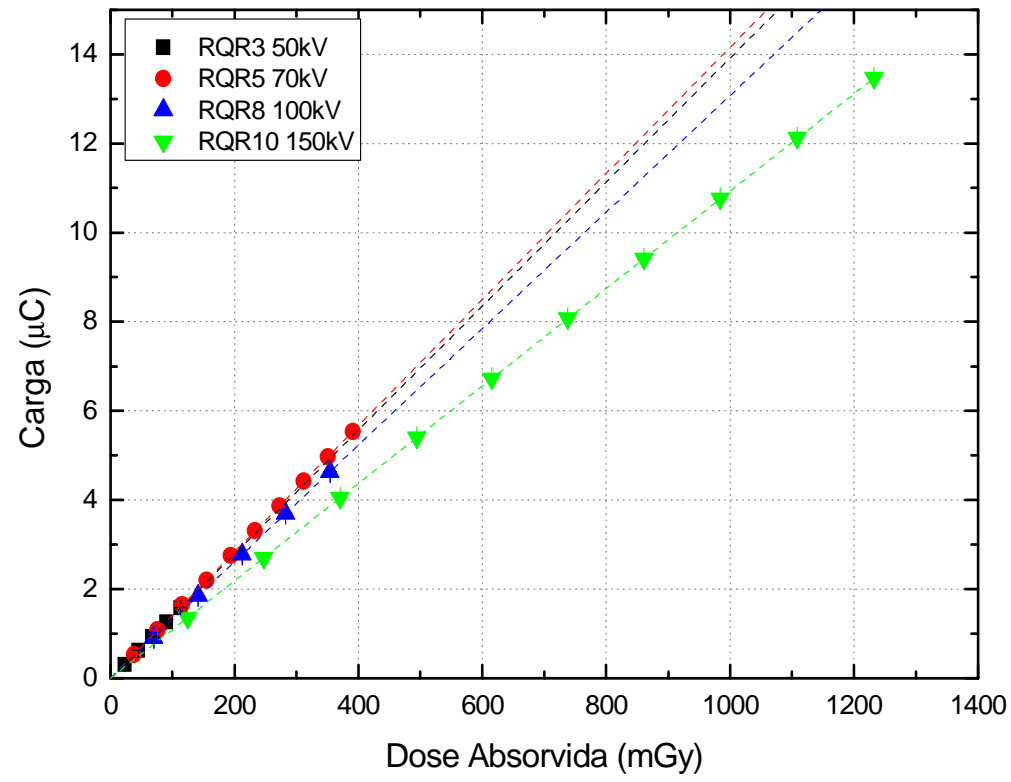

FIGURA 37: Curva dose-resposta do diodo EPI\#46 para as qualidades RQR. 


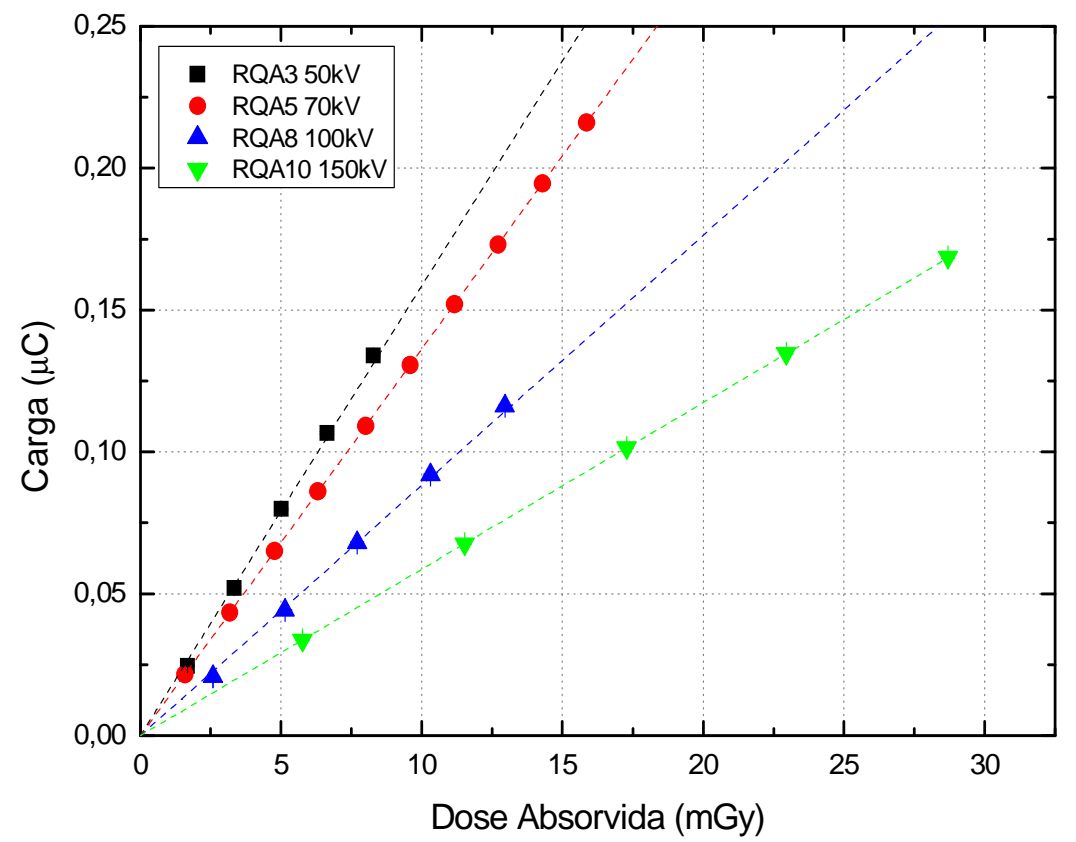

FIGURA 38: Curva dose-resposta do diodo EPI\#46 para as qualidades de radiodiagnóstico, feixes atenuados (RQA).

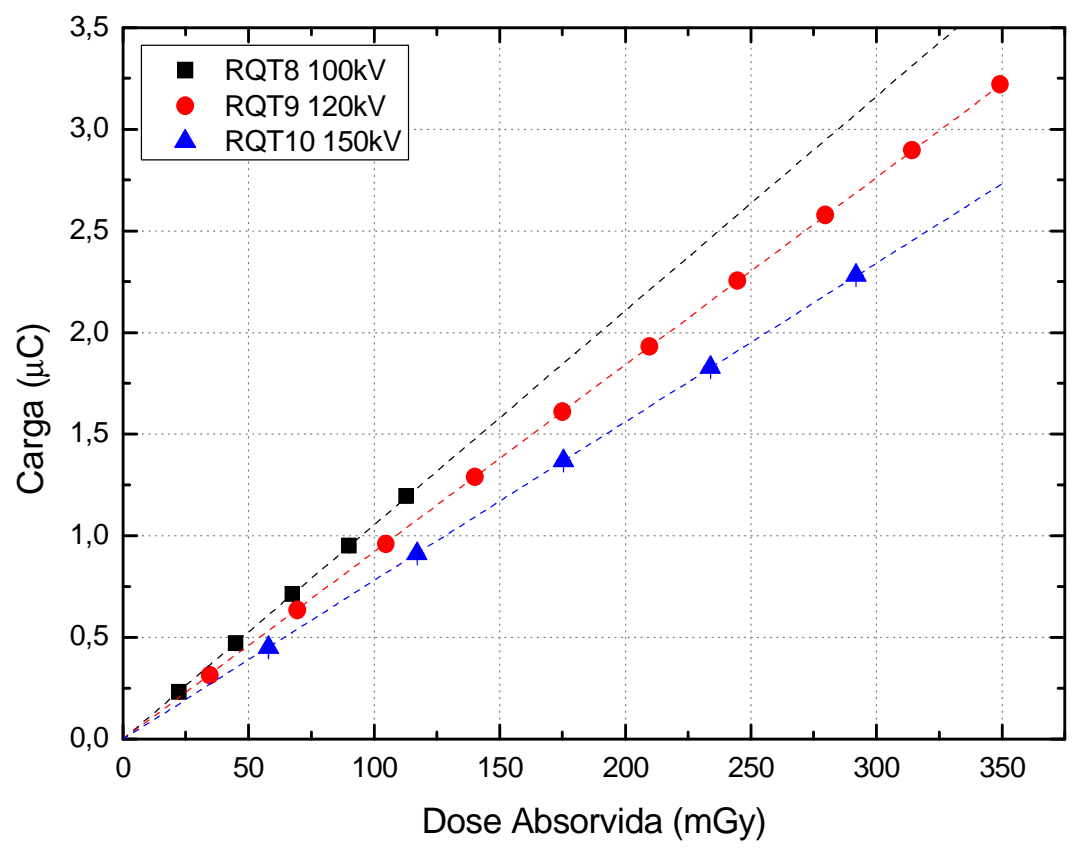

FIGURA 39: Curva dose-resposta do diodo EPI\#46 para as qualidades de tomografia computadorizada (RQT). 


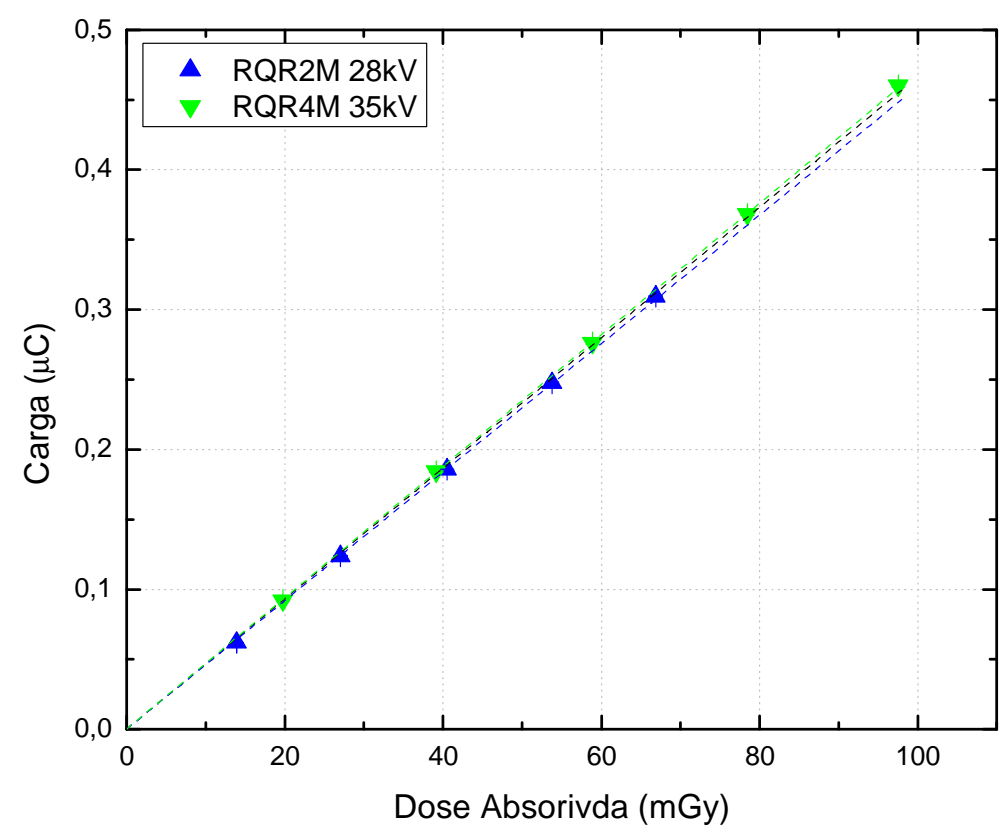

FIGURA 40: Curva dose-resposta do diodo EPI\#45 para sa qualidades de mamografia com feixes diretos (RQR-2M/4M).

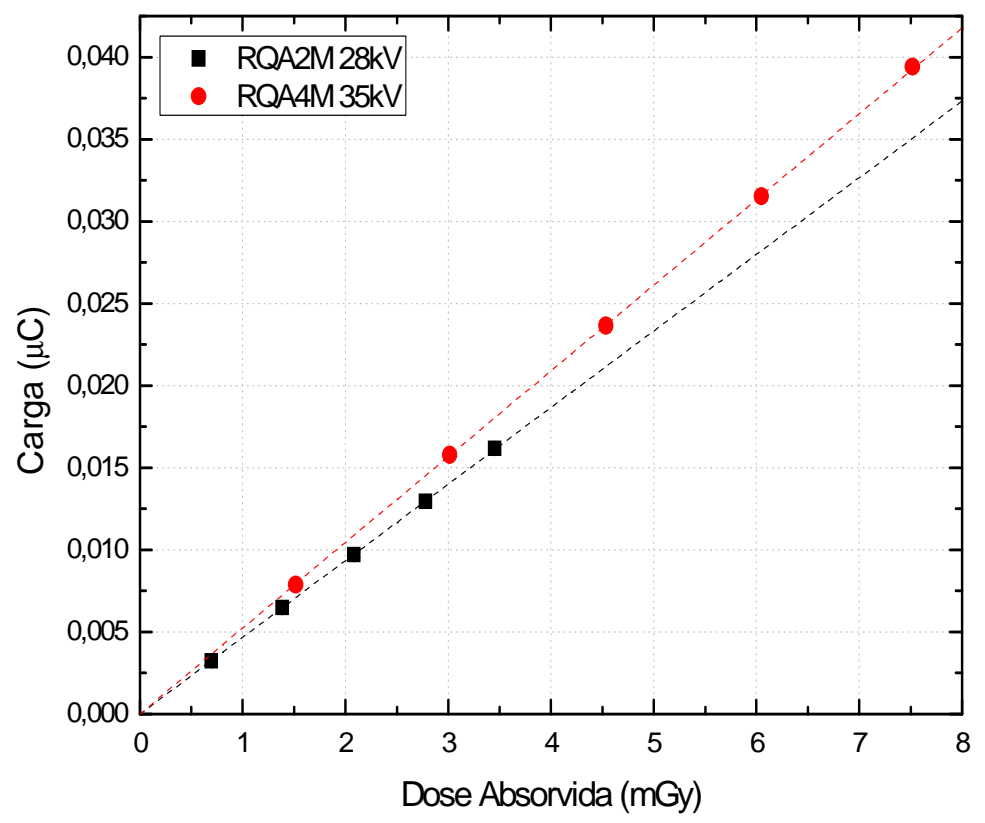

FIGURA 41: Curva dose-resposta do diodo EPI\#45 para as qualidades de mamografia com feixes atenuados (RQA-2M/4M). 


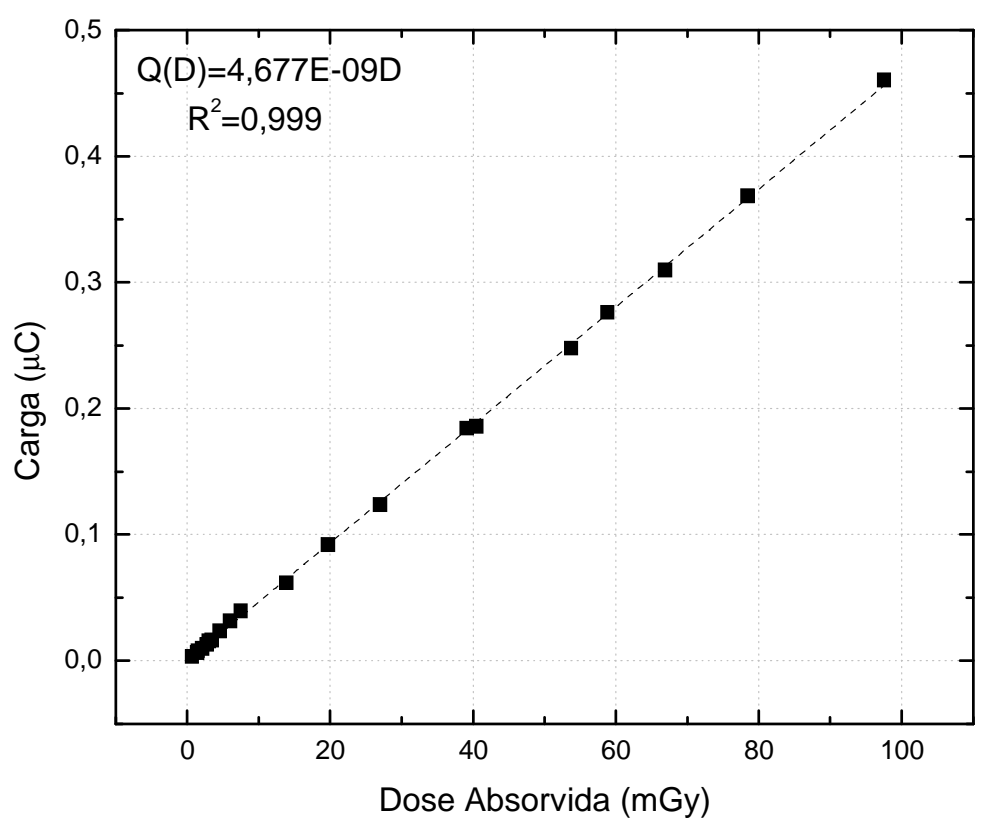

FIGURA 42: Curva carga dose para todas as qualidades de mamografia, feixes diretos e atenuados, para o diodo EPI\#45.

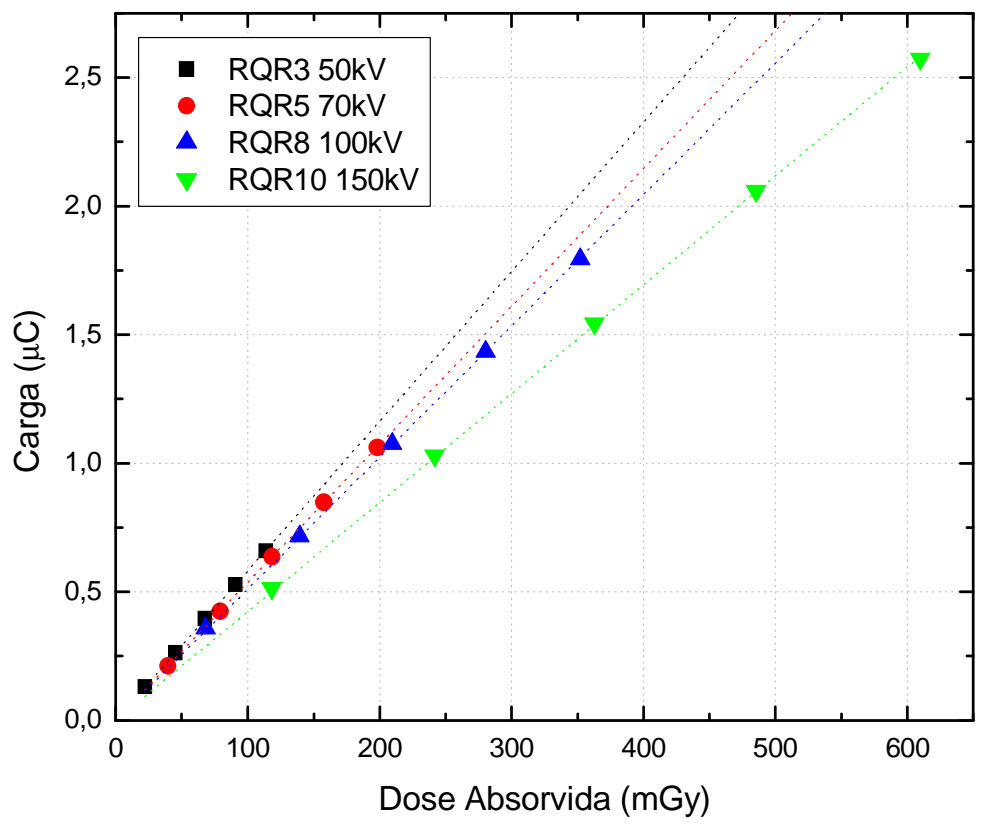

FIGURA 43: Curva dose-resposta do diodo EPI\#45 para as qualidades de radiodiagnóstico, feixes diretos (RQR). 


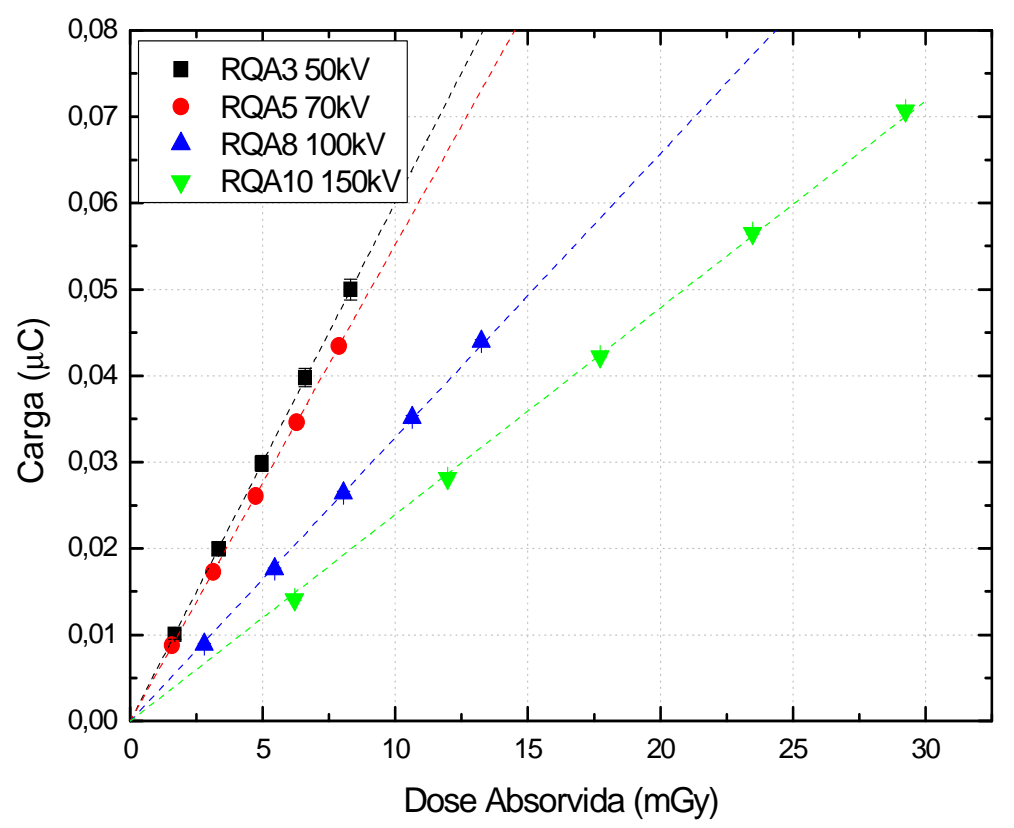

FIGURA 44: Curva dose-resposta do diodo EPI\#45 para as qualidades de radiodiagnóstico, feixes atenuados (RQA).

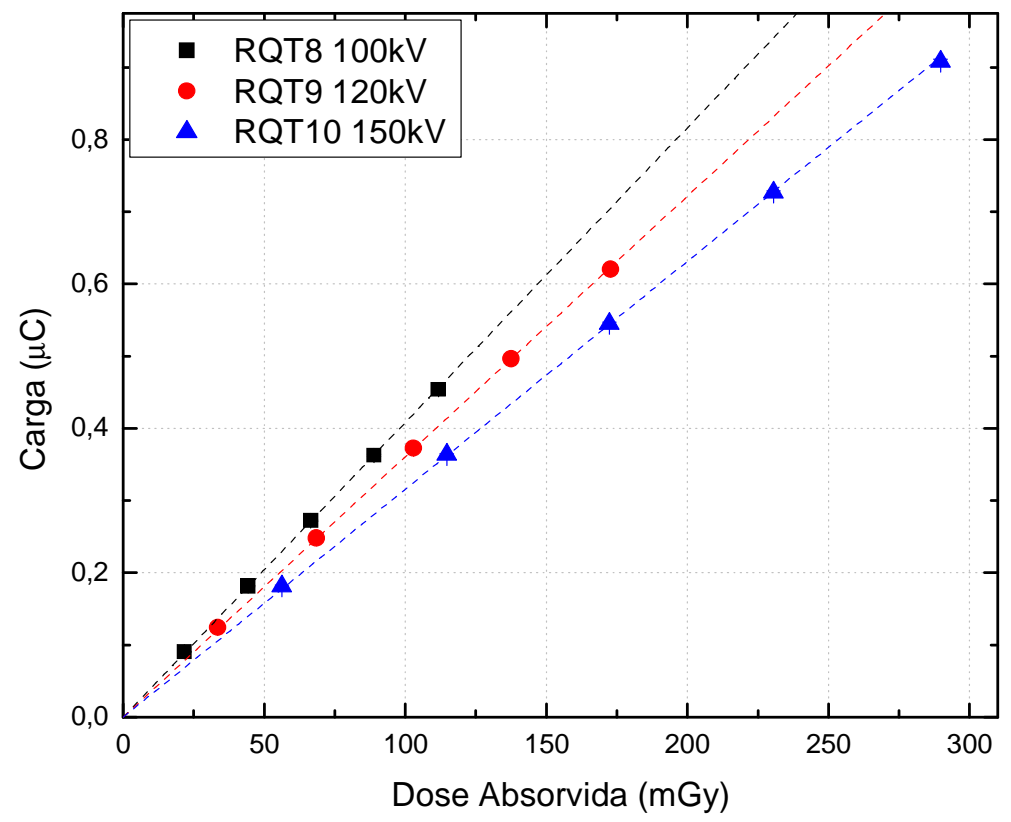

Figura 45: Curva dose-resposta do diodo EPI\#45 para as qualidades de tomografia computadorizada (RQT). 


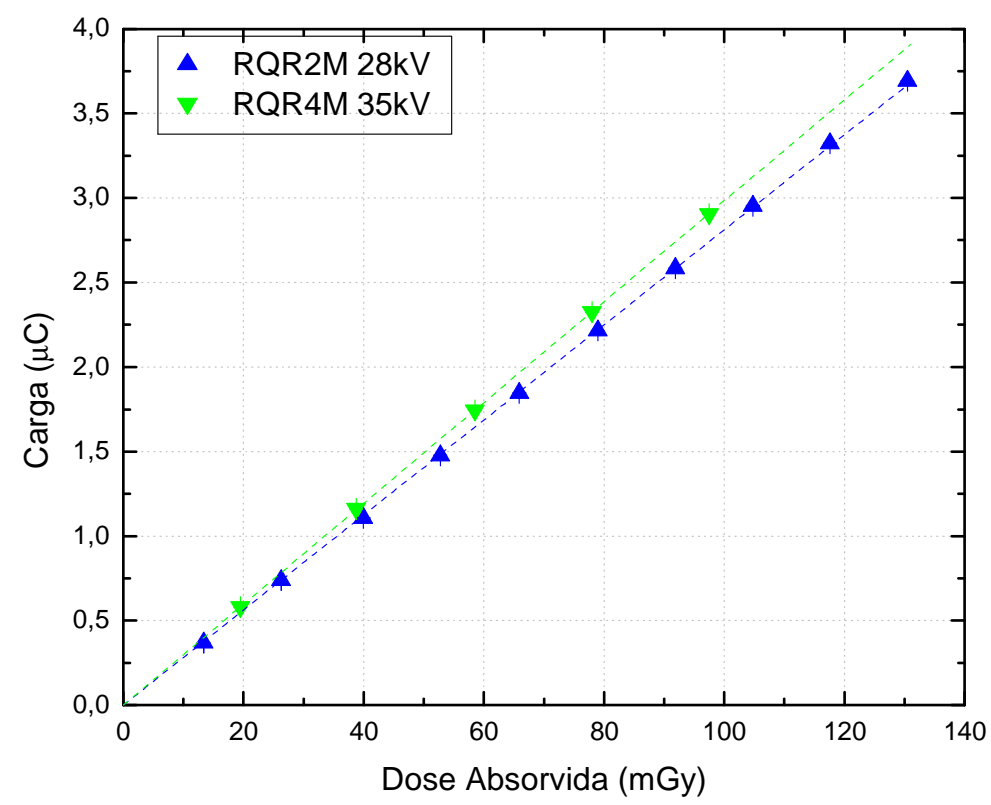

FIGURA 46: Curva dose-resposta do diodo FZ\#04 para as qualidades de mamografia com feixes diretos (RQR-2M/4M).

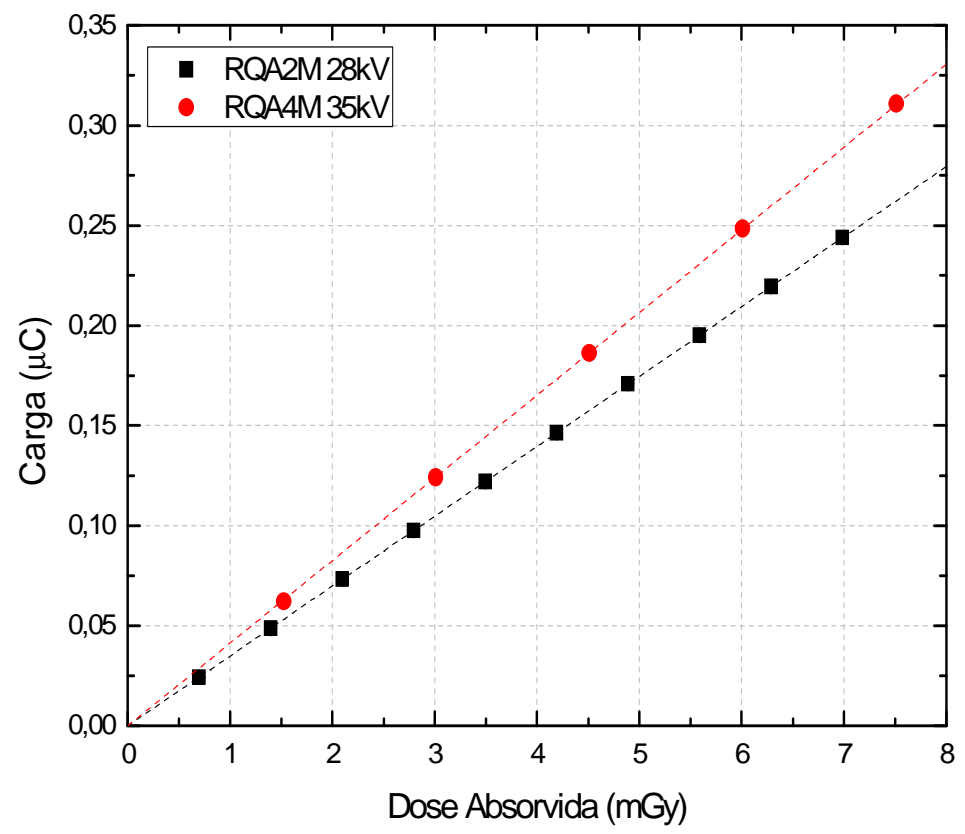

FIGURA 47: Curva dose-resposta do diodo FZ\#04 para as qualidades de mamografia com feixes atenuados (RQA-2M/4M). 


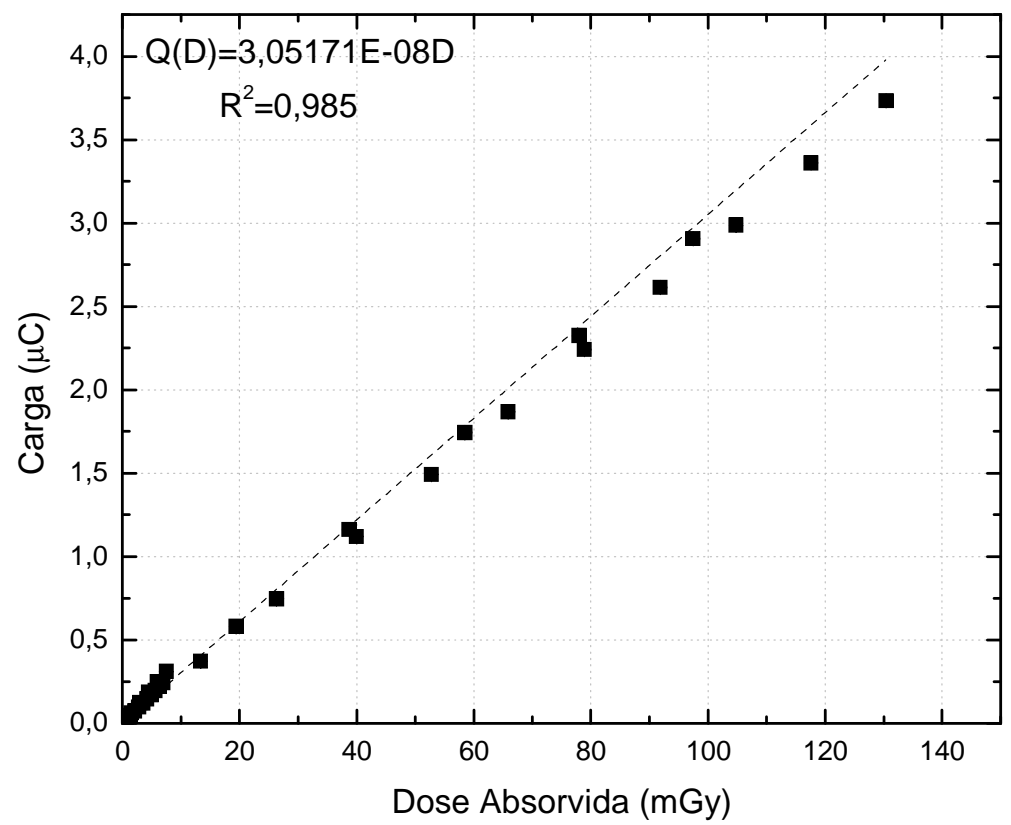

FIGURA 48: Curva carga dose para todas as qualidades de mamografia, feixes diretos e atenuados, para o diodo FZ\#04.

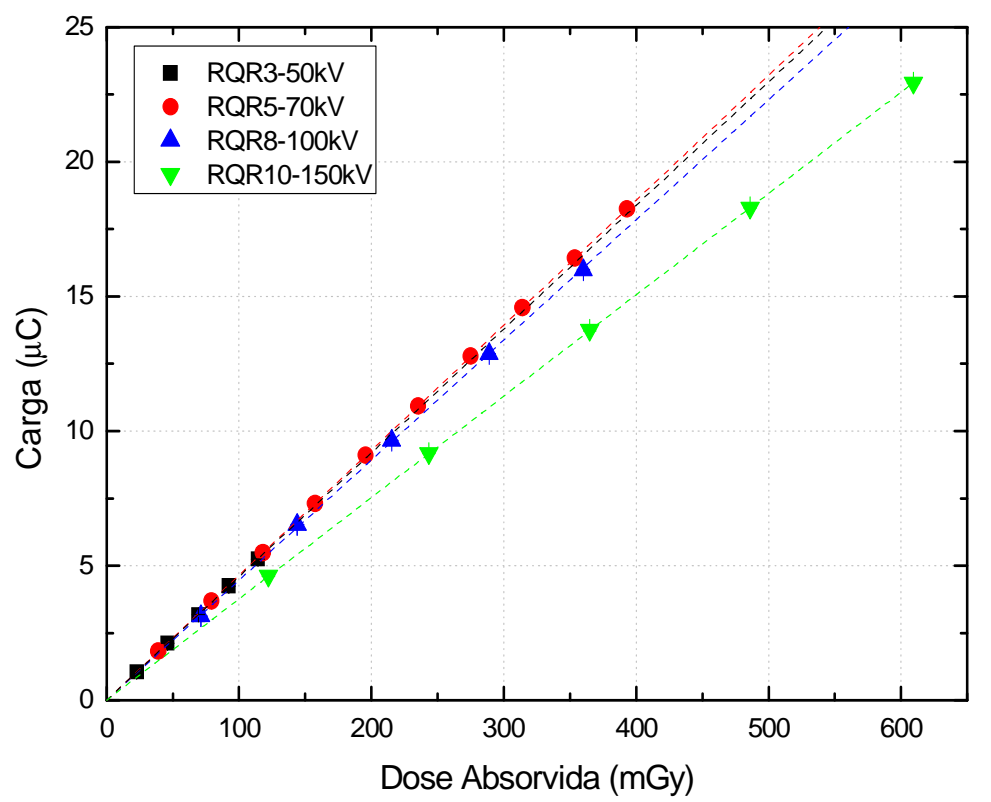

FIGURA 49: Curva dose-resposta do diodo FZ\#04 para as qualidades de radiodiagnóstico, feixes diretos (RQR). 


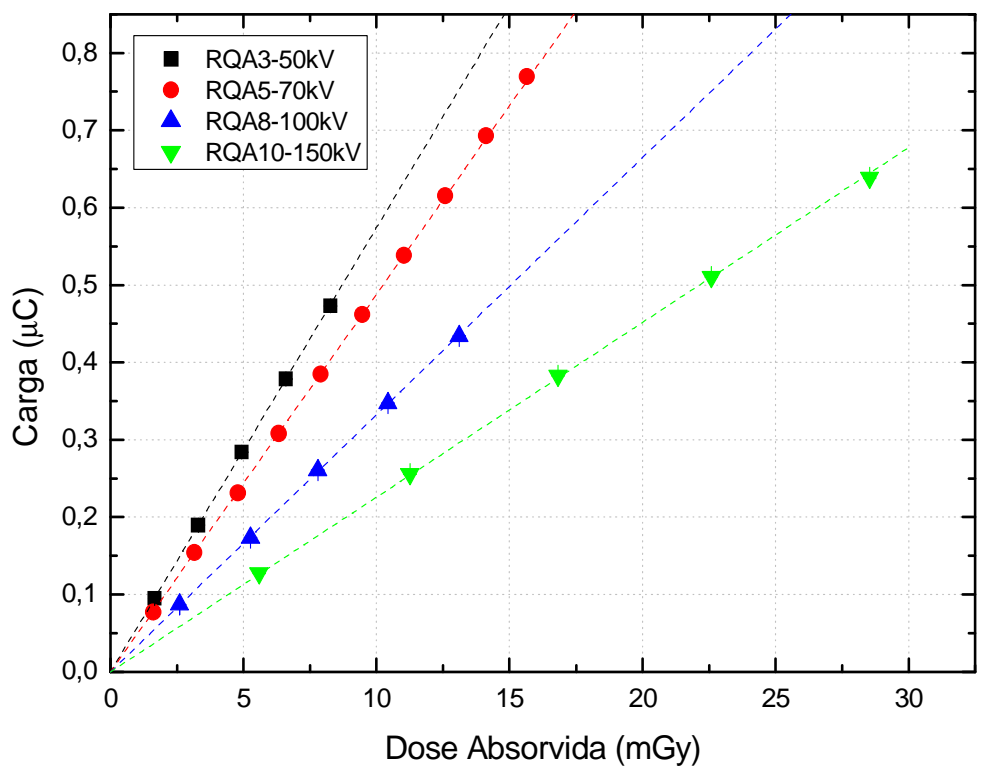

FIGURA 50: Curva dose-resposta do diodo FZ\#04 para as qualidades de radiodiagnóstico, feixes atenuados (RQA).

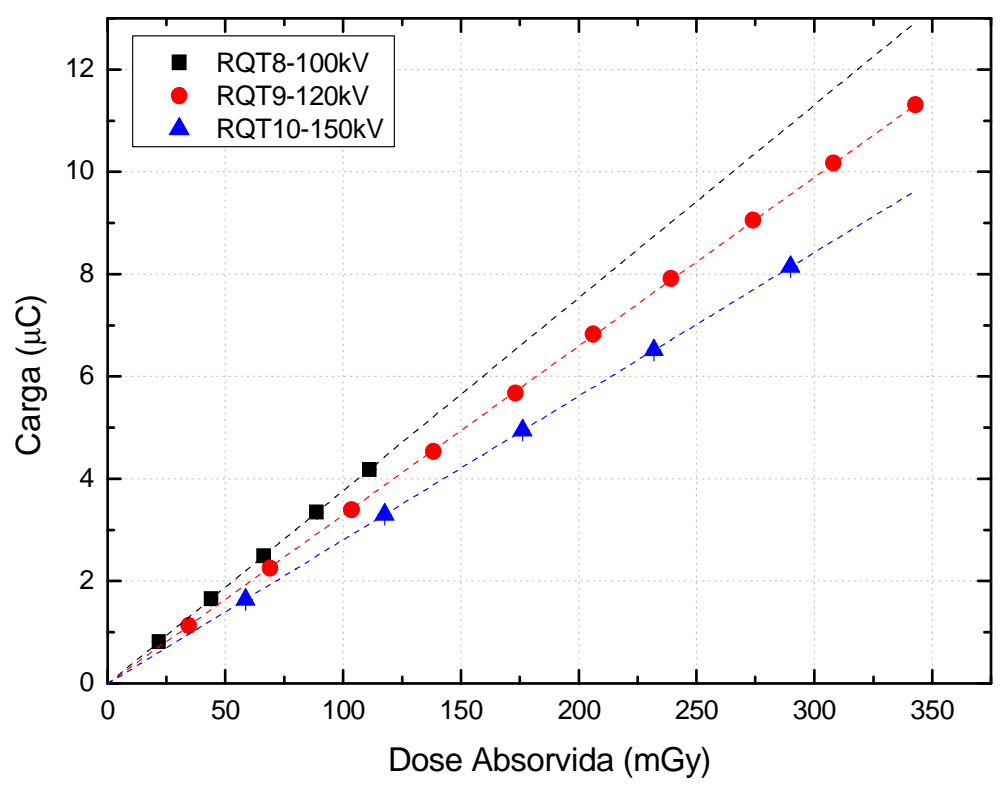

FIGURA 51: Curva dose-resposta do diodo FZ\#04 para as qualidades de tomografia computadorizada (RQT). 
atenuados (nos quais a energia efetiva é maior em relação aos feixes diretos de mesma qualidade pela eliminação pela filtração adicional dos fótons de menor energia). Este comportamento deve-se provavelmente à superposição dos espectros de energia dos raios $\mathrm{X}$, interação fotoelétrica ser predominante no Si para energias até $55 \mathrm{keV}$ e menor janela de entrada dos diodos epitaxiais em relação ao diodo FZ, tornando-os adequados para dosimetria de feixes de mamografia e radiodiagnóstico de até $70 \mathrm{keV}$.

\subsection{Linearidade de resposta com a dose para do diodo EPI\#46}

Para avaliar o comportamento dos sinais de corrente do diodo EPI\#46 em função do tempo de exposição foi realizado um estudo irradiando o dispositivo em intervalos de tempo crescentes. Em cada série de medição foram obtidos 5 pulsos de corrente em intervalos de tempo de 1, 2, 4, 5 e 10 minutos para as qualidades RQR5, RQT9 e RQR2M. A FIG.52 ilustra os pulsos de corrente e a FIG. 53 ilustra as curvas de dose resposta obtidos neste estudo. A TAB.6 apresenta os valores de doses absorvidas em cada série de medições para as diferentes qualidades de radiação estudadas.

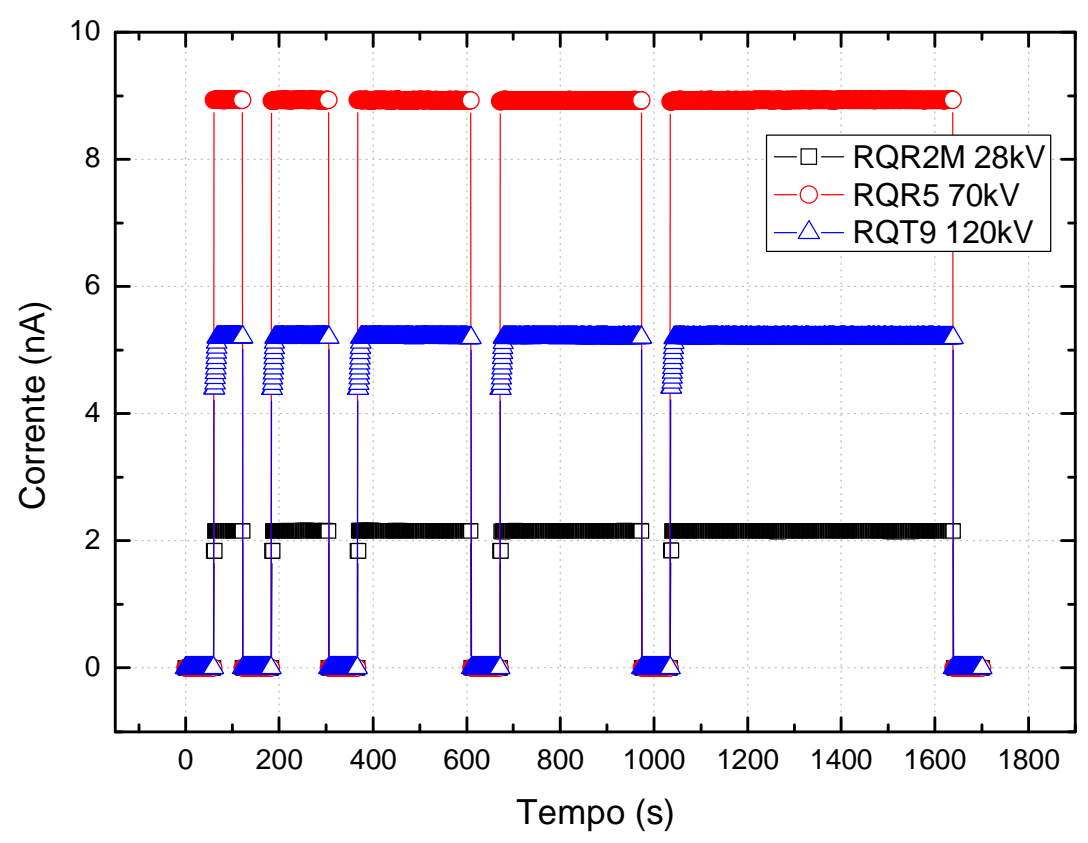

FIGURA 52: Corrente em função do tempo do diodo EPI\#46 para diferentes intervalos de tempo de irradiação nas qualidades RQR2M, RQR5 e RQT9. 
TABELA 6: Valores de dose de cada medição com intervalos de tempo de irradiação diferentes para o diodo EPI\#46.

\begin{tabular}{ccccc}
\hline \multicolumn{5}{c}{ Kerma no ar (mGy) } \\
\hline Medição & Tempo (min) & RQR2M & RQR5 & RQT9 \\
\hline 1 & 1 & $13,4(3)$ & $39,3(3)$ & $35(1)$ \\
2 & 2 & $26,2(5)$ & $78,3(6)$ & $69(2)$ \\
3 & 4 & $52(1)$ & $156(2)$ & $137(4)$ \\
4 & 5 & $65(1)$ & $195(2)$ & $171(5)$ \\
5 & 10 & $131(3)$ & $389(3)$ & $342(10)$ \\
\hline
\end{tabular}

Os resultados indicam excelente linearidade de resposta com a dose no intervalo medido, dentro do erro experimental e compatíveis com valores do coeficiente de variação correspondentes $(\mathrm{CV} \cong 0,2 \%)$

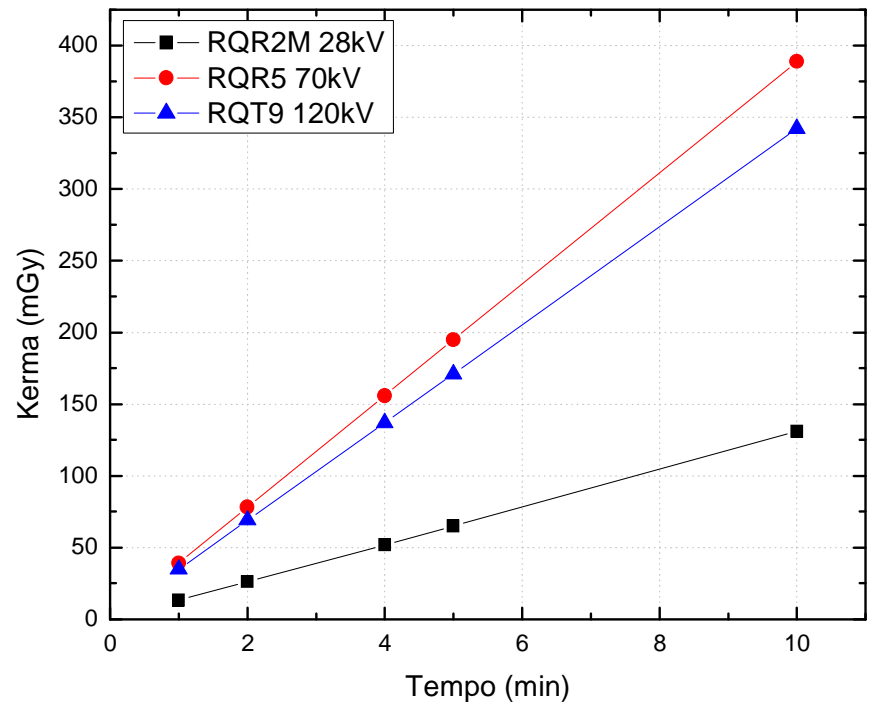

FIGURA 53: Curvas da dose em função dos tempos de irradiação do diodo EPI\#46 para as qualidades RQR2M, RQR5 e RQT9.

\subsection{Linearidade de resposta dos diodos com a taxa de Kerma}

O estudo da linearidade de resposta dos diodos para os feixes de referência das qualidades de mamografia, radiodiagnóstico e tomografia em função da taxa de Kerma foi feito mediante a alteração da corrente do tubo de raios $X$ entre $2 \mathrm{~mA}$ e $20 \mathrm{~mA}$, compreendendo um intervalo entre 0,8 e $77 \mathrm{mGy} / \mathrm{min}$ de taxa de Kerma, exceção para a qualidade RQA 5, em que a corrente foi variada de $5 \mathrm{~mA}$ a $20 \mathrm{~mA}$ de taxa de Kerma, em intervalos de $5 \mathrm{~mA}$, para garantir a estabilidade do feixe. As FIG.54 a 56 ilustram as curvas 
de corrente em função da taxa de Kerma dos diodos EPI\#46, FZ\#04 e EPI\#45, respectivamente. Os resultados evidenciam dependência linear das fotocorrentes com a taxa de Kerma, com coeficientes de correlação $\left(R^{2}\right)$ entre 0,9998 e 1,000 para os três diodos.

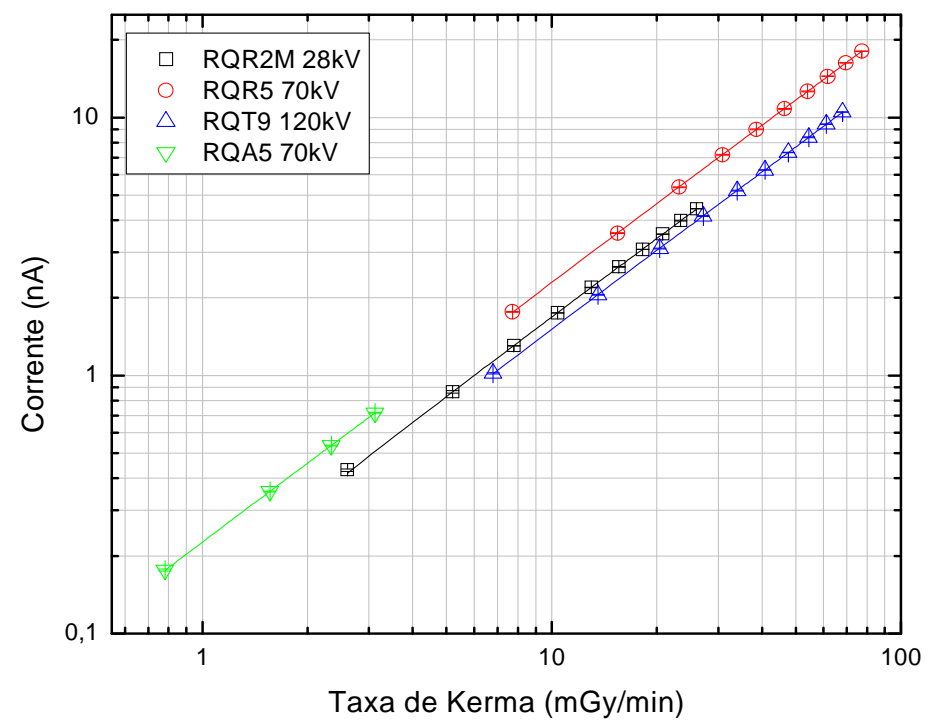

FIGURA 54: Curva da corrente em função da taxa de Kerma para o diodo EPI\#46 com os feixes de referência das qualidades estudadas.

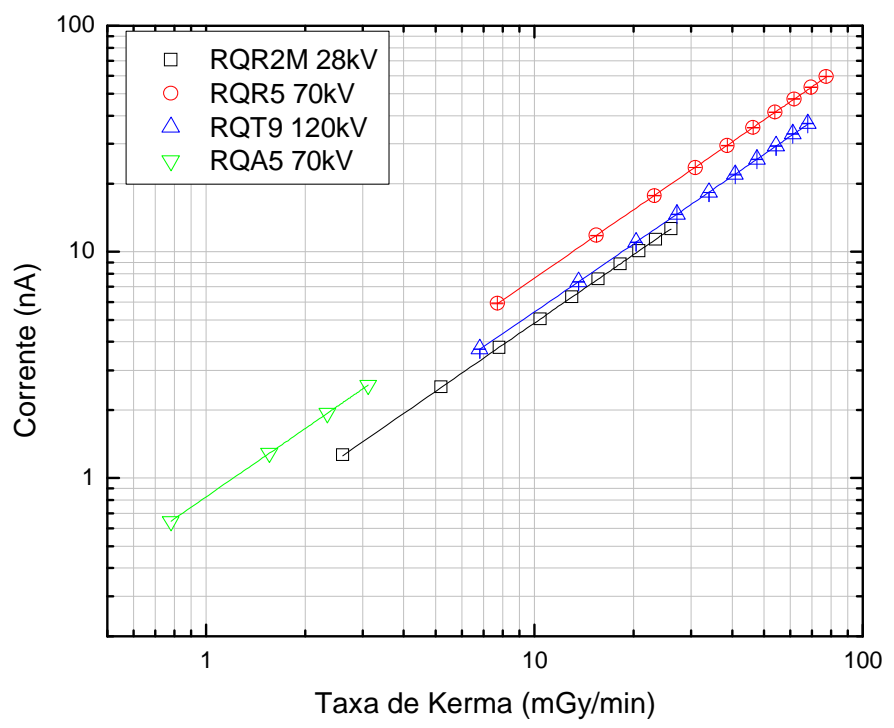

FIGURA 55: Curva da corrente em função da taxa de Kerma para diodo FZ\#04 com os feixes de referência das qualidades estudadas. 


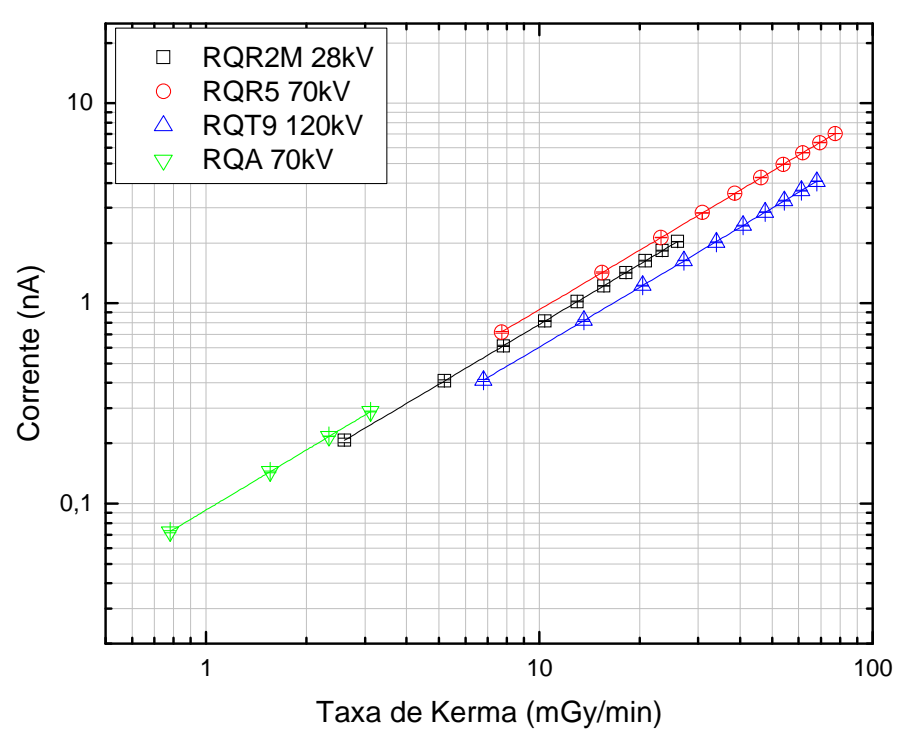

Figura 56: Curva da corrente em função da Taxa de Kerma para diodo EPI\#45 com os feixes de referência das qualidades estudadas.

As FIG.57 e 58 apresentam uma comparação das curvas das correntes normalizadas pelo volume sensível entre os diodos EPI\#46 e FZ\#04 em função da taxa de Kerma para as qualidades RQR5, RQT9, RQA5 e RQR2M. Estes resultados evidenciam que apesar de também apresentar resposta linear com a taxa de Kerma, o diodo FZ\#04 possui menor sensibilidade em corrente. Esta superioridade apresentada pelo diodo epitaxial está associada à menor espessura de sua janela, inerente ao processo de crescimento do cristal.

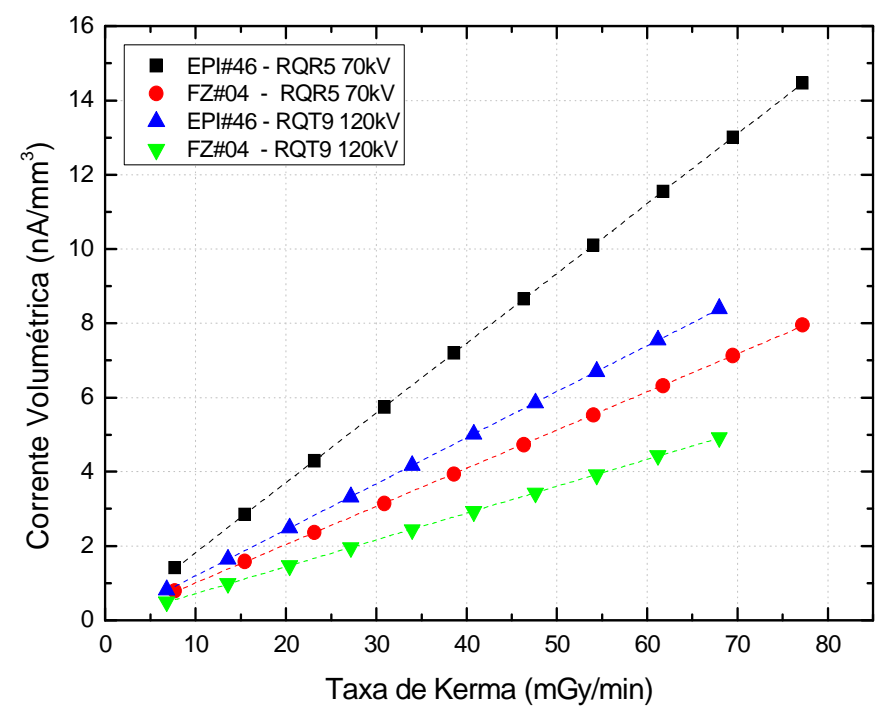

FIGURA 57: Corrente volumétrica dos diodos EPI\#46 e FZ\#04 em função da taxa de Kerma para as qualidades RQR5 e RQT9. 


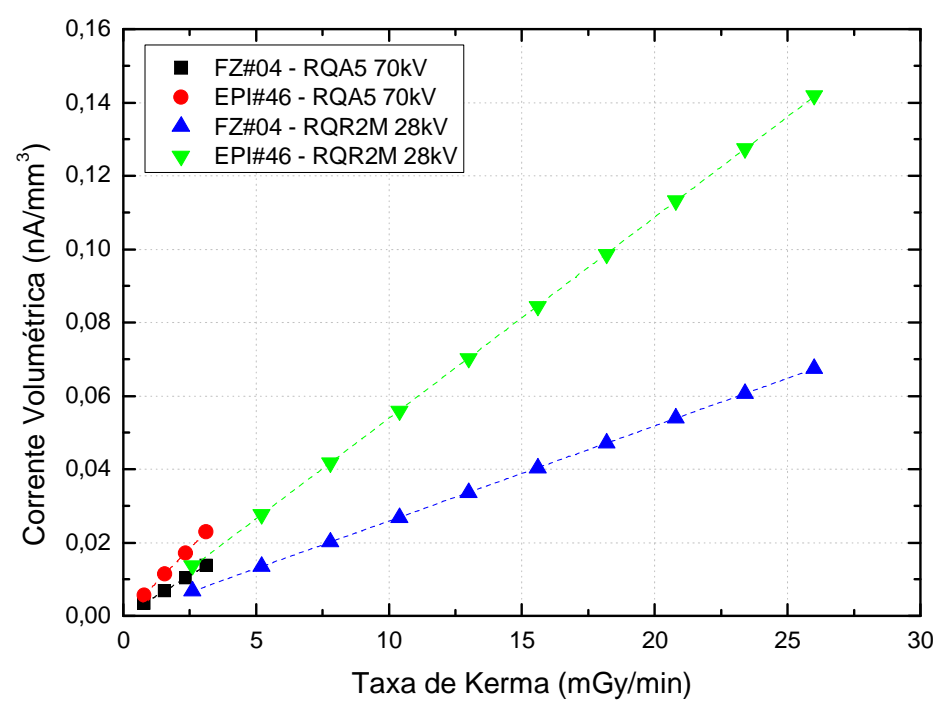

FIGURA 58: Corrente volumétrica dos diodos EPI\#46 e FZ\#04 em função da taxa de Kerma para as qualidades RQA5 e RQR2M.

\subsection{Sensibilidade}

\subsubsection{Sensibilidade em corrente}

A sensibilidade em corrente dos diodos é obtida a partir dos coeficientes angulares das curvas de corrente em função da taxa de Kerma. As TAB.7, 8 e 9 fornecem a sensibilidade em corrente para os diodos estudados e as FIG.59 a 61 mostram para diferentes qualidades de feixe a variação da sensibilidade em corrente com a taxa de Kerma. Fica evidente a discreta dependência da sensibilidade em corrente com a taxa de Kerma para os dispositivos no intervalo de $2,8 \%$.

TABELA 7: Sensibilidade em corrente do diodo EPI\#45 para os feixes de referência das qualidades estudadas neste trabalho.

\begin{tabular}{lcc}
\hline $\begin{array}{c}\text { Qualidade do } \\
\text { feixe }\end{array}$ & $\begin{array}{c}\text { Sensibilidade } \\
(\mu \mathrm{A} . \mathrm{s} / \mathrm{Gy})\end{array}$ & $\begin{array}{c}\text { Sensibilidade/Volume } \\
\left(\mu \mathrm{A} . \mathrm{s} / \mathrm{Gy} \cdot \mathrm{mm}^{3}\right)\end{array}$ \\
\hline RQR2M 28kV & $5,54(9)$ & $4,43(5)$ \\
RQR5 70kV & $4,69(3)$ & $3,75(2)$ \\
RQA5 70kV & $3,58(5)$ & $2,86(3)$ \\
RQT9 120kV & $5,47(1)$ & $4,37(1)$ \\
\hline
\end{tabular}


TABELA 8: Sensibilidade em corrente do diodo EPI\#46 para os feixes de referência das qualidades estudadas neste trabalho.

\begin{tabular}{lcc}
\hline $\begin{array}{c}\text { Qualidade do } \\
\text { feixe }\end{array}$ & $\begin{array}{c}\text { Sensibilidade } \\
(\mu \mathrm{A} . \mathrm{s} / \mathrm{Gy})\end{array}$ & $\begin{array}{c}\text { Sensibilidade/Volume } \\
\left(\mu \mathrm{A} . \mathrm{s} / \mathrm{Gy} \cdot \mathrm{mm}^{3}\right)\end{array}$ \\
\hline RQR2M 28kV & $10,14(3)$ & $8,11(5)$ \\
RQR5 70kV & $13,84(4)$ & $11,07(9)$ \\
RQA5 70kV & $13,73(2)$ & $10,99(3)$ \\
RQT9 120kV & $9,19(8)$ & $7,35(2)$ \\
\hline
\end{tabular}

TABELA 9: Sensibilidade em corrente do diodo FZ\#04 para os feixes de referência das qualidades estudadas neste trabalho.

\begin{tabular}{lcc}
\hline $\begin{array}{c}\text { Qualidade do } \\
\text { feixe }\end{array}$ & $\begin{array}{c}\text { Sensibilidade } \\
(\mu \mathrm{A} . \mathrm{s} / \mathrm{Gy})\end{array}$ & $\begin{array}{c}\text { Sensibilidade/Volume } \\
\left(\mu \mathrm{A} . \mathrm{s} / \mathrm{Gy} \cdot \mathrm{mm}^{3}\right)\end{array}$ \\
\hline RQR2M 28kV & $29,18(5)$ & $3,89(4)$ \\
RQR5 70kV & $46,01(4)$ & $6,13(6)$ \\
RQA5 70kV & $49,65(5)$ & $6,62(9)$ \\
RQT9 120kV & $32,46(7)$ & $4,32(1)$ \\
\hline
\end{tabular}

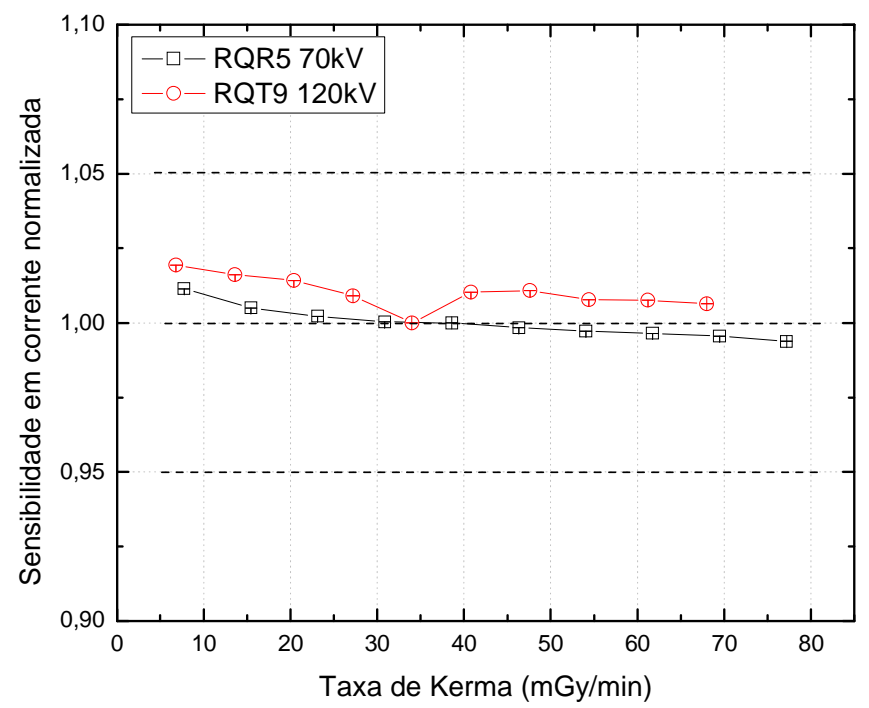

FIGURA 59: Sensibilidade em corrente do diodo EPI\#45 para os feixes RQR5 e RQT9. Valores de sensibilidade normalizados para os valores de referência destas qualidades. 


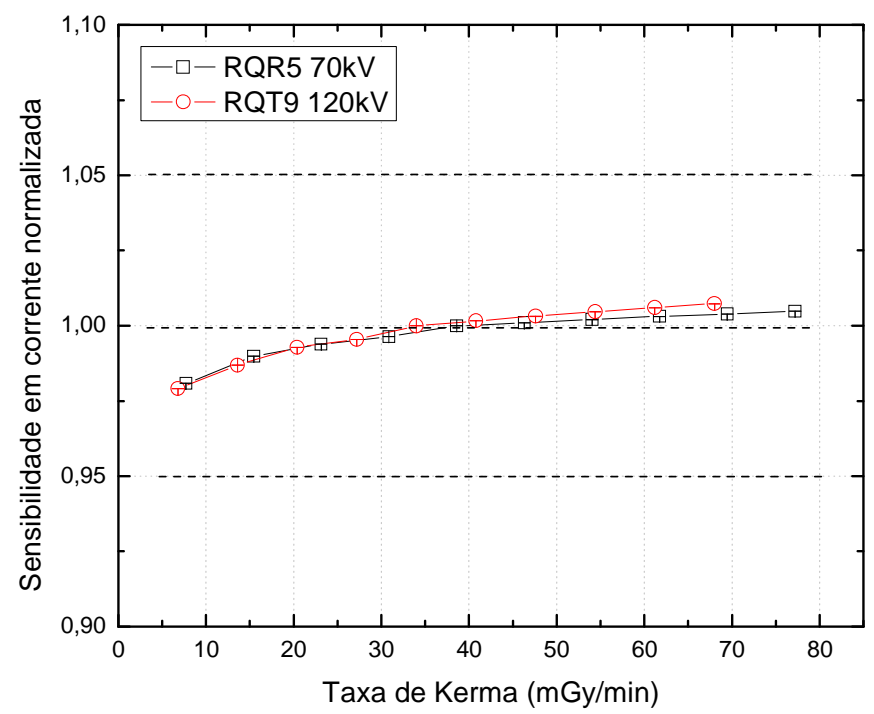

FIGURA 60: Sensibilidade em corrente do diodo EPI\#46 para os feixes de referência das qualidades RQR5 e RQT9. Valores de sensibilidade normalizados para os valores de referência destas qualidades.

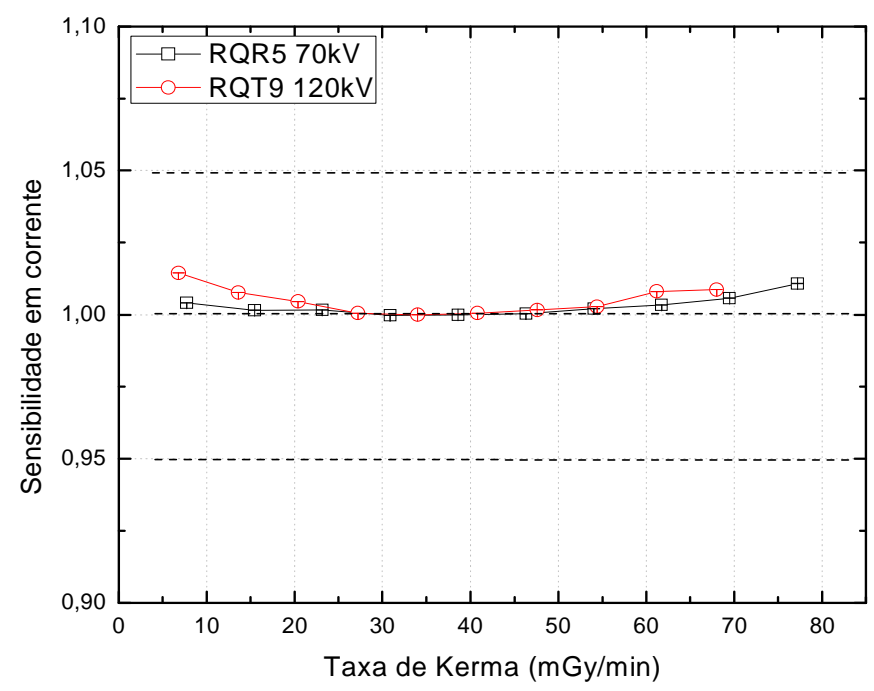

FIGURA 61: Sensibilidade em corrente do diodo FZ\#04 para os feixes de referência das qualidades RQR5 e RQT9. Valores de sensibilidade normalizados para os valores de referência destas qualidades.

\subsubsection{Sensibilidade em carga}

A sensibilidade em carga de um dosímetro é representada pelo coeficiente angular da curva dose-resposta. A TAB. 10 apresenta as sensibilidades obtidas através dos ajustes lineares das curvas dose-resposta para os diodos EPI\#45, 46 e FZ\#04. Os resultados confirmam, como esperado, que o diodo epitaxial sem pré-dose (EPI\#46) apresenta 
sensibilidade em carga superior (cerca de duas vezes e meia) à do diodo pré-irradiado, com valores no intervalo de 5,9 a 13,9 $\mathrm{nC} / \mathrm{mGy}$; de modo geral, para feixes com energias maiores aos de mamografia, este parâmetro diminuiu para energias crescentes dos feixes (FIG.62 a FIG.66), decorrente da menor secção de choque total para absorção de radiação $\mathrm{X}$ com o Si.

TABELA 10: Sensibilidade em carga dos diodos EPI\#45, \#46 e FZ\#04 para os feixes de mamografia, radiodiagnóstico e tomografia.

\begin{tabular}{cccc}
\hline $\begin{array}{c}\text { Qualidade do } \\
\text { feixe }\end{array}$ & $\begin{array}{c}\text { EPI\#45 } \\
\text { (nC/mGib) }\end{array}$ & $\begin{array}{c}\text { EPI\#46 } \\
\text { (nC/mGibilidade }\end{array}$ & $\begin{array}{c}\text { Sensibilidade } \\
(\mathrm{nC} / \mathrm{mGy})\end{array}$ \\
\hline RQR3 50kV & $5,82(2)$ & $13,91(5)$ & $45,95(1)$ \\
RQR5 70kV & $5,36(3)$ & $14,16(1)$ & $46,45(6)$ \\
RQR8 100kV & $5,12(9)$ & $13,18(1)$ & $44,61(2)$ \\
RQR10 150kV & $4,24(7)$ & $10,93(3)$ & $37,65(2)$ \\
\hline RQA3 50kV & $6,01(4)$ & $15,81(1)$ & $57,42(1)$ \\
RQA5 70kV & $5,52(1)$ & $13,68(2)$ & $23,43(2)$ \\
RQA8 100kV & $3,29(5)$ & $8,83(1)$ & $33,24(1)$ \\
RQA10 150kV & $2,39(5)$ & $5,95(3)$ & $22,58(1)$ \\
\hline RQR2M 28kV & $4,61(6)$ & $11,51(1)$ & $34,92(5)$ \\
RQR4M 35kV & $4,71(1)$ & $12,23(1)$ & $41,31(6)$ \\
RQA2M 28kV & $4,67(4)$ & $10,12(6)$ & $28,12(5)$ \\
RQA4M 35kV & $5,23(3)$ & $10,35(8)$ & $29,84(5)$ \\
\hline RQT8 100kV & $4,08(2)$ & $10,52(3)$ & $37,69(1)$ \\
RQT9 120kV & $3,61(2)$ & $9,31(1)$ & $32,77(5)$ \\
RQT10 150kV & $3,16(3)$ & $7,82(8)$ & $28,08(4)$ \\
\hline
\end{tabular}

O comportamento da sensibilidade em carga para as diferentes qualidades de feixe estudadas em função da taxa de Kerma mostram dependência de resposta dentro de 4\% para os diodos EPI\#46 e \#45 e de 5\% para o diodo FZ\#04, como ocorreu com a sensibilidade em corrente.

Para maior clareza, as FIG.67 a FIG.72 mostram a sensibilidade em carga normalizada em função da taxa de Kerma para as qualidades RQR2M, RQR5, RQT9 e RQA5 para os diodos EPI\#45, EPI\#46 e FZ\#04. 


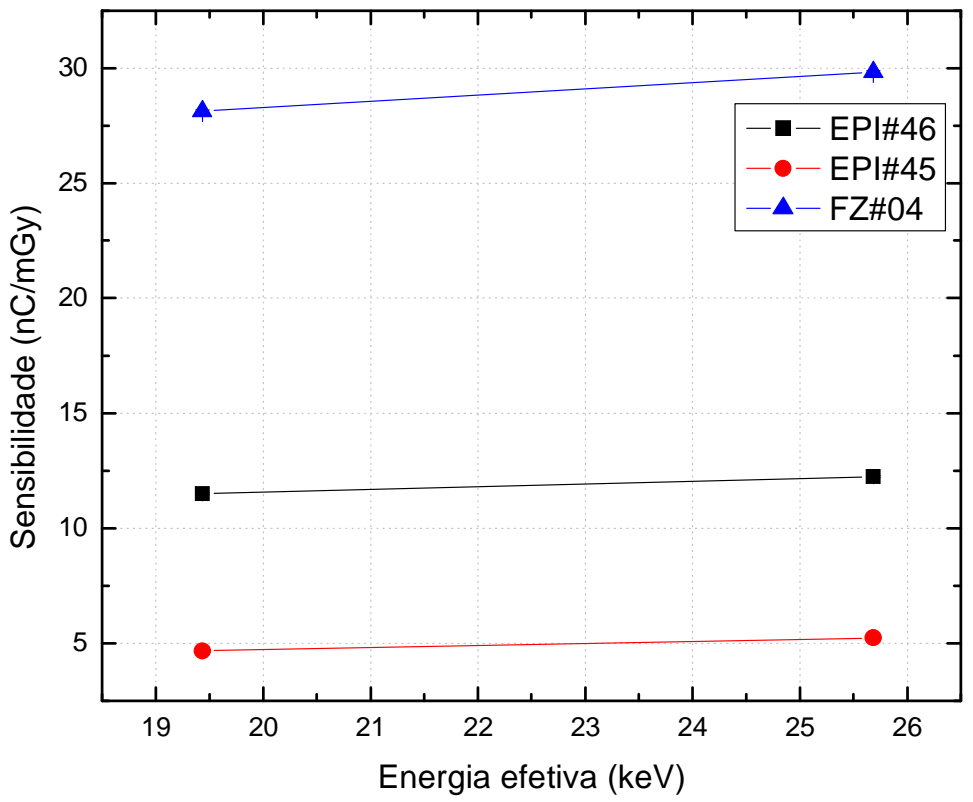

FIGURA 62: Sensibilidade em carga dos diodos EPI\#46, \#45 e FZ\#04 em função da energia efetiva do feixe para as qualidades de mamografia com feixes atenuados.

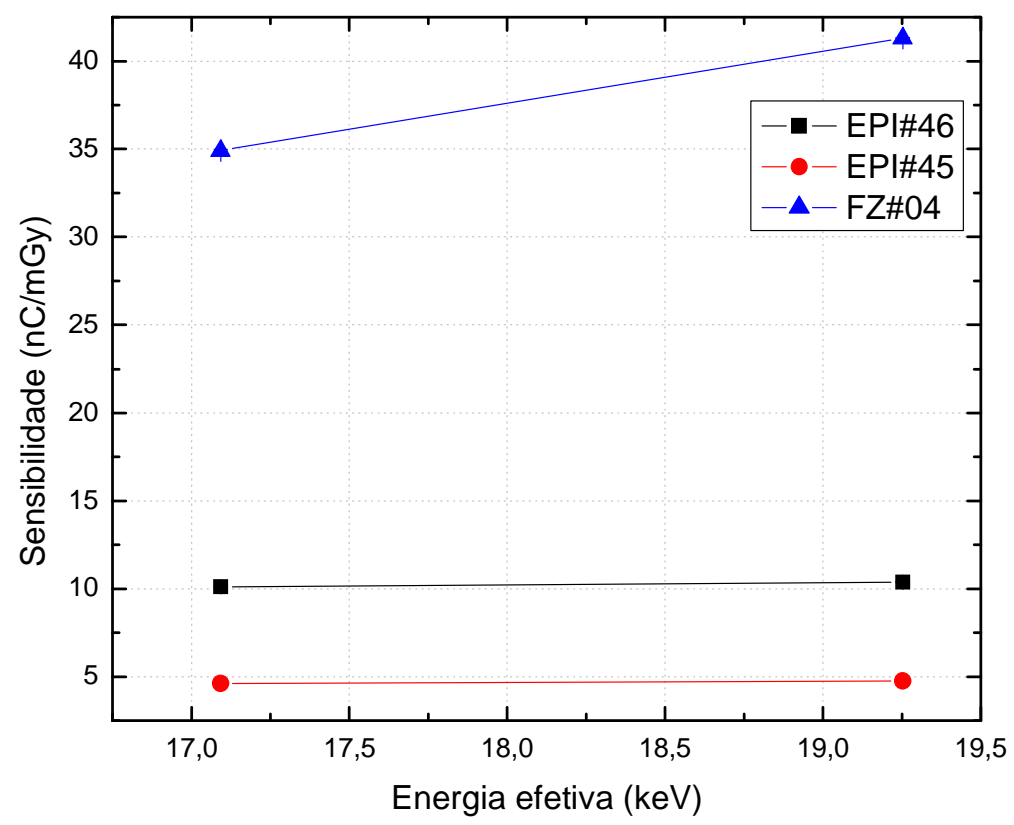

FIGURA 63: Sensibilidade em carga dos diodos EPI\#46, \#45 e FZ\#04 em função da energia efetiva do feixe para as qualidades de mamografia com feixes diretos. 


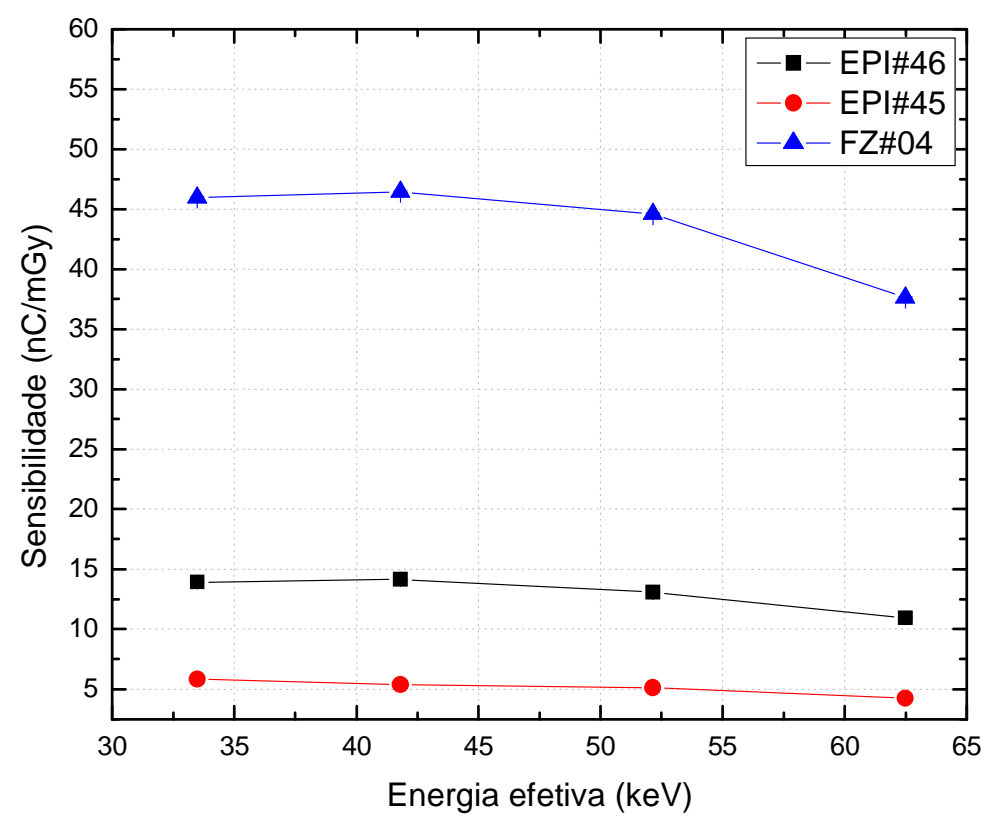

FIGURA 64: Sensibilidade em carga dos diodos EPI\#46, \#45 e FZ\#04 em função da energia efetiva do feixe para as qualidades de radiodiagnóstico com feixes diretos.

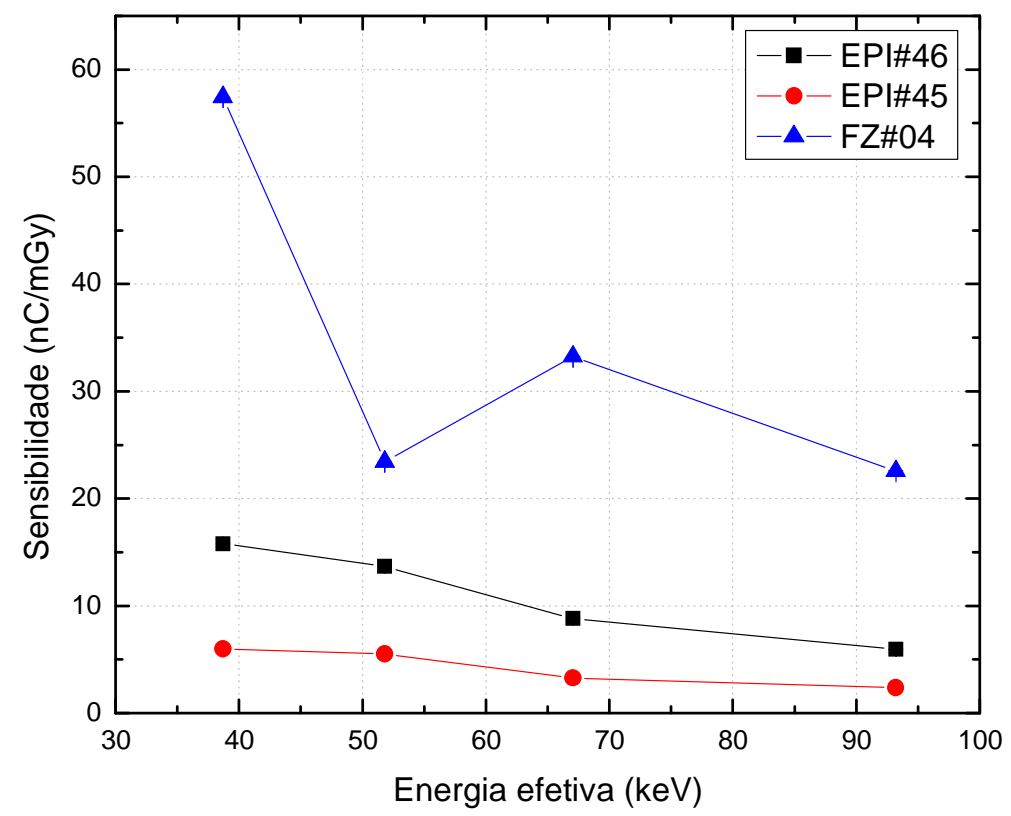

FIGURA 65: Sensibilidade em carga dos diodos EPI\#46, \#45 e FZ\#04 em função da energia efetiva do feixe para as qualidades de radiodiagnóstico com feixes atenuados. 


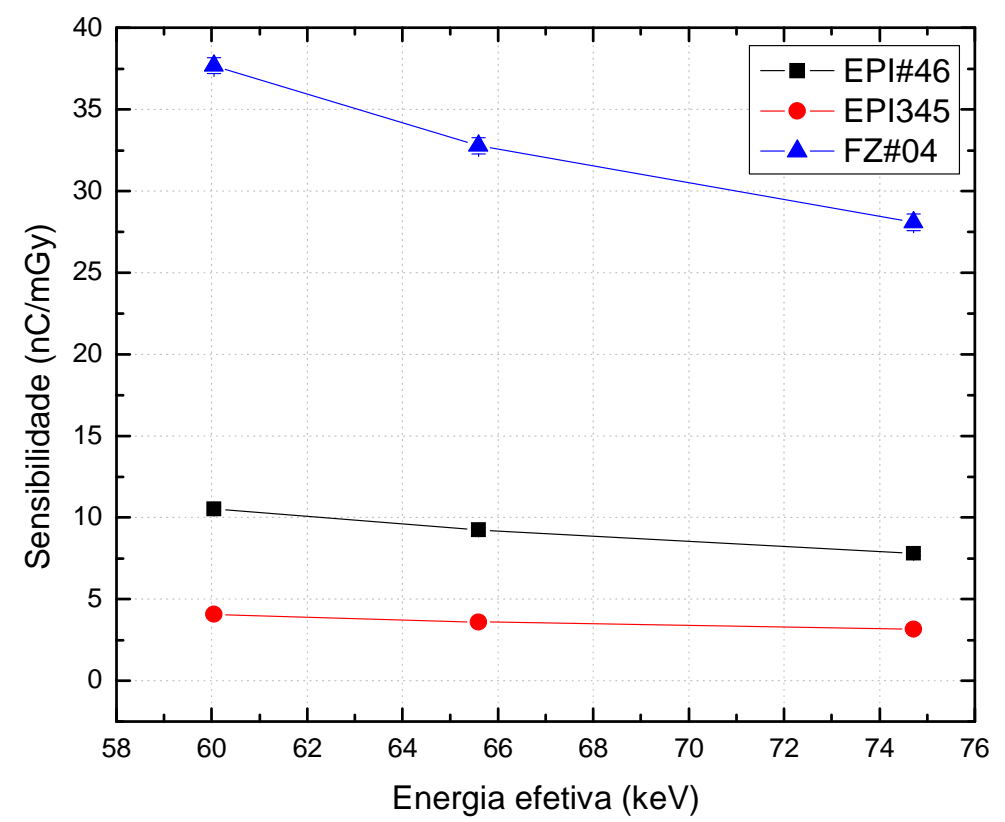

FIGURA 66: Sensibilidade em carga dos diodos EPI\#46, \#45 e FZ\#04 em função da energia efetiva do feixe para as qualidades de tomografia.

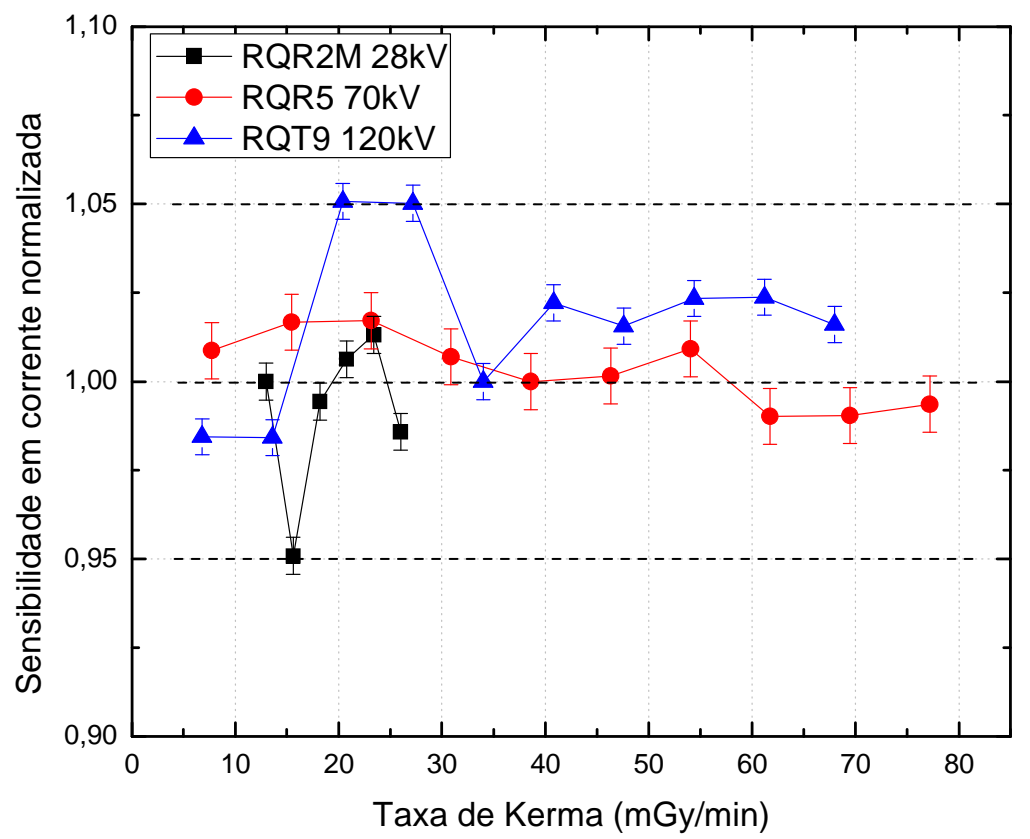

FIGURA 67: Sensibilidade em carga do diodo EPI\#45 em função da taxa de Kerma para as qualidades de mamografia, tomografia e radiodiagnóstico feixes diretos (valores normalizados para o feixe de referência). 


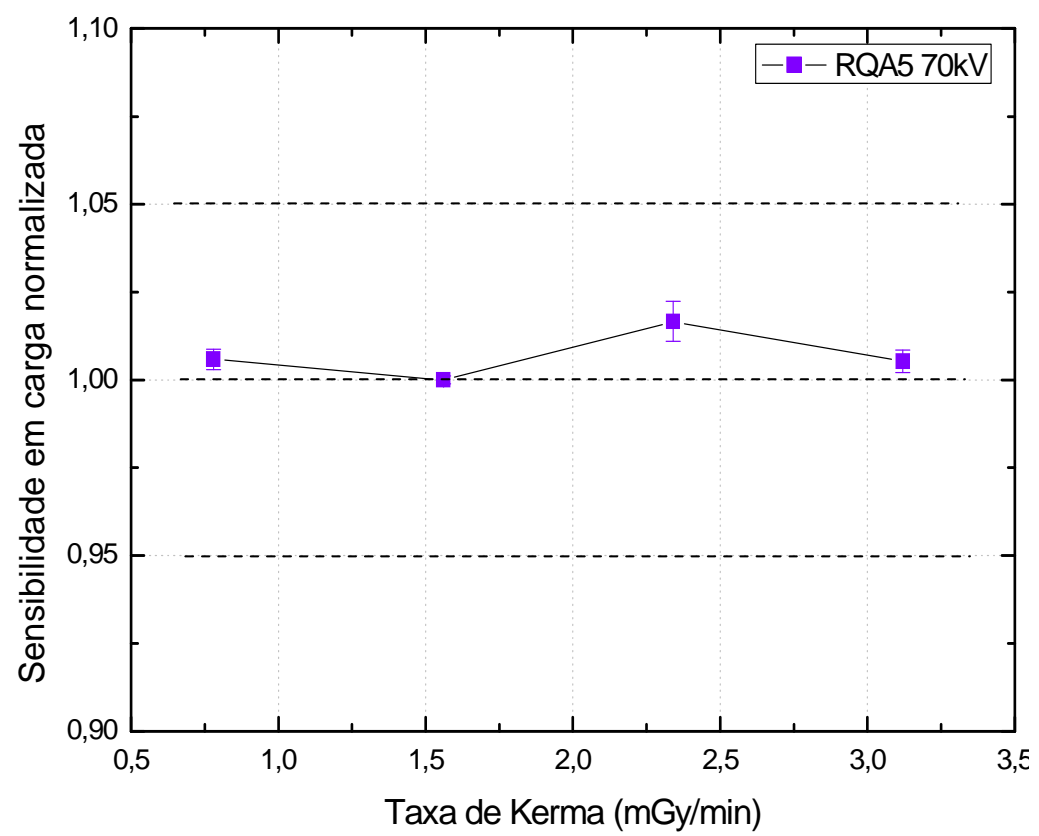

FIGURA 68: Sensibilidade em carga do diodo EPI\#45 em função da taxa de Kerma para a qualidade radiodiagnóstico feixes atenuados (valores normalizados para o feixe de referência).

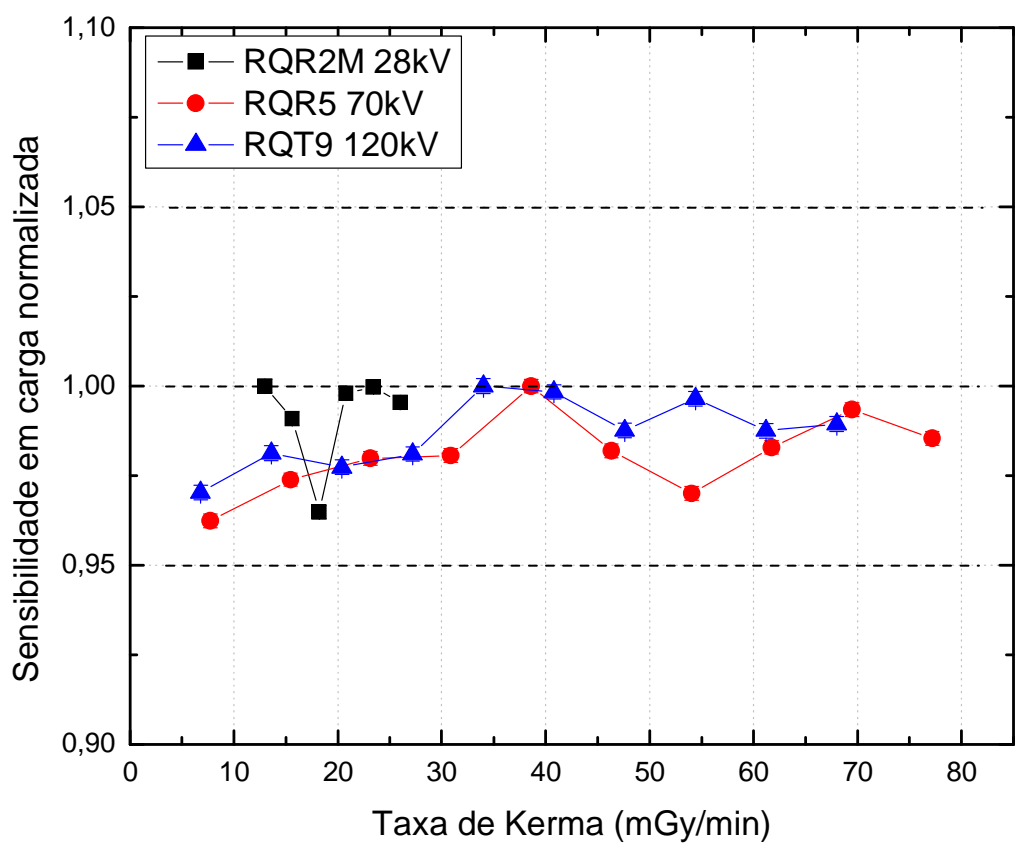

FIGURA 69: Sensibilidade em carga do diodo EPI\#46 em função da taxa de Kerma para as qualidades de mamografia, tomografia e radiodiagnóstico feixes diretos (valores normalizados para o feixe de referência). 


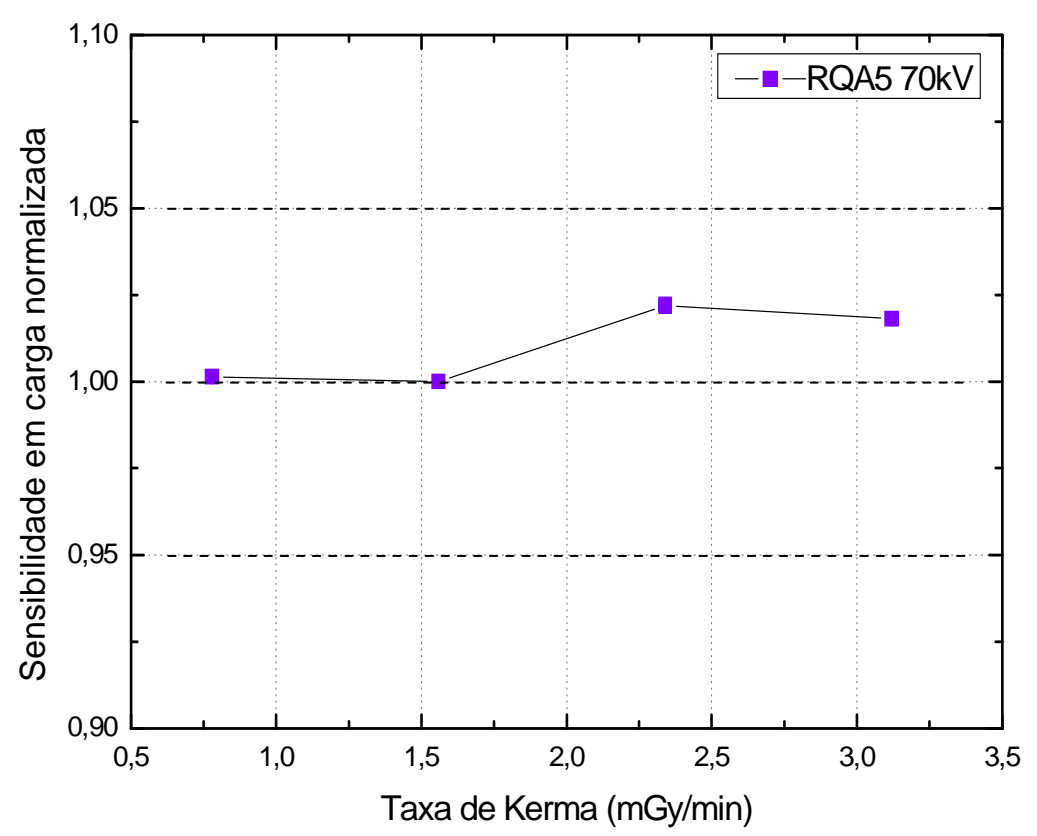

FIGURA 70: Sensibilidade em carga do diodo EPI\#46 em função da taxa de Kerma para a qualidade radiodiagnóstico feixes atenuados (valores normalizados para o feixe de referência).

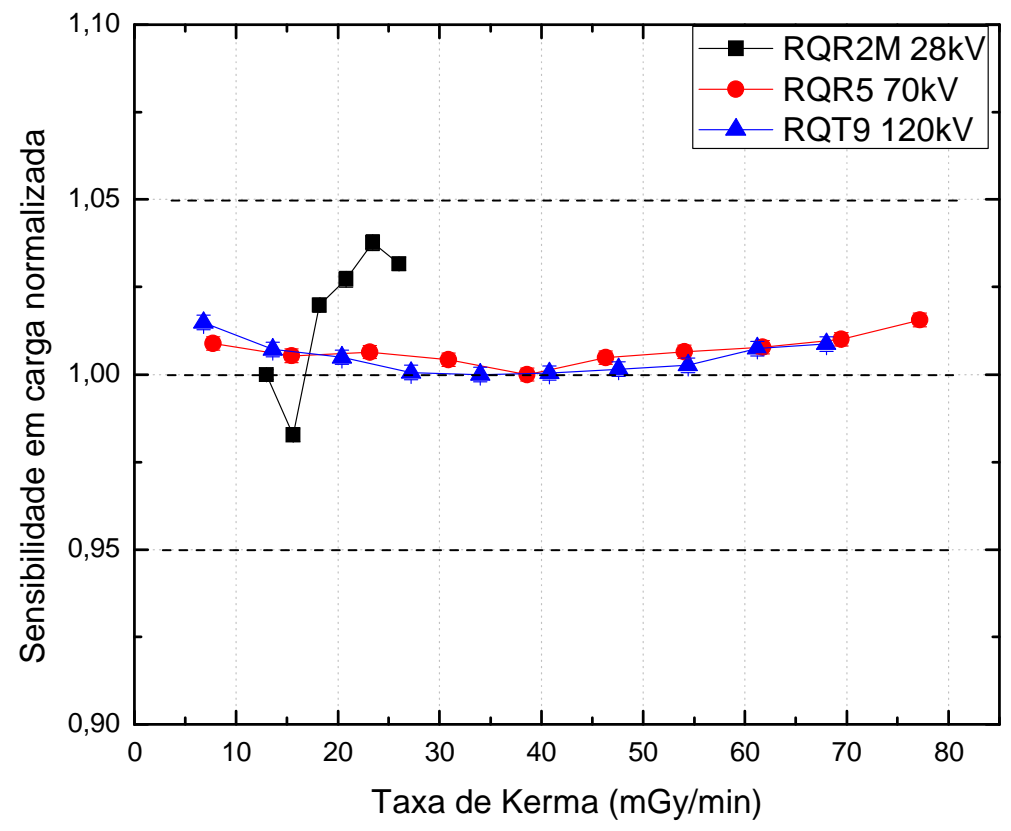

Figura 71: Sensibilidade em carga do diodo FZ\#04 em função da taxa de Kerma para as qualidades de mamografia, tomografia e radiodiagnóstico feixes diretos (valores normalizados para o feixe de referência). 


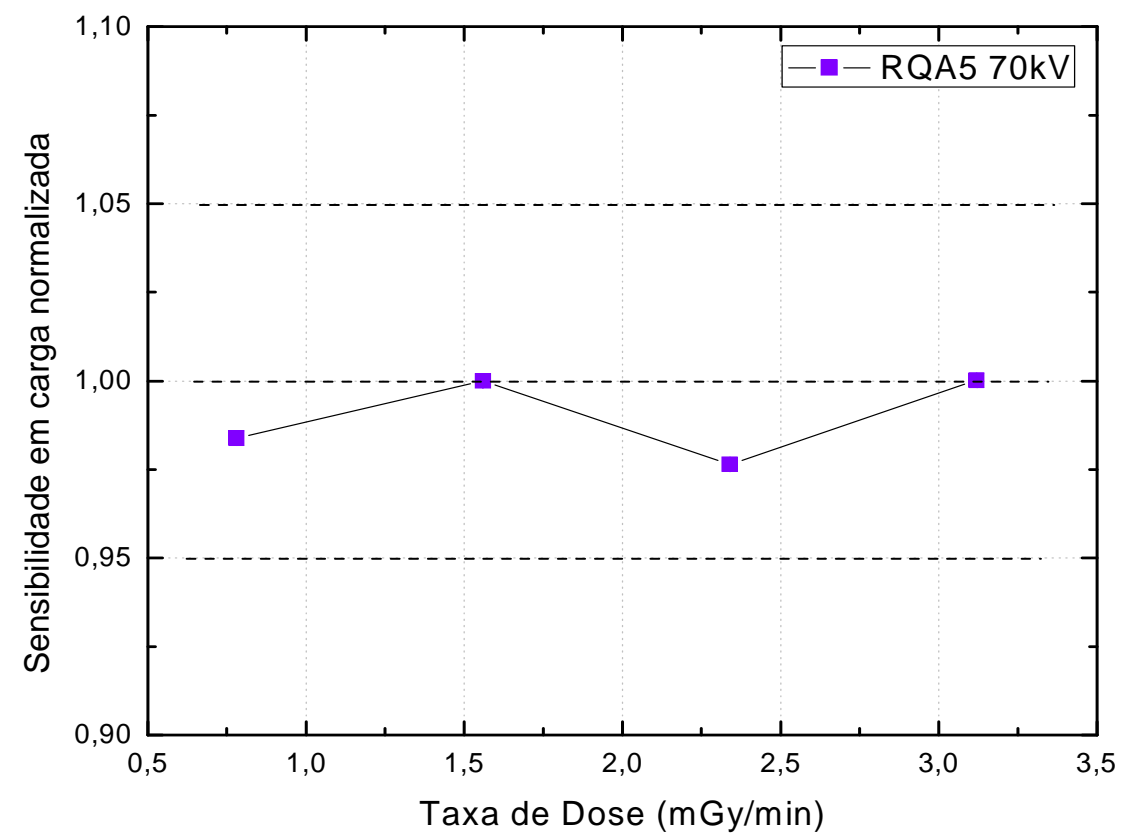

FIGURA 72: Sensibilidade em carga do diodo FZ\#04 em função da taxa de Kerma para a qualidade radiodiagnóstico feixes atenuados (valores normalizados para o feixe de referência).

\subsection{Modos de aquisição em corrente e em carga para o diodo EPI\#46}

Os dosímetros semicondutores comerciais utilizados em feixes clínicos fornecem geralmente a carga coletada pelo dispositivo. Em nossas medições, a corrente produzida como resultado da incidência da radiação representa o parâmetro dosimétrico medido, o que nos permite em tempo real observar qualquer alteração das condições de irradiação. Com a finalidade de verificarmos a equivalência dos dois métodos no que se refere à quantificação da carga coletada, realizou-se aquisições de cinco irradiações consecutivas, com duração de 15 s cada uma com o feixe RQR5, taxa de Kerma de 38,6 mGy/min, tanto em modo de corrente quanto de carga, utilizando o eletrômetro Keithley 6517B. O gráfico da FIG.73 ilustra as medições em modo carga e a FIG. 74 as medições de corrente. A TAB.11 mostra as comparações das cargas médias adquiridas pelos dois modos de aquisição, confirmando a equivalência entre ambos. 


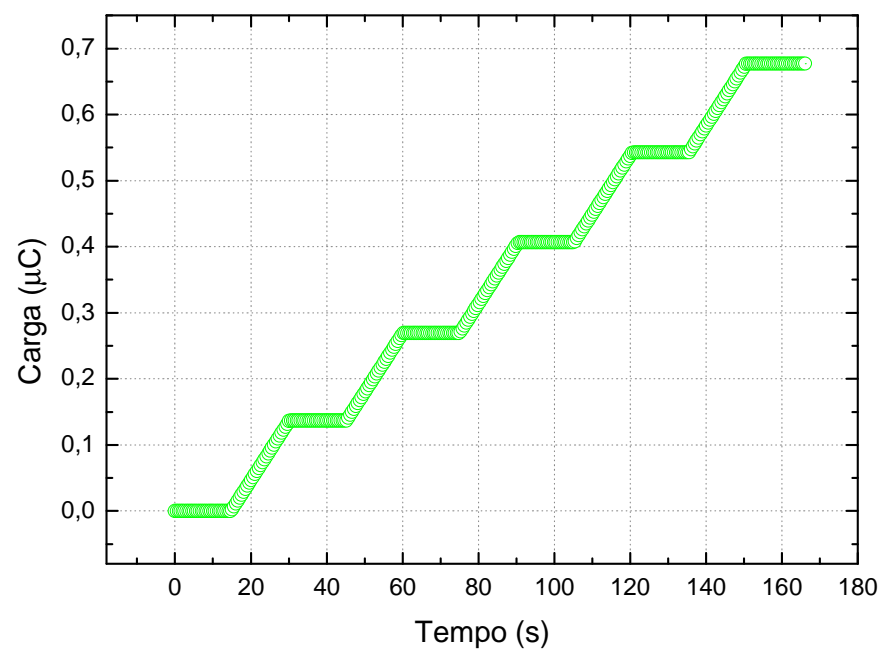

FIGURA 73: Carga acumulada pelo diodo EPI\#46 em função do tempo de irradiação para o feixe de qualidade RQR5.

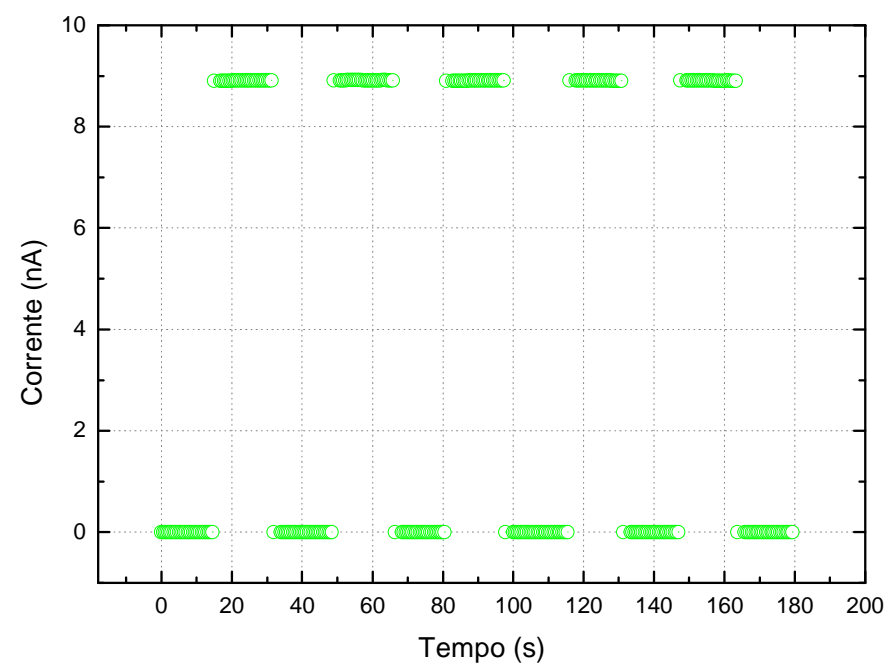

FIGURA 74: Corrente medida pelo diodo EPI\#46 em função do tempo de irradiação para o feixe de qualidade RQR5.

TABELA 11: Comparação dos valores da carga medida com o diodo EPI\#46 nos modos de aquisição em carga e em corrente com o eletrômetro Keithley 6517B.

\begin{tabular}{cc|c}
\hline \multicolumn{2}{c|}{ Carga média $(\mu \mathrm{C})$} & $\begin{array}{c}\text { Variação percentual } \\
(\%)\end{array}$ \\
\hline $\begin{array}{c}\text { Aquisição em modo } \\
\text { carga }\end{array}$ & $\begin{array}{c}\text { Aquisição em modo } \\
\text { corrente }\end{array}$ & 0,3 \\
\hline $0,643(5)$ & $0,644(1)$ &
\end{tabular}

\subsection{Dependência Angular}

Para o estudo da resposta direcional do diodo EPI\#46 foram realizadas medições com as qualidades de referência RQR5 (70 kV), RQR2M (28 kV) e RQA5 (70 kV), para 
intervalos angulares máximos dos diodos com relação ao feixe de $\pm 34^{\circ}$; para o diodo EPI\#45 foram realizadas medições para a qualidade de referência RQR2M para intervalos angulares de $\pm 20^{\circ}$. A dependência angular para a qualidade de tomografia não foi avaliada neste trabalho, pois a norma IEC 61647 [32] exige o uso de um conjunto de colimadores no feixe que não estava disponível no LCI no período de aquisição dos dados. Na FIG.75 é apresentada a resposta angular relativa do diodo EPI\#46 para as qualidades RQA5, RQR2M e RQR5 e do diodo EPI\#45 para a qualidade de RQR2M.

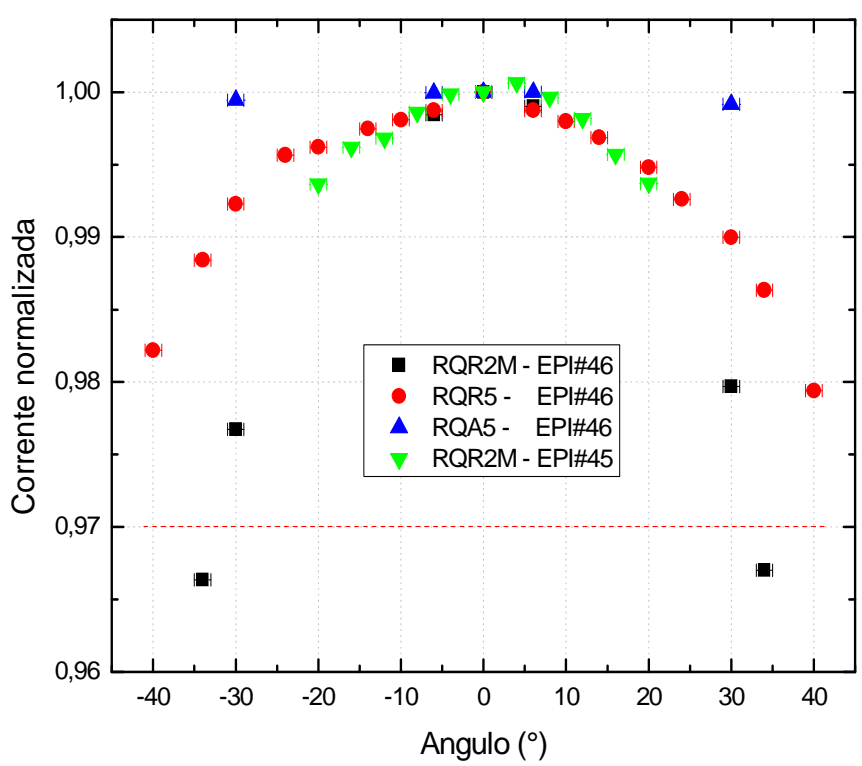

FIGURA 75: Dependência angular do diodo EPI\#46 para as qualidades de feixe RQR5, RQA5 e RQR2M e do diodo EPI\#45 para as qualidades de feixe RQR2M.

As medições revelaram a excelente resposta direcional dos diodos uma vez que para ângulos de até $30^{\circ}$ as correntes obtidas não são inferiores a 97\% do valor inicial para o diodo EPI\#46 e no intervalo de $\pm 20^{\circ}$ a $99,4 \%$ para o diodo EPI\#45, resultado melhor que o limite exigido pela norma IEC 61674, que impõe variação percentual de até 3\% para incidência da radiação $a \pm 5^{\circ}$.

\subsection{Cálculo dos coeficientes de calibração}

Em decorrência do LCI ser um laboratório de referência, possuindo certificados de calibração internacionais que garantem a propriedade de rastreabilidade, foi possível submeter os diodos estudados neste trabalho a um processo de calibração mediante determinação de coeficientes de calibração, $\mathrm{N}_{\mathrm{K}}$, para cada qualidade de feixe utilizado. 
Na TAB.12 são apresentados para os diodos usados neste trabalho os coeficientes de calibração obtidos, bem como os fatores de correção para qualidade do feixe, $\mathrm{k}_{\mathrm{Q}}$, e de temperatura, $\mathrm{k}_{\rho}$, correspondentes.

TABELA 12: Coeficientes de calibração e fatores de correção para os diodos EPI\#46, \#45 e FZ\#04 utilizando as qualidades estudadas neste trabalho.

\begin{tabular}{|c|c|c|c|c|c|c|}
\hline \multicolumn{3}{|c|}{ EPI\#45 } & \multicolumn{2}{|c|}{ EPI\#46 } & \multicolumn{2}{|c|}{ FZ\#04 } \\
\hline \multirow{2}{*}{$\begin{array}{l}\text { Qualidade do } \\
\text { feixe }\end{array}$} & \multicolumn{2}{|c|}{$\mathrm{N}_{\mathrm{k}}=165,787.10^{3} \mathrm{~Gy} / \mathrm{C}$} & \multicolumn{2}{|c|}{$\mathrm{N}_{\mathrm{k}}=65,531 \cdot 10^{3} \mathrm{~Gy} / \mathrm{C}$} & \multicolumn{2}{|c|}{$\mathrm{N}_{\mathrm{k}}=19,839.10^{3} \mathrm{~Gy} / \mathrm{C}$} \\
\hline & $\mathrm{k}_{\mathrm{Q}}$ & $\mathrm{k} \rho$ & $\mathrm{k}_{\mathrm{Q}}$ & $\mathrm{k} \rho$ & $\mathrm{k}_{\mathrm{Q}}$ & $\mathrm{k} \rho$ \\
\hline RQR3 & 0,974 & 1,083 & 0,994 & 1,085 & 0,993 & 1,098 \\
\hline RQR5 & 1 & 1,092 & 1 & 1,085 & 1 & 1,088 \\
\hline RQR8 & 1,316 & 1,086 & 1,079 & 1,078 & 1,055 & 1,097 \\
\hline \multirow[t]{2}{*}{ RQR10 } & 1,567 & 1,083 & 1,293 & 1,086 & 1,231 & 1,098 \\
\hline & \multicolumn{2}{|c|}{ EPI\#45 } & \multicolumn{2}{|c|}{ EPI\#46 } & \multicolumn{2}{|c|}{ FZ\#04 } \\
\hline \multirow{2}{*}{$\begin{array}{l}\text { Qualidade do } \\
\text { feixe }\end{array}$} & \multicolumn{2}{|c|}{$\mathrm{N}_{\mathrm{k}}=159,388.10^{3} \mathrm{~Gy} / \mathrm{C}$} & \multicolumn{2}{|c|}{$\mathrm{N}_{\mathrm{k}}=66,860 \cdot 10^{3} \mathrm{~Gy} / \mathrm{C}$} & \multicolumn{2}{|c|}{$\mathrm{N}_{\mathrm{k}}=36,811.10^{3} \mathrm{~Gy} / \mathrm{C}$} \\
\hline & $\mathrm{k}_{\mathrm{Q}}$ & $\mathrm{k} \rho$ & $\mathrm{k}_{\mathrm{Q}}$ & $\mathrm{k} \rho$ & $\mathrm{k}_{\mathrm{Q}}$ & $\mathrm{k} \rho$ \\
\hline RQA3 & 0,669 & 1,085 & 0,642 & 1,087 & 0,331 & 1,097 \\
\hline RQA5 & 1 & 1,086 & 1 & 1,085 & 1 & 1,097 \\
\hline RQA8 & 1,517 & 1,086 & 1,484 & 1,085 & 0,718 & 1,097 \\
\hline \multirow[t]{2}{*}{ RQA10 } & 2,278 & 1,085 & 2,291 & 1,085 & 1,071 & 1,095 \\
\hline & \multicolumn{2}{|c|}{ EPI\#45 } & \multicolumn{2}{|c|}{ EPI\#46 } & \multicolumn{2}{|c|}{ FZ\#04 } \\
\hline \multirow{2}{*}{$\begin{array}{l}\text { Qualidade do } \\
\text { feixe }\end{array}$} & \multicolumn{2}{|c|}{$\mathrm{N}_{\mathrm{k}}=197,345 \cdot 10^{3} \mathrm{~Gy} / \mathrm{C}$} & \multicolumn{2}{|c|}{$\mathrm{N}_{\mathrm{k}}=80,165 \cdot 10^{3} \mathrm{~Gy} / \mathrm{C}$} & \multicolumn{2}{|c|}{$\mathrm{N}_{\mathrm{k}}=31,990.10^{3} \mathrm{~Gy} / \mathrm{C}$} \\
\hline & $\mathrm{k}_{\mathrm{Q}}$ & $\mathrm{k} \rho$ & $\mathrm{k}_{\mathrm{Q}}$ & $\mathrm{k} \rho$ & $\mathrm{k}_{\mathrm{Q}}$ & $\mathrm{k} \rho$ \\
\hline RQA2M & 0,856 & 1,091 & 1,004 & 1,085 & 0,786 & 1,093 \\
\hline RQA4M & 0,817 & 1,093 & 0,898 & 1,086 & 0,687 & 1,090 \\
\hline RQR2M & 1 & 1,092 & 1 & 1,087 & 1 & 1,091 \\
\hline RQR4M & 0,972 & 1,090 & 0,951 & 1,085 & 0,952 & 1,091 \\
\hline \multicolumn{3}{|c|}{ EPI\#45 } & \multicolumn{2}{|c|}{ EPI\#46 } & \multicolumn{2}{|c|}{ FZ\#04 } \\
\hline \multirow{2}{*}{$\begin{array}{l}\text { Qualidade do } \\
\text { feixe }\end{array}$} & \multicolumn{2}{|c|}{$\mathrm{N}_{\mathrm{k}}=253,652.10^{3} \mathrm{~Gy} / \mathrm{C}$} & \multicolumn{2}{|c|}{$\mathrm{N}_{\mathrm{k}}=92,310.10^{3} \mathrm{~Gy} / \mathrm{C}$} & \multicolumn{2}{|c|}{$\mathrm{N}_{\mathrm{k}}=27,712 \cdot 10^{3} \mathrm{~Gy} / \mathrm{C}$} \\
\hline & $\mathrm{k}_{\mathrm{Q}}$ & $\mathrm{k} \rho$ & $\mathrm{k}_{\mathrm{Q}}$ & $\mathrm{k} \rho$ & $\mathrm{k}_{\mathrm{Q}}$ & $\mathrm{k} \rho$ \\
\hline RQT8 & 0,854 & 1,091 & 0,860 & 1,086 & 0,806 & 1,177 \\
\hline RQT9 & 1 & 1,093 & 1 & 1,087 & 1 & 1,096 \\
\hline RQT10 & 1,224 & 1,093 & 1,199 & 1,087 & 1,179 & 1,099 \\
\hline
\end{tabular}




\section{CONCLUSÕES}

Neste trabalho foram construídas e calibradas três sondas dosimétricas baseadas no uso de diodos epitaxiais e de fusão zonal de $\mathrm{Si}$, tolerantes a danos de radiação, para aplicações em dosimetria de feixes clínicos de radiação X. Estes diodos, utilizados aqui com e sem pré-dose, foram escolhidos por apresentarem pequena espessura da janela de entrada e da zona de depleção (esta inferior a $100 \mu \mathrm{m}$ ), conferindo a estes dispositivos maiores sensibilidade e resistência aos danos de radiação quando comparados aos demais diodos comumente empregados em dosimetria para imagens médicas. Entretanto, tratam-se de diodos fabricados sob encomenda, não disponíveis no mercado nacional.

O uso dos diodos em modo fotovoltaico possibilitou aquisição em tempo real das correntes geradas nas amostras pela incidência da radiação, assim como reduziu a contribuição da corrente de fuga e da temperatura nas medidas, o que sempre foi uma grande limitação dos sistemas dosimétricos polarizados reversamente aplicados em dosimetria clínica. Como consequência, ampliou-se o intervalo de dose de radiação $X$ acumulada suportada pelo diodo sem pré-irradiação para até $10 \mathrm{~Gy}$.

O diodo epitaxial sem pré-dose, para dose acumulada de até 49,15 Gy, apresentou repetibilidade $(\leq 0,3 \%)$, reprodutibilidade de resposta $(\leq 2,0 \%)$, dependência angular $(\leq 1,0 \%)$ e linearidade em corrente que atendem às recomendações da norma IEC 61674 [34] para dosímetros semicondutores. A caracterização dosimétrica permitiu ainda estabelecer os limites de operação em termos de taxa de Kerma $(0,04 \mathrm{mGy} / \mathrm{min}$ a $120 \mathrm{mGy} / \mathrm{min})$, dose (10 Gy), com sensibilidades em corrente (13,8 $\mu \mathrm{A} . \mathrm{s} / \mathrm{Gy})$ e em carga $(15,8 \mathrm{nC} / \mathrm{mGy})$ independentes da taxa de Kerma no intervalo abrangido por este trabalho. $\mathrm{O}$ comportamento do diodo epitaxial pré-irradiado foi similar ao anterior em termos de estabilidade de resposta, porém, com sensibilidade em corrente e em carga duas vezes e meia menor, sem entretando comprometer seu uso em aplicações médicas. A estabilidade de resposta desse diodo em longo prazo pôde ser estudada até o presente para 206,5 Gy, observando-se um decréscimo de apenas 0,6\% em relação a 0 Gy (pré-dose de 200 kGy), indicando claramente que não atingimos ainda seu limite superior de dose. Quando comparados ao diodo FZ, os epitaxiais revelaram-se superiores quanto à 
sensibilidade, estabilidade em longo prazo, dependência energética e com a taxa de Kerma, além de mais resistentes a danos de radiação. A dependência energética para os diodos avaliados foi considerada desprezível para feixes de mamografia e discreta para feixes de radiodiagnóstico com energias até $70 \mathrm{kV}$; para energias superiores, tornou-se significativa e precisa ser estudada com maior detalhe.

No tocante aos danos estruturais, não foi observada qualquer alteração nas sondas dosimétricas até o limite de 40 Gy. A queda de sensibilidade com a dose apresentada pelo diodo EPI\#46 não impossibilitou detecção de correntes mesmo para as menores taxas de Kerma, permanecendo com ótima relação sinal/ruído.

Neste contexto, os resultados abriram a possibilidade de aplicação bem sucedida de diodos epitaxiais, pré-irradiados ou não, na área de dosimetria de radiodiagnóstico com vantagens sobre os dispositivos comerciais como os de fusão zonal. 


\section{APÊNDICE A - Simulações dos espectros das qualidades de raios $\mathrm{X}$ utilizadas neste trabalho}

Nas FIG. 76 a 79 são apresentados os resultados de simulação dos espectros de energia da ampola de raios X Pantak-Seifert utilizando programa baseado no Método de Monte Carlo, disponível no sítio da Siemens, em acordo com os trabalhos de Boone, Seibert, Fewell e Jennings [54-57]. Para essas simulações foram consideradas as filtrações inerente de $\mathrm{Be}$ e as adicionais de $\mathrm{Al}, \mathrm{Cu}$ e $\mathrm{Mo}$, quando pertinentes; os valores de taxa de kerma no ar empregados foram os da Tabela 2.

\section{Qualidades de radiodiagnóstico com feixes diretos (RQR)}

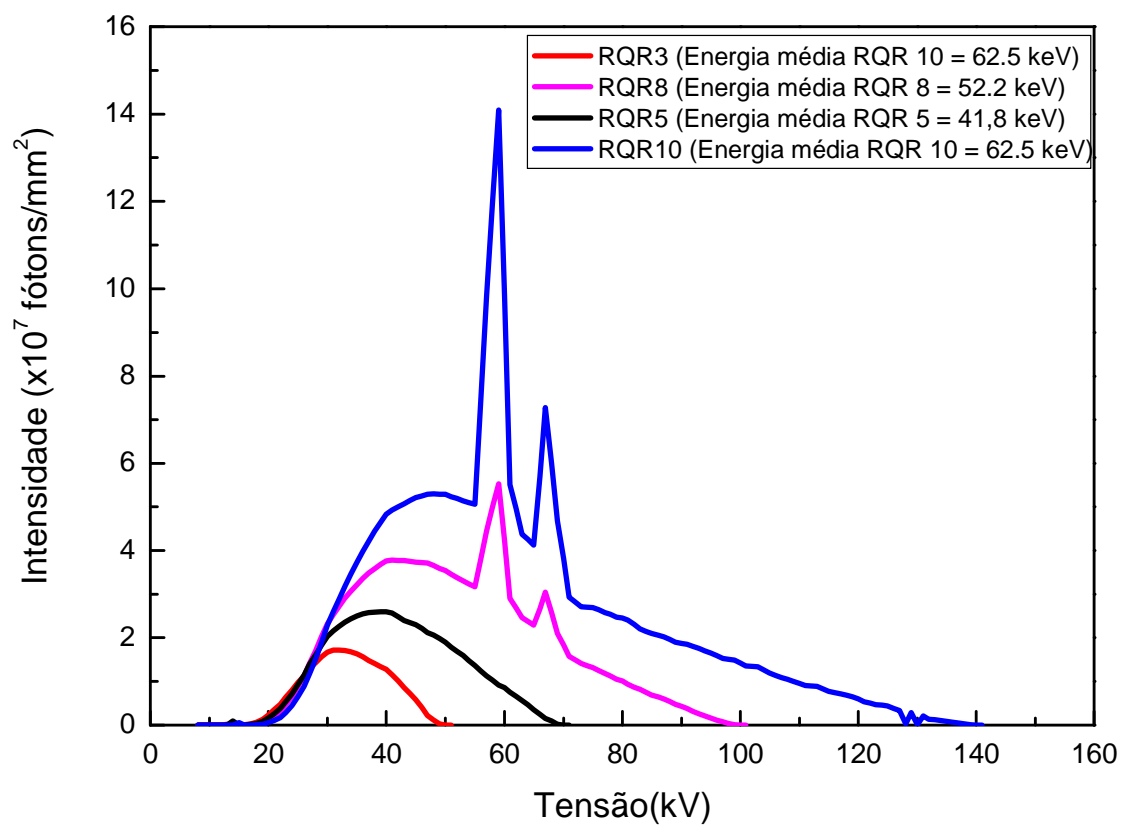

Figura 76: Espectros de energia para as qualidades de radiodiagnóstico com feixes diretos $(\mathrm{RQR})$ 
Qualidades de radiodiagnóstico com feixes atenuados (RQA)

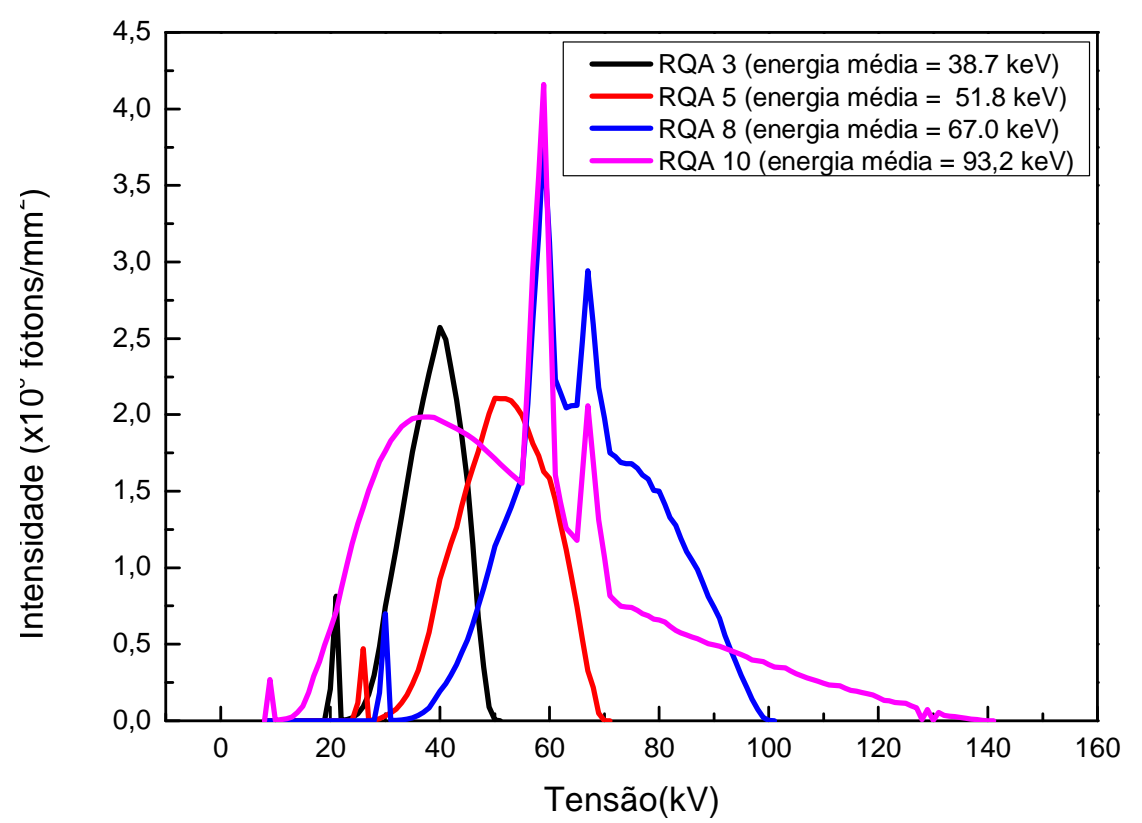

FIGURA 77: Espectros de energia para as qualidades de radiodiagnóstico com feixes atenuados (RQA).

\section{Qualidades de mamografia com feixes atenuados e diretos (RQA/R 2/4M)}

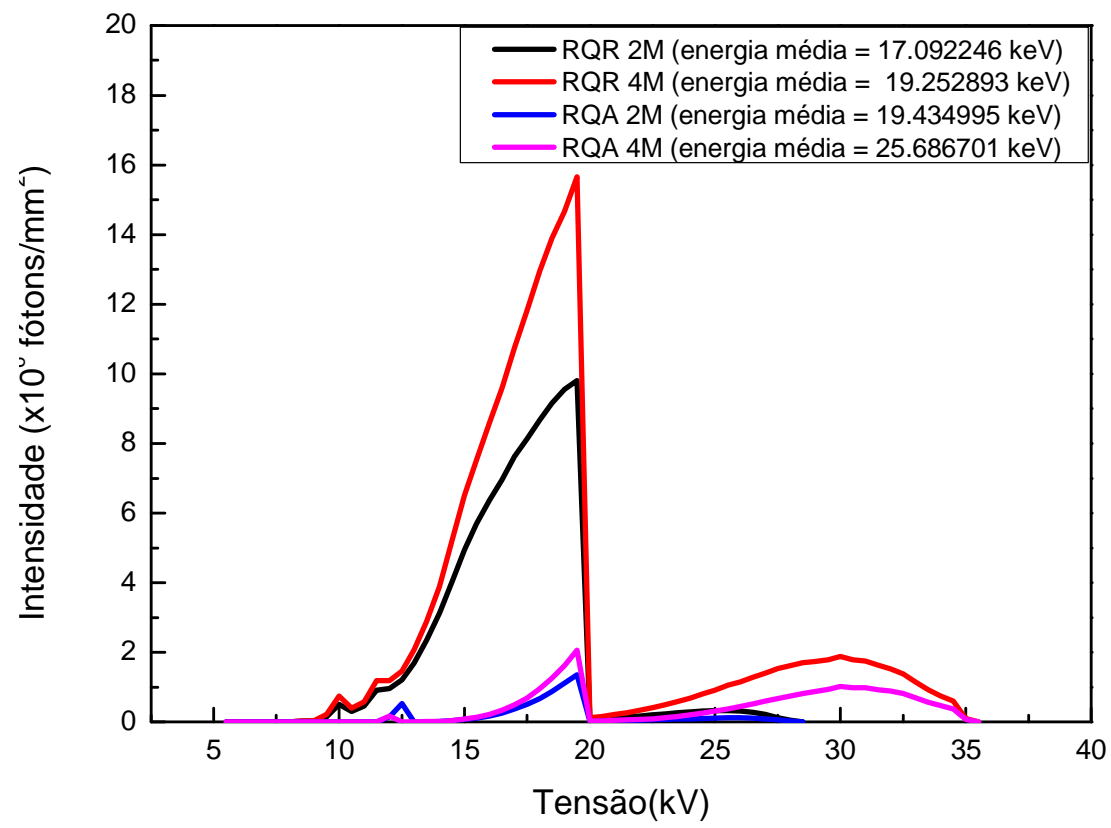

FIGURA 78: Espectros de energia para as qualidades de mamografia com feixes diretos e atenuados (RQA/R 2/4M). 
Qualidades de tomografia computadorizada (RQT)

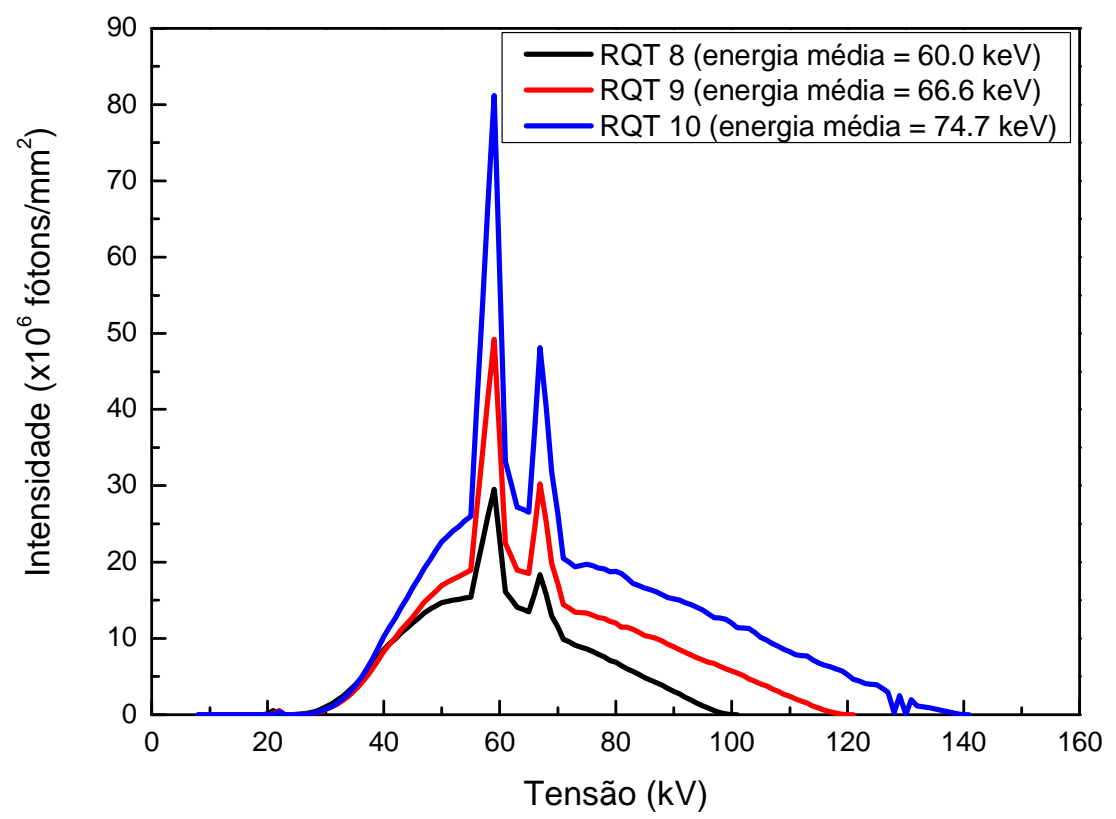

FIGURA 79: Espectros de energia para as qualidades de tomografia computadorizada (RQT). 


\section{REFERÊNCIAS BIBLIOGRÁFICAS}

[1] - DIXON, R.L.; EKSTRAND, K.E. Silicon diode dosimetry. Int. J. Appl. Radiat. Isot. v.33, p.1171-1176, 1982.

[2] - AOKI, K.; KOYAMA, M. Measurement of diagnostic x-ray spectra using a silicon photodiode. Med. Phys. v. 16, n. 4, p.529-536, 1989.

[3] - SLAPA, M.; TRACZYK, M. A new concept of dosimeter with silicon photodiodes. IEEE Trans. Nucl. Sci. v. 43(3), p.1855-1859, 1996.

[4] - MALI, T.; CINDRO, V.; MIKUZ, M. Silicon microstrip detectors for digital mammography - evaluation and apatial resolution study. Nucl. Instrum. Methods Phys. Res., Sect. A. v. 460, p.76-80, 2001.

[5] - PAVEL, N.A. Particle detectors for biomedical applications - demands and trends. Nucl. Instrum. Methods Phys. Res., Sect. A. v. 478, p.1-12, 2002.

[6] - METZGER, W.; ENGDAHL, J.; ROSSNER, W.; BOSLAU, O.; KEMMER, J. Large-area silicon drift detectors for new applications in nuclear medicine imaging. IEEE Trans. Nucl. Sci. v. 51(4), p.1631-1635, 2004.

[7] - GRIESSBACH, I.; LAPP, M.; BOHSUNG, J.; GADEMANN, G.; HARDER, D. Dosimetric characteristics of a new unshielded silicon diode and its application in clinical photon and electron beams. Med. Phys. v. 32(12), p.3750-3754, 2005.

[8] - CAMARGO, F.; KHOURY, H.J.; NASCIMENTO, C.R.; ASFORA, V.K.; BUENO, C.C. Evaluation of a multi-guard ring structure (MGR) diode as diagnostic X-ray dosimeter. Nucl. Instrum. Methods Phys. Res., Sect. A. v. 580, p.194-196, 2007.

[9] - ROSENFELD, A.B. Electronic dosimetry in radiation therapy. Radiat. Meas. v. 41, p. S134-S153, 2007.

[10] - JURSINIC, P. Implementation of an in vivo dosimetry program and changes in diode characteristics over a 4-year clinical history. Med. Phys. V.28, p8, 2011.

[11] - PINI, S.; BRUZZI, M.; BUCCIOLINI, M.; BORCHI, E.; LAGOMARSINO, S.; MENICHELLI, D.; MIGLIO, S.; NAVA, F.; SCIORTINO, S. High-bandgap semiconductor dosimeters for radiotherapy applications. Nucl. Instrum. Methods Phys. Res., Sect. A. v. 514, p.135-140, 2003.

[12] - SAINI, A.S.; ZHU, T.C. Dose rate SDD dependence of commercially available diode detectors. Med. Phys. v. 31(4), p. 914-924, 2004.

[13] - WITTENBURG, K. Radiation damage in pin-photodiodes. Nucl. Instrum. Methods Phys. Res., Sect. A. v. 270, p.56-61, 1988.

[14] - LUTZ, G. Silicon radiation detectors. Nucl. Instrum. Methods Phys. Res., Sect. A. v. 367, p. 21-33, 1995. 
[15] - LI, Z.; LI, C.J.; VERBITSKAYA, E. Study of bulk damage in high resistivity silicon detectors irradiated by high dose of $60 \mathrm{Co} \boldsymbol{\gamma}$-radiation. IEEE Trans. Nucl. Sci. v. 44(3), p.834-839, 1997.

[16] - SADROZINSKI, H.F.W. Applications of silicon detectors. IEEE Trans. Nucl. Sci. v. 48(4), p.933-940, 2001.

[17] - BORER, K.; JANOS, S.; LI, Z.; DEZILLIE, B.; VIA, C.DA.; GRANATA, V.; CASAGRANDE, L.; DE BOER, R.W.I.; LOURENÇO, C.; NIINIKOSKI, T.O.; PALMIERI, V.G.; CHAPUY, S.; DIMCOVSKI, Z.; et.al. Charge collection efficiency of an irradiated cryogenic double-p silicon detector. Nucl. Instrum. Methods Phys. Res., Sect. A. v. 462, p. 474-483, 2001.

[18] - AL-MOHAMAD, A.; CHAHOUD, M. Gamma-ray irradiation effects on highpower diodes and bipolar transistors. Nucl. Instrum. Methods Phys. Res., Sect. A. v. 538, p. 703-707, 2005.

[19] - VERBITSKAYA, E.; EREMIN, V.; ILYASHENKO, I.; LI, Z.; HARKONEN, J.; TUOVINEN, E.; LUUKKA, P. Operation of heavily irradiated silicon detectors in nondepletion mode. Nucl. Instrum. Methods Phys. Res., Sect. A. v. 557, p. 528-536, 2006.

[20] - BOSISIO, L.; DITTONGO, S.; QUAI, E.; RACHEVSKAIA, I. Observation of substrate-type inversion in high-resistivity silicon structures irradiated with highenergy electrons. IEEE Trans. Nucl. Sci. v. 50(1), p.219-225, 2003.

[21] - LINDSTROM, G.; MOLL, M.; FRETWURST, E. Radiation hardness of silicon detectors - a challenge from high-energy physics. Nucl. Instrum. Methods Phys. Res., Sect. A. v. 426, p. 1-15, 1999.

[22] - CANDELORI, A. Radiation-hard detectors for very high luminosity colliders. Nucl. Instrum. Methods Phys. Res., Sect. A. v. 560, p. 103-107, 2006.

[23] - ALESSANDRO, B.; BEOLÉ, S.; BONAZZOLA, G.; CRESCIO, E.; DABROWSKI, W.; GIUBELLINO, P.; GRYBOS, P.; IDZIK, M.; MARTINETTO, M.; MARZARI-CHIESA, A.; MASERA, M.; PRINO, F.; RAMELLO, L.; MENDES, P.R.; RICCATI, L.; SITTA, M. Radiation damage of silicon strip detectors in the NA50 experiment. Nucl. Instrum. Methods Phys. Res., Sect. A. v. 419, p. 556-569, 1998.

[24] - ALESSANDRO, B.; BEOLÉ, S.; BONAZZOLA, G.; CRESCIO, E.; DABROWSKI, W.; GIUBELLINO, P.; GRYBOS, P.; IDZIK, M.; MARTINETTO, M.; MARZARI-CHIESA, A.; MASERA, M.; PRINO, F.; RAMELLO, L.; MENDES, P.R.; RICCATI, L.; SITTA, M. Analysis of radiation effects on silicon strip detectors in the NA50 experiment. Nucl. Instrum. Methods Phys. Res., Sect. A. v. 432, p. 342-357, 1999.

[25] - XIE, X.B.; CHO, H.S.; LIANG, G.W.; HUANG, W.; LI, Z.; CHIEN, C.Y. Electrical characterization of a radiation-hardened silicon pixel desing for CMS. Nucl. Instrum. Methods Phys. Res., Sect. A. v. 476, p. 665-669, 2002.

[26] - ZONTAR, D. Radiation monitoring at belle. Nucl. Instrum. Methods Phys. Res., Sect. A. v. 501, p. 164-166, 2003.

[27] - HARKÖNEN, J.; ABERU, M.; ANBINDERIS, P.; ANBINDERIS, T.; D'AMBROSIO, N.; DE BOER, W.; et.al. Recent results from the CERN RD39 collaboration on super-radiation hard cryogenic silicon detectors for LHC and LHC upgrade. Nucl. Instrum. Methods Phys. Res., Sect. A. v. 535, p. 384-388, 2004.

[28] - MOLL, M. Radiation tolerant semiconductor sensors for tracking detectors. Nucl. Instrum. Methods Phys. Res., Sect. A. v. 565, p. 202-211, 2006. 
[29] - LiNDSTROM, G., FRETWURST, E., HONNIGER, F., KRAMBERGER, G., MOLLER-IVENS, M., PINTILIE, I., SCHRAMM, A. Radiation tolerance of epitaxial silicon detectors at very large proton fluencies. Nucl. Instrum. Methods Phys. Res., Sect. A. v. 556, p. 451-458, 2006.

[30] - KHOMENKOVA, V., BISEllOA, D., BRUZZI, M., CANDELORIA, A., LITOVCHENKOA, A., PIEMONTE, C., RANDO, R., RAVOTTI, F., ZORZI, N. Irradiation effects on thin epitaxial silicon detectors. Nucl. Instrum. Methods Phys. Res., Sect. A. v. 568, p. 61-65, 2006.

[31] - CREANZA, D., BASSIGNANA, D., BORRELlOC, L., BOSCARDIN, M., BRUZZI, M., PALMA, M. DE, FOCARDI, E., MACCHIOLO, A., MANNA, N., MENICHELli, D., MESSINEO, A., PIEMONTE, C., POZZA, A., RADICCI, V., SCARINGELLA, M., ZORZI, N. Comparison of the radiation hardness of Magnetic Czochralski and Epitaxial silicon substrates after $26 \mathrm{MeV}$ proton and reactor neutron irradiation. Nucl. Instrum. Methods Phys. Res., Sect. A. v. 579, p. 608-613, 2007.

[32] - FRETWURST, E., HONNIGER, F., KRAMBERGER, G., LINDSTROM, G., PINTILIE, I., RODER, R. Radiation damage studies on $\mathrm{MCz}$ and standard and oxygen enriched epitaxial silicon devices. Nucl. Instrum. Methods Phys. Res., Sect. A. v. 583, p. 58-63, 2007.

[33] - BRUZZI, M., BUCCIOLINI, M., CASATI, M., MENICHELLI, D., TALAMONTI, C., PIEMONTI, C., SVENSSON, B. G. Epitaxial silicon devices for dosimetry applications. Appl. Phys. Letters, v. 90, p. 172109/1-171109-3, 2007.

[34] - INTERNATIONAL ELECTROTECHNICAL COMMISSION. Medical diagnostic $\mathrm{X}$-ray equipment Medical electrical equipment - Dosimeters with ionization chambers and/or semi-conductor detectors as used in $\mathrm{X}$-ray diagnostic imaging. IEC 61674. Genève: IEC, 1997.

[35] - INTERNATIONAL ATOMIC ENERGY AGENCY. Dosimetry in diagnostic

radiology. An international code of practice. Technical Reports Series 457. Vienna: IAEA, 2007.

[36] - KHAN, Faiz M.; KHAN, F. M. The physics of radiation therapy. Philadelphia: Lippincott Williams \& Wilkins, 2003.

[37] - National Institute of Standards and Technology - Disponível em: <http://physics.nist.gov/PhysRefData/Xcom/html/xcom1.html>. Acesso em: 08 nov. 2013.

[38] - ATTIX, Frank Herbert. Introduction to radiological physics and radiation dosimetry. Wiley. com, 2008.

[39] - MAYLES, Philip; NAHUM, Alan; ROSENWALD, Jean-Claude (Ed.).Handbook of radiotherapy physics: theory and practice. CRC Press, 2010.

[40] - PIERRET, Robert F.; NEUDECK, Gerold W. Advanced semiconductor fundamentals. Reading, Massachusetts: Addison-Wesley, 1987.

[41] - SZE, S.M. Semiconductor Devices Physics and Tecnology. New York, N.Y.:John Willey \& Sons, 1985.

[42] - KITTEL, Charles; KITTEL, By Charles. Introduction to solid state physics. 1986.

[43] - LUTZ, G. Semiconductor Radiation Detectors. Springer, 1999. 
[44] - COLINGE, J.P.; COLINGE, C.A. Physics of Semiconductor Devices. Kluwer Academic Publishers, 2002.

[45] - SANTOS, T. C. Título: Dosimetria de elétrons em processos de irradiação com diodos resistentes a danos de radiação. 2012. 138. Tese (Doutorado) - Instituto de Pesquisas Energéticas e Nucleares - IPEN. São Paulo - 2012.

[46] - RIKNER, G., GRUSSEL, E. Effects of radiation damage on p-type silicon detectors. Phys. Med. Biol. v. 28, p. 1261-1267.

[47] - TALAMONTI, C, et al,. Preliminary dosimetric characterization of a silicon segmented detector for 2D dose verifications in radiotherapy. Nucl. Instrum. Methods Phys. Res., Sect. A. v. 583, p. 114-118.

[48] - TALAMONTI, C, et al. Bidimensional silicon dosimeter: development and characterization. Nucl. Instrum. Methods Phys. Res., Sect. A. v. 658, p. 84-89.

[49] - SANTOS, T. C. dos, et al. Evaluation of rad-hard epitaxial silicon diode in radiotherapy electron beam dosimetry. Radiat. Meas. v. 46, p. 1662-1665.

[50] - INTERNATIONAL COMMSSION ON RADIATION UNITS \& MEASUREMENTS. Brit. J. Radiol. 1. 363. 1928.

[51] - INTERNATIONAL COMMSSION ON RADIATION UNITS \& MEASUREMENTS. Report 33. Washington, 1980.

[52] - INTERNATIONAL COMMSSION ON RADIATION UNITS \& MEASUREMENTS. Report 60. Woodmont Avenue Bethesda, Maryland, 1998.

[53] - INTERNATIONAL ELECTROTECHNICAL COMMISSION. Medical diagnostic $\mathrm{X}$-ray equipment. Radiation conditions for use in the determination of characteristics. 2nd ed. IEC 61267. Genève: IEC, 2005.

[54] - SIMULAÇÃO de espectros de raios X - Siemens. Disponível em: $<$ https://w9.siemens.com/cms/oemproducts/home/xraytoolbox/spektrum/pages/default. aspx >. Acesso em: 18 ago. 2013.

[55] - BOONE, M. J.; SEIBERT, A. An accurate method for computer-generating tungsten anode X-ray spectra from 30 to 140 kV; Medical Physics 24(11), 1661-1670, 1997.

[56] - BOONE, M. J; FEWELL, T, R.; JENNINGS, R. J. Molybdenum, rhodium, and tungsten anode spectral models using interpolating polynomials with application to mammography; Medical Physics 24(12), 1863-1874, 1997.

[57] - BOONE, M. J. Spectral modeling and compilation of quantum fluence in radiography and mammography; Proceedings of the SPIE 3336, 592-601, 1998.

[58] - PASCOALINO, K, S. Título: ESTUDO COMPARATIVO DAS RESPOSTAS DE DIODOS DE SI PARA DOSIMETRIA DE RADIAÇÃO GAMA. 2010. Dissertação de mestrado - Instituto de Pesquisas Energéticas e Nucleares - IPEN. São Paulo - 2010.

[59] - CAMARgo, F. Título: Desenvolvimento de Dosímetros com Diodos de Si Resistentes à Radiação para Dosimetria de Altas Doses. 2009. Tese (Doutorado) Instituto de Pesquisas Energéticas e Nucleares - IPEN. São Paulo - 2009.

[60] - NASCIMENTO, J. S. Development of a semiconductor parameter analyser. Private Communication. 
[61] - BUREAU INTERNATIONAL DES POIDS ET MESURES. JCGM 100:2008. Evaluation of measurement data - Guide to the expression of uncertainty in measurement - GUM 2008.

[62] - ISO/ASTM 51707. Standard guide for estimating uncertainties in dosimetry for radiation processing. 2005.

[63] - BIZETTO, C, A. Título: CARCATERIZAÇÃo DAS PROPRIEDADES DOSIMÉTRICAS DE DIODOS DE SILÍCIO EMPREGADOS EM RADIOTERAPIA COM FEIXE DE FÓTONS. 2013. Dissertação de mestrado Instituto de Pesquisas Energéticas e Nucleares - IPEN. São Paulo - 2013. 